\title{
MONITORAGE \\ ET GRANDS SYNDROMES HÉMODYNAMIQUES
}

\section{Cathéter artériel}

La mise en place d'un cathéter artériel a plusieurs avantages:

- mesure fiable et continue de la pression artérielle: Elle est indispensable dans tous les états de choc circulatoire, d'hypertension sévère ou de manière générale en cas de perfusion d'agents vasoactifs;

- facilitation des prélèvements sanguins: en particulier en cas de nécessité de monitoriser les gaz artériels plusieurs fois par jour;

- reconnaissance facilitée des arythmies et de leurs conséquences circulatoires.

La meilleure mesure de pression artérielle est obtenue dans une grosse artère (comme une artère fémorale). Plus le diamètre de l'artère se rétrécit, plus la pression différentielle (différence entre les pressions systolique et diastolique) s’accroît (fig. 1).

La pression différentielle (ou "pulse pressure ») est par ailleurs influencée par différents éléments cardiaques et vasculaires.

Elle augmente en cas de:

- augmentation du volume éjectionnel du ventricule gauche;

- diminution de distensibilité des vaisseaux (athérosclérose);

- insuffisance aortique.

Elle diminue en cas de:

- diminution du volume éjectionnel;

- vasoconstriction périphérique. 


\section{Reconnaissance d'une hypovolémie sur le tracé de pression artérielle}

Au cours de la ventilation mécanique, l'augmentation cyclique des pressions intrathoraciques à chaque insufflation réduit le retour veineux et donc la précharge ventriculaire droite. L'augmentation des pressions transpulmonaires à l'inspiration peut simultanément augmenter la postcharge ventriculaire droite. Ces éléments entraînent une diminution inspiratoire du volume éjectionnel du ventricule droit. Quelques cycles plus tard, cet effet se transmet au ventricule gauche, dont la diminution du volume éjectionnel se traduit par une diminution de pression artérielle lors de la phase expiratoire. En revanche, ces effets sont résolus lors de la phase inspiratoire lorsque la précharge ventriculaire gauche se rétablit et qu'il existe même un effet de « purge » du réseau veineux pulmonaire.

Tous ces éléments sont amplifiés au cours des états d'hypovolémie, qui sont donc caractérisés par une diminution de la pression artérielle et de la pression pulsée au cours de la phase expiratoire (fig. 2).

Pour apprécier le phénomène, il faut toutefois que le malade soit bien adapté au respirateur (éventuellement sous sédation profonde).

\section{Cathéter veineux central}

Le cathéter veineux central permet:

- l'administration éventuelle de larges quantités de liquides;

- l'administration de solutions irritantes (hyperosmolaires comme l'alimentation parentérale, des concentrations élevées de potassium, des médicaments comme la diphénylhydantoine ou l'amiodarone;

- la mesure de la pression veineuse centrale: la PVC est déterminée par la volémie, la compliance vasculaire et la fonction ventriculaire droite. Sa valeur normale est de 2 à $7 \mathrm{mmHg}$.

La pression veineuse centrale est déterminée par la volémie, la compliance vasculaire et la fonction ventriculaire droite.

Sa valeur normale est de 2 à $7 \mathrm{mmHg}$.

L'examen attentif de la courbe de pression veineuse centrale, semblable à celle de pression auriculaire droite, permet un certain nombre d'observations (fig. 3).

L'onde a, qui prend place juste avant le premier bruit B1, correspond à la contraction auriculaire (elle disparaît en cas de fibrillation auriculaire). L'onde $\mathrm{z}$, négative, qui la suit, correspond à la relaxation auriculaire. La seconde onde positive c correspond à la protrusion de la valve tricuspide dans l'oreillette droite au cours de la contraction isovolémique ventriculaire. L'onde $\mathrm{x}$, négative, correspond à nouveau à la relaxation auriculaire. Quand la valve tricuspide se ferme, l'onde v correspond à la distension auriculaire. Elle est plus importante en cas d'insuffisance tricuspide. L'onde y correspond à la vidange de l'oreillette après l'ouverture de la valve tricuspide. Elle est particulièrement abrupte en cas de péricardite constrictive. Le tableau I reprend les principales anomalies de ces ondes. 


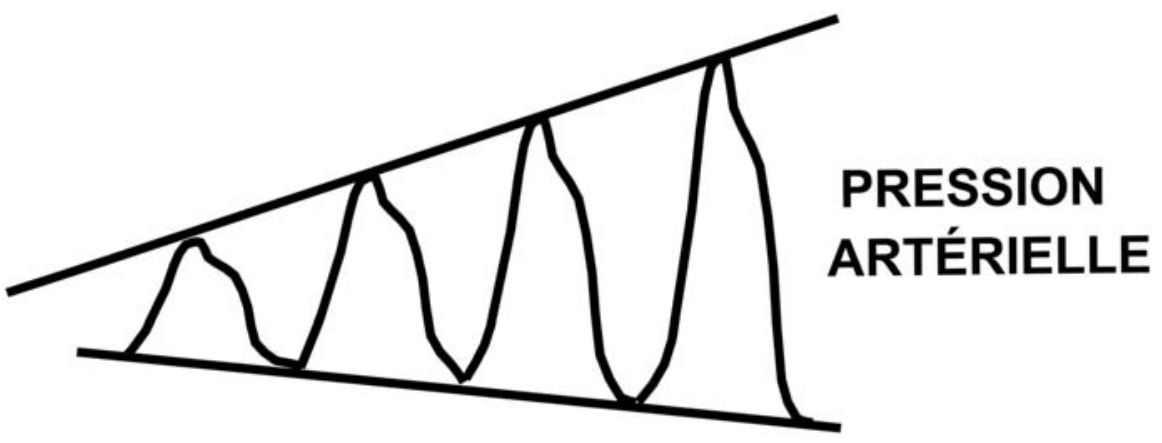

\section{calibre de l'artère}

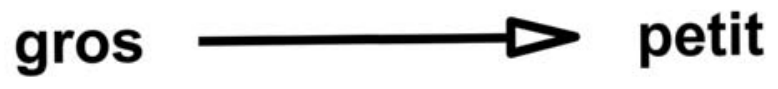

Fig. 1 - Evolution du tracé de pression artérielle en fonction du diamètre de l'artère.

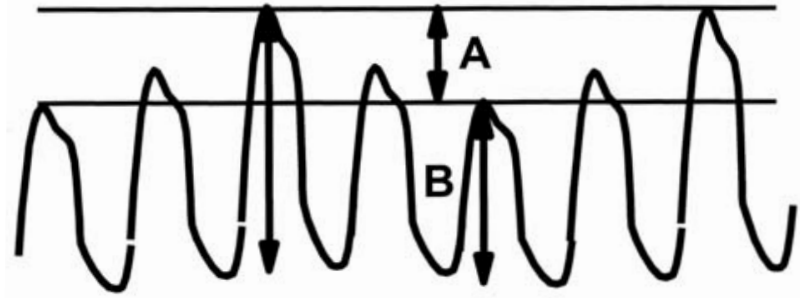

PRESSION ARTÉRIELLE

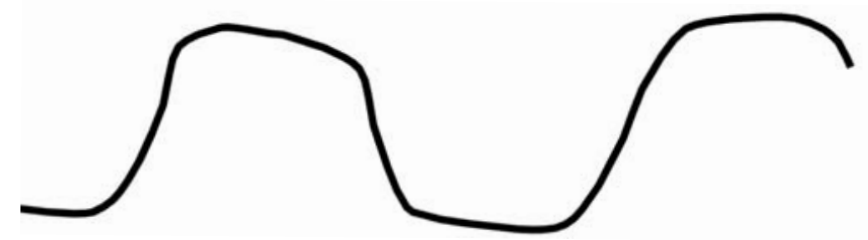

PRESSION DANS LES VOIES AÉRIENNES

Fig. 2 - Représentation schématique des fluctuations de pression artérielle au cours du cycle respiratoire en cas d'hypovolémie chez un malade traité par ventilation mécanique. 


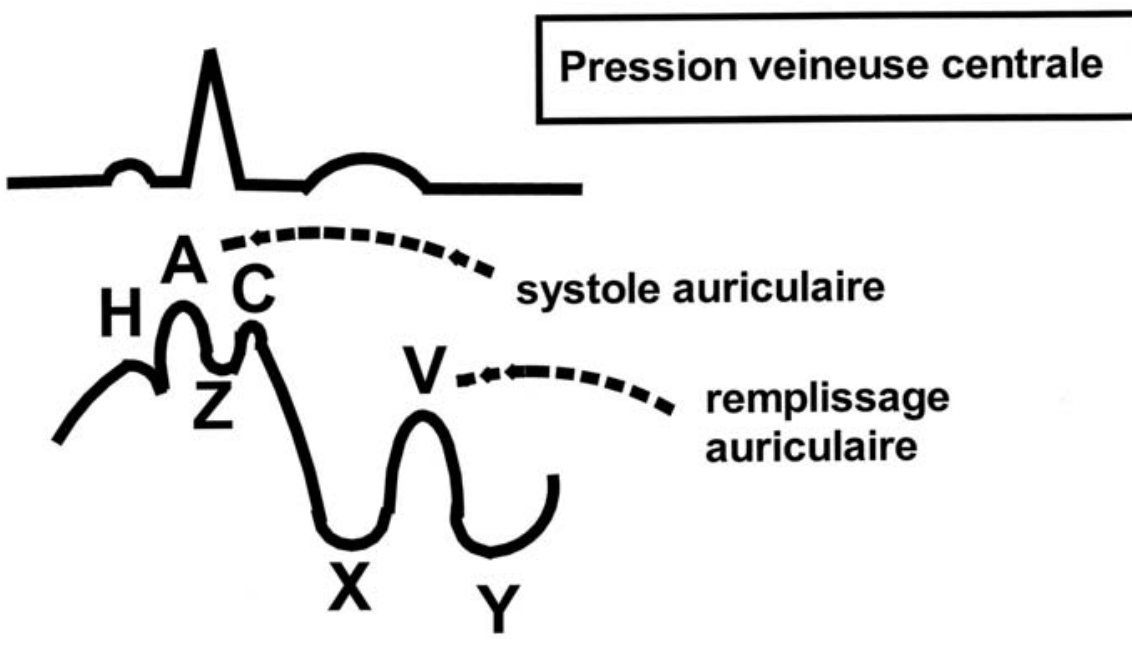

Fig. 3 - Les ondes de la pression veineuse centrale.

Tableau I - Principales anomalies du tracé de pression auriculaire droite.

\begin{tabular}{|c|c|c|}
\hline Onde a & $\begin{array}{l}\text { absente } \\
\text { élargie } \\
\text { en canon }\end{array}$ & $\begin{array}{l}\text { fibrillation auriculaire } \\
\text { sténose tricuspide, hypertension artérielle pulmonaire } \\
\text { dissociation auriculo-ventriculaire, tachycardie ventriculaire }\end{array}$ \\
\hline Onde $\mathrm{x}$ & $\begin{array}{l}\text { absente } \\
\text { importante }\end{array}$ & $\begin{array}{l}\text { insuffisance tricuspide } \\
\text { hypertension artérielle pulmonaire }\end{array}$ \\
\hline Onde v & importante & insuffisance tricuspide, péricardite constrictive \\
\hline Onde y & $\begin{array}{l}\text { lente } \\
\text { rapide } \\
\text { absente }\end{array}$ & $\begin{array}{l}\text { sténose tricuspide, myxome de l'oreillette } \\
\text { péricardite constrictive, insuffisance tricuspide } \\
\text { tamponnade }\end{array}$ \\
\hline
\end{tabular}

\section{Cathéter pulmonaire de Swan-Ganz}

Le cathéter pulmonaire, de longue dimension, est muni d'un ballonnet gonflable qui permet sa progression par «flottaison » dans le torrent circulatoire. Le cathéter, introduit par voie intraveineuse, progresse au travers de l'oreillette droite et du ventricule droit dans l'artère pulmonaire. Une fois en place, le cathéter pulmonaire permet de mesurer trois types de variables: pressions, débit cardiaque et contenu en oxygène du sang veineux mêlé. 


\section{Placement du cathéter pulmonaire}

\section{Vérification des facteurs de risque}

Troubles de coagulation: l'administration de FFP ou la transfusion de plaquettes peut s'avérer nécessaire en cas d'altération sévère de la coagulation.

Stabilisation respiratoire: toute hypoxémie doit être d'abord corrigée.

Correction de troubles électrolytiques: il peut être judicieux de corriger une hypokaliémie sévère ou une hypoxémie avant d'introduire le cathéter.

Arythmies ventriculaires fréquentes ou malignes: on peut administrer $100 \mathrm{mg}$ de Xylocaïne ${ }^{\circledR}$, à titre prophylactique, avant l'introduction du cathéter.

Bloc de branche gauche complet: vu le risque d'arrêt cardiaque en cas d'atteinte de la branche droite du faisceau de Hiss, il est recommandé de préparer un pacemaker prêt à l'emploi.

Présence d'un pacemaker (surtout temporaire): il peut être préférable de placer le cathéter sous contrôle radioscopique, pour éviter de déloger le pacemaker.

\section{Préparation du malade}

Informer le malade s'il est capable de comprendre.

Placer le malade si possible en décubitus dorsal (si pas de contre-indication).

Placer un monitorage sonore de l'activité cardiaque.

\section{Préparation du médecin}

Masque et bonnet, brossage des mains, gants, blouse.

\section{Préparation de l'insertion du cathéter}

Désinfection de la peau.

Placement des champs stériles.

Anesthésie locale.

Insertion de l'introducteur (méthode de Seldinger)

Ponctionner la veine (généralement la veine jugulaire interne).

Introduire l'extrémité souple du guide métallique dans l'aiguille et retirer celle-ci. Inciser la peau au bistouri longitudinalement sur $3 \mathrm{~mm}$. 
Avancer l'introducteur autour du guide métallique (mouvement combiné de pression et de rotation).

Retirer le guide métallique et la partie interne de l'introducteur (se méfier du risque d'embolie gazeuse).

\section{Préparation du cathéter}

Désemballage, rinçage.

Vérification de l'étanchéité du ballonnet (1,5 cc d'air) et de la thermistance (connexion à l'appareil de mesure de débit cardiaque).

Rinçage des différentes voies.

Enfiler la protection («sheet»).

\section{Introduction du cathéter pulmonaire}

Avancement d'environ $20 \mathrm{~cm}$ avant gonflement du ballonnet $(1,5 \mathrm{cc})$.

Reconnaissance des différentes pressions (fig. 4).

Arrêt de la progression lorsque la pression occlusive est obtenue avec 1,5 cc d'air;

Fixation du cathéter.

\section{Vérification radiologique}

On réalise systématiquement une radiographie de thorax pour vérifier la bonne position du cathéter: l'extrémité du cathéter ne peut dépasser la limite du hile pulmonaire; si ce n'est pas le cas, il faut retirer le cathéter de quelques centimètres (fig. 5).

\section{Mesure hémodynamique}

\section{Mesure des pressions}

On peut mesurer trois types de pressions:

- les pressions de l'artère pulmonaire (systolique, diastolique, moyenne) par l'extrémité distale du cathéter;

- la pression occluse (ou occlusive) de l'artère pulmonaire (PAPO) est mesurée au niveau de l'extrémité distale du cathéter, lorsque le ballonnet distal est transitoirement gonflé. Le cathéter est alors entraîné dans le sang et se bloque dans une branche secondaire de l'artère pulmonaire, en interrompant le passage de sang dans ce segment. La pression mesurée alors est celle existant au-delà des capillaires pulmonaires, c'est-à-dire dans les veines pulmonaires. Cette pression est en principe identique à celle de l'oreillette gauche (voir plus loin); 

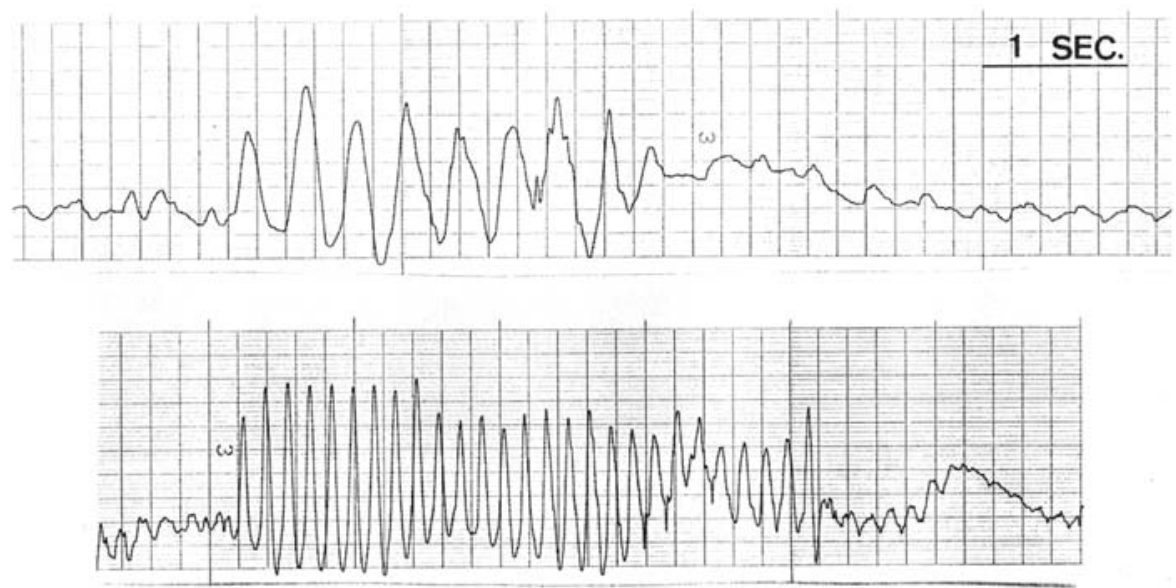

$1 \mathrm{SEC}$.

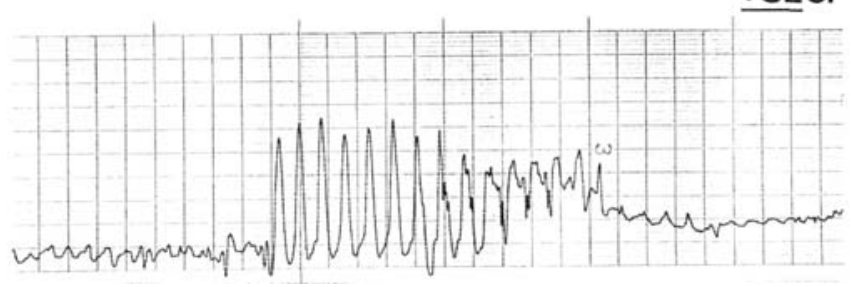

Fig. 4 - Insertion du cathéter pulmonaire montrant l'évolution de pression dans l'oreillette droite, le ventricule droit, l'artère pulmonaire et enfin la pression occlusive (ou capillaire bloqué).

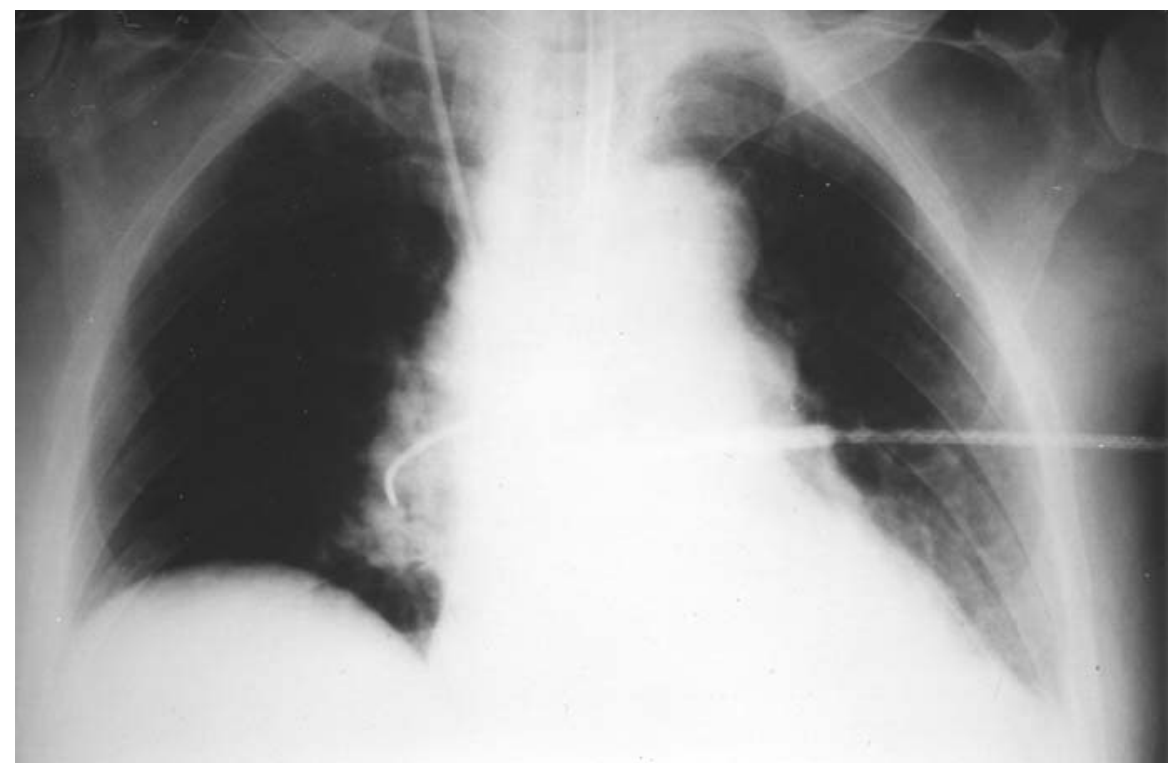

Fig. 5 - Radiographie du thorax montrant que le cathéter de Swan-Ganz est trop avancé. 
- la pression auriculaire droite (POD): par l'extrémité proximale du cathéter; cette pression est la même que la pression veineuse centrale mesurée par un cathéter veineux central.

Par convention, le niveau de référence des pressions (niveau 0) est placé au niveau de l'oreillette droite. Sur le plan pratique, on considère que l'oreillette droite se projette sur la ligne médio-axillaire (partie moyenne du thorax ou " mid-chest») au niveau du $4^{\mathrm{e}}$ espace intercostal. Ce niveau de référence a l'avantage de rester valable en position couchée et en position semi-assise.

Les pressions intrathoraciques fluctuent au cours du cycle respiratoire: ces fluctuations, qui sont négligeables chez l'individu normal, peuvent devenir marquées en cas de dyspnée (bronchospasme en particulier) ou au cours de la ventilation mécanique. Il est important de mesurer les pressions en fin d'expiration, au moment où les pressions intrathoraciques sont égales à la pression atmosphérique (fig. 6). Notons toutefois que ces pressions ne sont pas nécessairement égales à la pression atmosphérique en cas d'auto-PEEP (voir Ventilation mécanique p. 64). La mesure des pressions sur un tracé peut être utile. Les appareils modernes de monitorage permettent le placement d'une ligne repère que l'on amène à ce niveau pour faciliter la mesure.

\title{
mesure des pressions en fin d'expiration
}

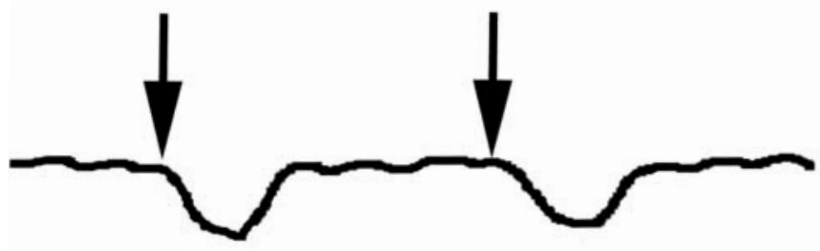

\author{
ventilation \\ spontanée
}

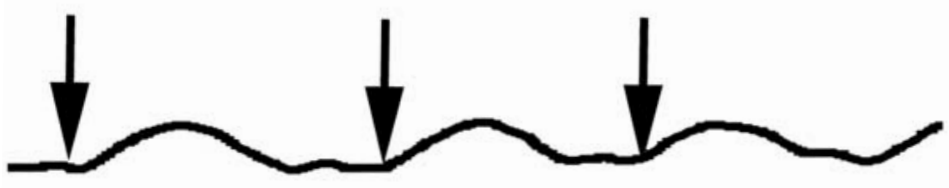

\section{ventilation mécanique}

Fig. 6 - Toutes les pressions intravasculaires doivent être mesurées en fin d'expiration.

On peut mesurer successivement les pressions de l'artère pulmonaire (et la pression occlusive ou PAPO) et la pression de l'oreillette droite par le même transducteur de pression en utilisant un système de robinets. 
Valeurs normales:

- pression de l'artère pulmonaire: 20/8 mmHg (moyenne $12 \mathrm{mmHg}$ );

- pression occlusive de l'artère pulmonaire (PAPO): $8 \mathrm{mmHg}$;

- pression de l'oreillette droite (POD): $5 \mathrm{mmHg}$.

La mesure de la pression occlusive (PAPO) se fait en gonflant transitoirement le ballonnet.

\section{Comment s'assurer que le tracé de PAPO est valide?}

En cas de doute quant à la validité de la PAPO, on peut s'assurer de trois critères:

- la PAPO doit être inférieure ou égale à la PAP diastolique;

- la morphologie doit comporter les ondes auriculaires « a » et « v »; elles ne sont toutefois pas toujours bien visibles;

- en cas de doute, on peut encore mesurer les gaz sanguins en position occluse « wedgée »): la $\mathrm{PO}_{2}$ sera plus élevée que dans le sang artériel, et la $\mathrm{PaCO}_{2}$ plus basse (zone bien ventilée).

\section{Comment s'assurer que la mesure de la PAPO n'est pas influencée par les pressions intra-alvéolaires?}

- la reconnaissance des ondes « a » et « $\mathrm{v}$ » sur le tracé;

- le retrait facile de sang par le cathéter, lorsque le ballonnet est gonflé;

- le degré de transmission des pressions des voies aériennes à la PAPO: l'augmentation de la PAPO au cours de la phase inspiratoire ne peut pas dépasser $50 \%$ des changements de pression dans les voies aériennes; de même, la PAPO ne doit pas être influencée à plus de $50 \%$ par une augmentation de PEEP;

- mesure de la PAPO nadir: PAPO la plus basse lors de la déconnexion très transitoire (quelques secondes) du respirateur.

\section{La PAPO reflète-t-elle bien la pression télédiastolique du ventricule gauche?}

La PAPO peut sous-estimer la pression auriculaire gauche dans les cas suivants:

- insuffisance aortique;

- réduction de l'arbre artériel pulmonaire: pneumectomie, embolie pulmonaire massive;

- diminution de compliance ventriculaire gauche;

Elle peut par contre surestimer la pression auriculaire gauche dans les cas suivants:

- augmentation des pressions alvéolaires: BPCO, ventilation avec PEEP élevée surtout en cas d'hypovolémie associée;

- tachycardie importante (RC > 130/min);

- pathologie mitrale: sténose ou insuffisance.

- anomalies veineuses pulmonaires (rare) : tumeur, fibrose, thromboses; 
Tableau II - Les 10 principes de mesure de la PAPO.

S'assurer de la position correcte du cathéter pulmonaire (radiographie de thorax de contrôle).

Gonfler le ballonnet sous contrôle visuel du tracé de manière à interrompre le gonflement dès l'obtention du tracé; retirer quelque peu le cathéter en cas de tracé permanent de pression occlusive ou en cas d' " overwedge».

Gonfler le ballonnet lentement et précautionneusement; interrompre l'insufflation d'air dès l'apparition du tracé de pression occlusive.

Utiliser 1,5 cc d'air (ni plus, ni moins) lors de l'insufflation du ballonnet (sinon, revoir position du cathéter).

Ne jamais rincer ( flusher») le cathéter lorsque le ballonnet est gonflé.

Minimiser le temps de lecture de la pression occlusive: max. 3 cycles respiratoires ou 10 secondes. Ne pas utiliser la valve de fermeture de l'extrémité du ballonnet (cette valve ne peut être fermée que lors du placement du cathéter).

Laisser le ballonnet se dégonfler spontanément en fin de lecture (ne pas réaspirer l'air).

Éviter les mesures fréquentes de pression occlusive (la surveillance de la pression diastolique de l'artère pulmonaire peut suffire entre deux mesures, puisque le gradient entre la PAP diastolique et la PAPO est en général stable).

$\mathrm{Ne}$ jamais injecter de liquide dans le ballon (laisser la seringue en place).

En cas de rupture du ballonnet, fermer son orifice par un morceau de sparadrap (pour éviter l'insufflation involontaire d'air dans la circulation).

\section{Mesure du débit cardiaque par thermodilution}

La mesure du débit cardiaque par thermodilution est basée sur l'enregistrement de la courbe de dilution d'un indicateur thermique (température inférieure à celle du corps) injecté dans l'oreillette droite: le cathéter est équipé d'une thermistance mesurant la température du sang dans l'artère pulmonaire à quelques $\mathrm{cm}$ de l'extrémité distale. La diminution légère et transitoire de la température du sang dans l'oreillette droite entraîne une diminution transitoire de la température du sang dans l'artère pulmonaire, après un certain laps de temps. Un appareil permet le calcul automatisé du débit cardiaque à partir de la surface de la courbe obtenue, selon la formule

$$
\mathrm{V}(\mathrm{TB}-\mathrm{TI})-\mathrm{K} 1 \mathrm{~K} 2
$$

$\mathrm{CO}=$

TB (t) dt

dans laquelle:

CO: cardiac output (débit cardiaque);

$\mathrm{V}$ : volume d'injectat;

TB: température basale;

TI: température de l'injectat;

K1 ET K2: constantes;

TB $(\mathrm{t}) \mathrm{dt}$ : changement de température au cours du temps. 
La technique classique de thermodilution nécessite l'injection rapide par l'extrémité proximale du cathéter d'une quantité connue d'eau froide. Les cathéters utilisés aujourd'hui sont plus souvent équipés d'un système de thermistance intraventriculaire permettant une mesure quasi continue du débit cardiaque sans devoir pratiquer ces injections manuelles.

En cas d'injection manuelle, il faut prêter attention à un certain nombre d'éléments:

- on injecte en général du glucosé $5 \%$ en eau; on peut aussi injecter une solution salée (physiologique), mais le risque d'hypervolémie est plus grand;

- cette solution est en général préalablement refroidie dans un système de serpentin plongé dans un bassin de glace pilée (température finale d'environ $8{ }^{\circ} \mathrm{C}$ ). La température de l'injectat est déterminée à l'entrée du cathéter. Pour des raisons de facilité, certains utilisent un injectat à température ambiante, sans perdre beaucoup de la qualité de la mesure;

- la quantité injectée est connue et précise: en général $10 \mathrm{~mL}$ chez l'adulte;

- l'injection doit être rapide (environ 4 secondes; pression exercée par la paume de la main sur le piston est importante) mais régulière;

- chez le malade sous ventilation mécanique, il est préférable de synchroniser la mesure avec le cycle respiratoire (le débit cardiaque fluctuant au cours du cycle respiratoire): nous commençons les injections à la fin de la phase d'insufflation de gaz par le respirateur;

- plusieurs mesures (3 à 5) successives nécessaires pour permettre le calcul d'une moyenne arithmétique.

La mesure du débit cardiaque par thermodilution a ses limitations:

- insuffisance tricuspide: le sens des altérations n'est pas toujours prévisible: le temps de transit de l'indicateur est généralement prolongé, si bien que la courbe de thermodilution est aplatie et le débit cardiaque est surestimé; la recirculation de l'indicateur peut aussi augmenter la surface sous la courbe, et le débit cardiaque est alors surestimé;

- shunt intracardiaque gauche-droit: la recirculation de l'indicateur produit un étalement de la courbe, conduisant à une sous-estimation du débit cardiaque. En cas de shunt droit-gauche, la perte de l'indicateur thermique entraîne une surestimation du débit cardiaque;

- les changements rapides de température (comme au cours de la circulation extracorporelle) modifient la ligne de base: l'installation rapide de l'hypothermie entraîne une sous-estimation, tandis qu'un réchauffement rapide entraîne une surestimation du débit cardiaque;

- les bas débits cardiaques, en dessous de 2,5 L/min, peuvent être surestimés.

\section{Valeurs normales}

Le débit cardiaque normal est d'environ $5 \mathrm{~L} / \mathrm{min}$ chez l'adulte de taille moyenne. Il est proportionnel aux dimensions de l'individu, si bien qu'il doit être ramené à la surface corporelle (body surface area ou BSA). Cette dernière peut être calculée au départ du poids en kgs $(\mathrm{P})$ et de la taille en $\mathrm{cm}(\mathrm{T})$ par la formule:

$\mathrm{BSA}=0,202$. P 0,425. T 0,725.

Pour un individu de taille et de poids normaux, la valeur avoisine 1,7 $\mathrm{M}^{2}$.

L'index cardiaque, obtenu en divisant le débit cardiaque par la BSA, est normalement de 2,5 à $3,5 \mathrm{~L} / \mathrm{min} / \mathrm{m}^{2}$. 
Fraction d'éjection ventriculaire droite: certains cathéters sont équipés d'une thermistance à réponse rapide, qui permet la mesure de la fraction d'éjection ventriculaire droite (RVEF) à partir de la courbe de thermodilution.

SV (stroke volume ou volume éjectionnel)

RVEF $=$

RVEDI (volume télédiasolique du ventricule droit)

Le SV est obtenu en divisant le débit cardiaque par la fréquence cardiaque, tandis que la RVEF est obtenue par une méthode différente. Cette mesure de la RVEF permet donc:

- d'apprécier la fonction cardiaque droite mieux que par la simple mesure du débit cardiaque;

- de calculer le RVEDVI, un meilleur index de la précharge ventriculaire droite que la pression auriculaire droite.

Toutefois, la mesure est non fiable en cas d'insuffisance tricuspide.

\section{Mesure des gaz artériels et veineux mêlés}

Le sang veineux mêlé est le mélange de sang provenant de toutes les régions de l'organisme, brassé dans les cavités droites avant d'être oxygéné dans les capillaires pulmonaires. L'analyse de ce sang permet donc de mesurer l'extraction d'oxygène par les tissus, en mesurant la saturation en oxygène de l'hémoglobine du sang veineux mêlé $\left(\mathrm{SvO}_{2}\right)$.

Celle-ci peut être obtenue par un prélèvement de sang veineux mêlé (par l'extrémité distale du cathéter pulmonaire). $\mathrm{La} \mathrm{SvO}_{2}$ peut aussi être monitorisée de manière continue si le cathéter pulmonaire est équipé de fibres optiques transmettant une intensité lumineuse à plusieurs longueurs d'ondes.

Dans les conditions physiologiques, la saturation veineuse en oxygène est plus élevée dans la veine cave inférieure que dans la veine cave supérieure, en raison de l'extraction d'oxygène faible par le rein. En revanche, au cours des insuffisances circulatoires, l'extraction d'oxygène peut devenir proportionnellement plus importante dans cette région, et le gradient peut s'inverser. C'est pourquoi la saturation en oxygène d'un échantillon veineux prélevé par un cathéter veineux central ne permet qu'une évaluation approximative de la $\mathrm{SvO}_{2}$.

La valeur normale de la $\mathrm{SvO}^{2}$ est de 70 à $75 \%$ (correspondant à une $\mathrm{PvO}^{2}$ de 35 à $40 \mathrm{mmHg}$ ).

$\mathrm{La} \mathrm{SvO}_{2}$ met en rapport le transport en oxygène $\left(\mathrm{DO}_{2}\right)$ en rapport avec la consommation d'oxygène $\left(\mathrm{VO}_{2}\right)$.

De l'équation de Fick, on tire:

$\mathrm{V} \mathrm{O}_{2}=\mathrm{CO} \times\left(\mathrm{Ca} \mathrm{O}_{2}-\mathrm{Cv} \mathrm{O}\right)$

$\mathrm{V} \mathrm{O}_{2}=\mathrm{CO} \times \mathrm{Hb} \times 1,38 \times\left(\mathrm{Sa} \mathrm{O}_{2}-\mathrm{Sv} \mathrm{O}\right)_{2} \times 10$

$\mathrm{Sv} \mathrm{O}_{2}=\mathrm{Sa} \mathrm{O}_{2}-\frac{\mathrm{VO}^{\circ}}{\mathrm{CO} \times \mathrm{Hb} \times 13,8}$

( $\mathrm{CO}=$ cardiac output ou débit cardiaque $) ; \mathrm{Hb}=$ hémoglobine $)$

Ainsi, une diminution de la $\mathrm{SvO}_{2}$ peut être due à trois facteurs (fig. 7): 
- hypoxémie (une diminution de $\mathrm{SaO}_{2}$ entraîne une diminution directe de la $\left.\mathrm{SvO}_{2}\right)$;

- anémie (avec compensation incomplète par le débit cardiaque);

- une augmentation du rapport entre la demande en oxygène et le débit cardiaque.

Elle peut être physiologique au cours de l'effort. Chez le malade alité, elle est généralement pathologique, due à un débit cardiaque insuffisant pour une demande donnée: insuffisance cardiaque, hypovolémie, embolie pulmonaire massive...

Une élévation de la $\mathrm{SvO}_{2}$ au-dessus de la normale peut être due à trois facteurs (fig. 7):

- un désordre de type distributif (sepsis): c'est la cause la plus fréquente;

- une demande en oxygène réduite (anesthésie, hypothermie...);

- un débit cardiaque excessif (hypervolémie, excès d'agents vasoactifs).
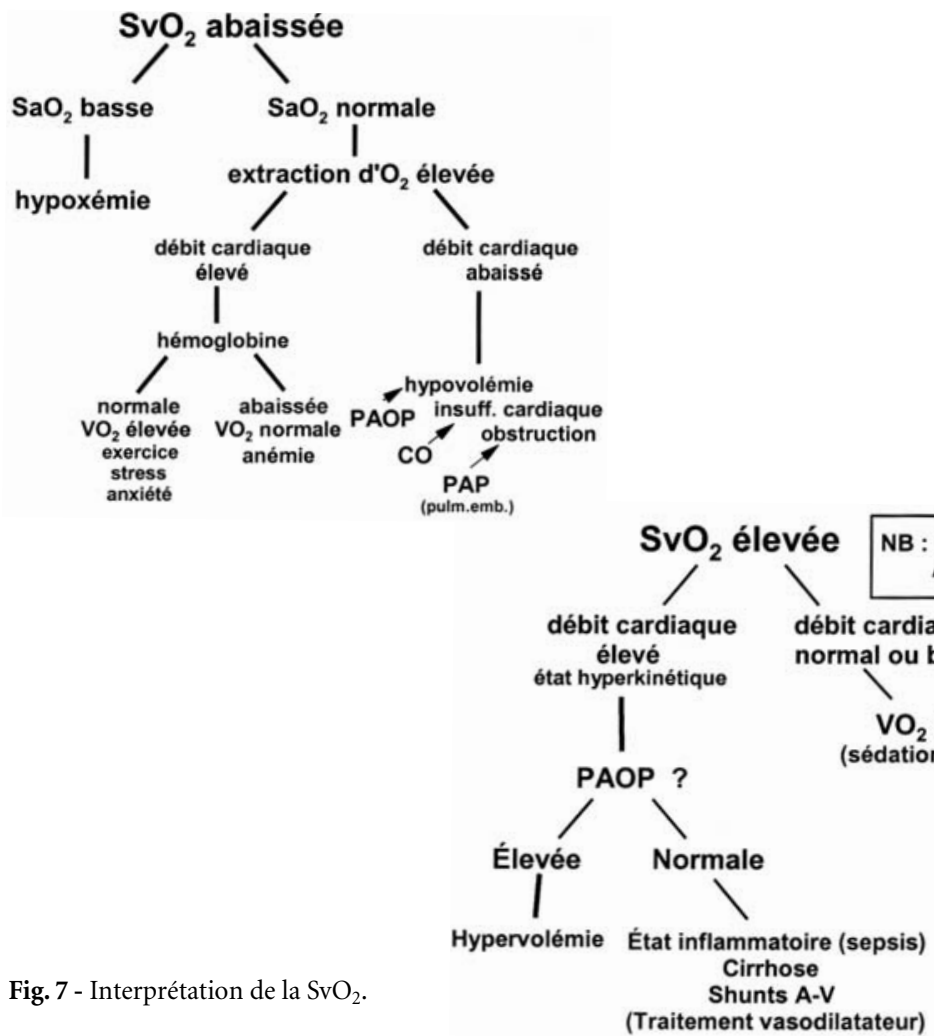

Fig. 7 - Interprétation de la $\mathrm{SvO}_{2}$.

(Traitement vasodilatateur)

Une $\mathrm{PaO}_{2}$ normale de $100 \mathrm{mmHg}$ correspond à une saturation en oxygène $\left(\mathrm{SO}_{2}\right)$ de l'hémoglobine de $97 \%$, tandis qu'une $\mathrm{PaO}_{2}$ de $60 \mathrm{mmHg}$ correspond à une $\mathrm{SaO}_{2}$ de 90 \%. Dans le sang veineux mêlé, la $\mathrm{PvO}_{2}$ est normalement de 35-40 mmHg et la $\mathrm{SvO}_{2}$ de 70-75 \%. La $\mathrm{P} 50$, ou $\mathrm{PO}_{2}$ correspondant à une $\mathrm{SO}_{2}$ de $50 \%$, est normalement aux environs de $27 \mathrm{mmHg}$ (fig. 7). 


\section{Complications du cathétérisme pulmonaire}

On peut les rassembler en sept points:

\section{Problèmes d'insertion difficile}

Pneumothorax.

Hématome sur ponction artérielle (en particulier la carotide).

Embolie gazeuse.

Lésion neurologique...

\section{Recommandations}

La ponction veineuse doit être prudente.

En cas de développement d'hématome suite à la ponction veineuse centrale, il faut éviter d'aborder immédiatement l'autre côté (risque d'obstruction des voies aériennes supérieures en cas d'hématome bilatéral).

Il faut empêcher l'entrée d'air par l'introducteur lors de l'entrée du cathéter.

\section{Arythmies}

Extrasystoles supra- et ventriculaires par irritation de l'endocarde (en particulier lors du passage dans le ventricule droit).

Bloc de branche droit - risque de bloc A-V complet en cas de bloc de branche gauche préalable.

\section{Recommandations}

On peut administrer de la lidocaïne (100 mg) avant l'insertion du cathéter chez le patient à risque.

Il faut vérifier que le ballonnet est entièrement gonflé (1,5 cc d'air) avant le passage vers le ventricule droit.

Il faut préparer un pacemaker chez le patient présentant un bloc de branche gauche. En cas de difficultés, il peut être souhaitable de recourir à la fluoroscopie pour faciliter le placement du cathéter.

\section{Nœud dans le cathéter}

Un nœud peut se former en cas de mise en place difficile, lors de manipulations en avant et en arrière. 


\section{Recommandation}

Il ne faut pas avancer le cathéter de plus de $15 \mathrm{~cm}$ dans le ventricule droit.

\section{Thrombose et infarctus pulmonaire}

Ces complications peuvent se manifester par un infiltrat radiologique en aval de l'extrémité du cathéter.

\section{Recommandations}

Il ne faut jamais maintenir un cathéter trop avancé (l'extrémité ne peut dépasser l'image du hile pulmonaire).

Lors de la mesure de la pression occlusive, il ne faut pas garder le ballonnet gonflé pendant plus de trois cycles respiratoires.

\section{Lésion endocardique/lésion du pilier}

Il s'agit en général d'une découverte incidente d'autopsie, sans répercussion clinique; l'endocardite tricuspide reste exceptionnelle.

\section{Recommandation}

Il ne faut jamais retirer le cathéter avec le ballonnet gonflé.

\section{Rupture de l'artère pulmonaire}

Il s'agit de la complication la plus redoutable, heureusement exceptionnelle ( $<1 / 1000$ cathétérismes), mais mortelle dans $50 \%$ des cas.

- Elle se manifeste par une hémoptysie massive qui peut être rapidement suivie d'un choc circulatoire - éventuellement infiltrat radiologique correspondant à la présence de sang + éventuellement hémothorax.

\section{Facteurs favorisants}

- âge avancé;

- hypertension artérielle pulmonaire;

- anticoagulation;

- hypothermie;

- cathéter trop avancé. 


\section{Recommandation}

Il faut vérifier la bonne position du cathéter pulmonaire et le retirer systématiquement s'il est trop avancé.

\section{Infections}

Comme pour tout cathéter intraveineux; le risque est accru par les manipulations (mesure du débit cardiaque, prélèvement de sang veineux mêlé...).

\section{Recommandations}

Il faut respecter scrupuleusement les mesures de stérilité lors de la manipulation du cathéter.

Il n'est pas recommandé de remplacer systématiquement le cathéter après un certain laps de temps prédéterminé. En revanche, le besoin du cathéter doit être réévalué quotidiennement.

\section{Retrait du cathéter}

Le retrait d'un cathéter pulmonaire doit être prudent:

s'assurer que le ballonnet est bien dégonflé, afin de ne pas léser les structures vasculaires et veineuses;

ne pas insister en présence de résistance: il vaut mieux réavancer quelque peu le cathéter et éventuellement s'interrompre pour réaliser une radiographie ou un examen fluoroscopique;

mettre le patient à plat et retirer le cathéter lors de la phase expiratoire pour limiter le risque d'embolie gazeuse;

surveiller le monitoring pour s'assurer de l'absence d'arythmies;

éventuellement couper l'extrémité distale du cathéter en vue d'un examen bactériologique.

\section{Techniques moins invasives}

\section{Systèmes PiCCO et COLD}

Ces systèmes comprennent un cathéter artériel équipé d'une thermistance permettant la mesure du débit cardiaque par thermodilution, après passage de l'indicateur au travers des poumons (thermodilution transpulmonaire). Le débit cardiaque est estimé par injection soit de vert d'indocyanine (système COLD), soit de glucosé en eau froide (système PiCCO), soit de faible quantité de lithium 
(LidCO) par un cathéter veineux central. Bien que la méthode de thermodilution transpulmonaire soit fiable, ces techniques ne donnent accès ni à la PAPO ni à la $\mathrm{SvO}_{2}$.

Ces techniques permettent une évaluation continue du débit cardiaque par l'analyse du tracé artériel ( "pulse contour analysis»), mais cette évaluation suppose que l'impédance vasculaire soit constante. Il faut donc recalibrer le système (en remesurant le débit cardiaque par thermodilution) chaque fois que la situation hémodynamique a changé soit spontanément, soit sous l'effet de changements thérapeutiques (en particulier d'agents vasoactifs).

L'analyse de la courbe de dilution permet aussi l'estimation du volume sanguin intrathoracique, un indicateur de la précharge ventriculaire, ainsi que de l'eau extravasculaire pulmonaire.

\section{Échocardiographie}

L'échocardiographie et le cathétérisme de Swan-Ganz peuvent être parfois concurrents, ils sont plus souvent complémentaires (tableau III).

Tableau III - Avantages et inconvénients de l'échocardiographie.

\begin{tabular}{|l|l|}
\hline Avantages & Désavantages \\
\hline Non-invasif. & Opérateur-dépendant. \\
Mise en place rapide. & Appareil-dépendant. \\
Visualisation de la contractilité & Patient-dépendant (surtout pour le \\
segmentaire et de la fonction & transœsophagien). \\
valvulaire. & Évaluation généralement ponctuelle. \\
& Évaluation bi- (et non tri-) \\
& dimensionnelle. \\
& Coût de l'appareillage. \\
\hline
\end{tabular}

La voie transœsophagienne est supérieure à la voie transthoracique, surtout chez les malades obèses, traités par ventilation mécanique, ou présentant de l'emphysème sous-cutané. La voie transœsophagienne est contre-indiquée en cas de pathologie œsophagienne.

L'échocardiographie peut être extrêmement utile pour évaluer:

- le degré de distension des cavités cardiaques (dilatation des cavités droites);

- les dyskinésies segmentaires: en faveur d'un problème coronarien;

- la contractilité globale;

- la fonction diastolique;

- la présence de valvulopathies ou de végétations; 
- la présence d'épanchement péricardique;

- prédire la réponse au remplissage vasculaire (variations respiratoires du flux aortique et du diamètre de la veine cave supérieure).

L'échocardiographie peut donc être utile (fig. 8):

- soit avant la mise en place éventuelle d'un cathéter de Swan-Ganz: dans le but de poser un diagnostic qui peut déjà orienter le traitement (tamponnade, dilatation ventriculaire droite, défaut de remplissage vasculaire...);

- soit quand le cathéter de Swan-Ganz est déjà en place (à visée complémentaire [valvulopathie, dyskinésies, végétations...])

L'échographie a aussi ses limitations (tableau III).

Chaque USI devrait disposer d'un appareil d'échocardiographie 24 heures/24. L'usage de la technique doit faire partie de la formation de base de l'intensiviste.

\section{Cathéterisme pulmonaire \\ Échocardiographie}

\section{diagnostic monitoring diagnostic monitoring} Hypovolémie

Pathologie valvulaire Insuff. cardiaque Insuff. VD Choc septique
Tamponnade
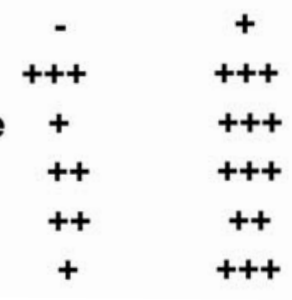

Fig. 8 - Avantages respectifs du cathétérisme pulmonaire et de l'électrocardiogramme.

\section{Doppler transœsophagien}

Cette technique permet l'appréciation du débit sanguin aortique (aorte descendante) de manière continue et quasi-non invasive. Cette méthode présente l'avantage de mesurer le volume éjectionnel battement par battement, permettant la prédiction de la réponse au remplissage vasculaire (soit par fluctuation du flux aortique au cours du cycle respiratoire, soit lors d'une épreuve de lever de jambes) L'analyse des courbes permet une certaine appréciation (toutefois grossière) des facteurs de précharge, de contractilité et de postcharge.

\section{Bio-impédance}

Cette technique est relativement fiable chez l'individu normal mais très (trop) approximative chez le malade grave. 
La limitation des mesures non-invasives est le manque d'accès à une mesure de saturation en oxygène du sang veineux mêlé $\left(\mathrm{SvO}_{2}\right)$.

\section{Interprétation des mesures hémodynamiques}

\section{Les pressions intravasculaires}

Les pressions hydrostatiques à l'intérieur d'un vaisseau sont influencées par la force de contraction ventriculaire, la résistance et l'élasticité de la paroi artérielle, la viscosité et le volume sanguin.

Les pressions moyennes sont généralement obtenues électroniquement par le système de monitorage. On peut aussi les calculer en ajoutant un tiers de la pression différentielle (systolique - diastolique) à la pression diastolique.

L'hypotension artérielle est généralement définie par une pression artérielle systolique inférieure à $90 \mathrm{mmHg}$. Cette valeur est toutefois très arbitraire, car les individus jeunes peuvent tolérer des niveaux très bas de pression artérielle sans évidence d'altérations de perfusion tissulaire. De plus, les valeurs normales de pression artérielle varient en fonction de l'âge.

L'hypertension artérielle pulmonaire peut être:

- secondaire (ou postcapillaire): la PAPO est élevée, indiquant une pathologie cardiaque gauche (insuffisance cardiaque, pathologie mitrale ou aortique...) et/ou une hypervolémie;

- primaire (ou précapillaire): La PAPO n'est pas élevée, ou en tout cas le gradient entre la PAP diastolique et la PAPO est accru (supérieur à $2 \mathrm{mmHg}$ ), indiquant une pathologie pulmonaire plutôt qu'une élévation des pressions de remplissage gauche (fig. 9 et tableau IV).

La reconnaissance d'une onde $\mathrm{V}$ proéminente évoque le diagnostic d'insuffisance mitrale, mais n'est toutefois pas pathognomonique. Si l'auscultation n'est pas décisive, l'échographie est l'examen de choix pour confirmer ou infirmer ce diagnostic.

La pression de l'oreillette droite est normalement inférieure (de l'ordre de 2-4 $\mathrm{mmHg}$ ) à la PAPO. Ce gradient PAPO-POD peut s'inverser dans une série de situations associées à une dysfonction ventriculaire droite (tableau V).

\section{Le débit cardiaque}

Le débit cardiaque résulte de l'éjection d'un volume éjectionnel un certain nombre de fois par minute (fréquence cardiaque). Les trois facteurs influençant le volume éjectionnel sont la contractilité, la précharge et la postcharge (fig. 10).

La précharge représente le degré d'étirement de la fibre myocardique avant sa contraction. Pour le ventricule, il s'agit du volume télédiastolique. La mesure du volume télédiastolique n'est pas facile en clinique (même par échographie, qui donne une image bi- et non tridimensionnelle), surtout de manière répétée. Les mesures de pression sont plus utiles à guider les remplissage vasculaire, d'autant plus 


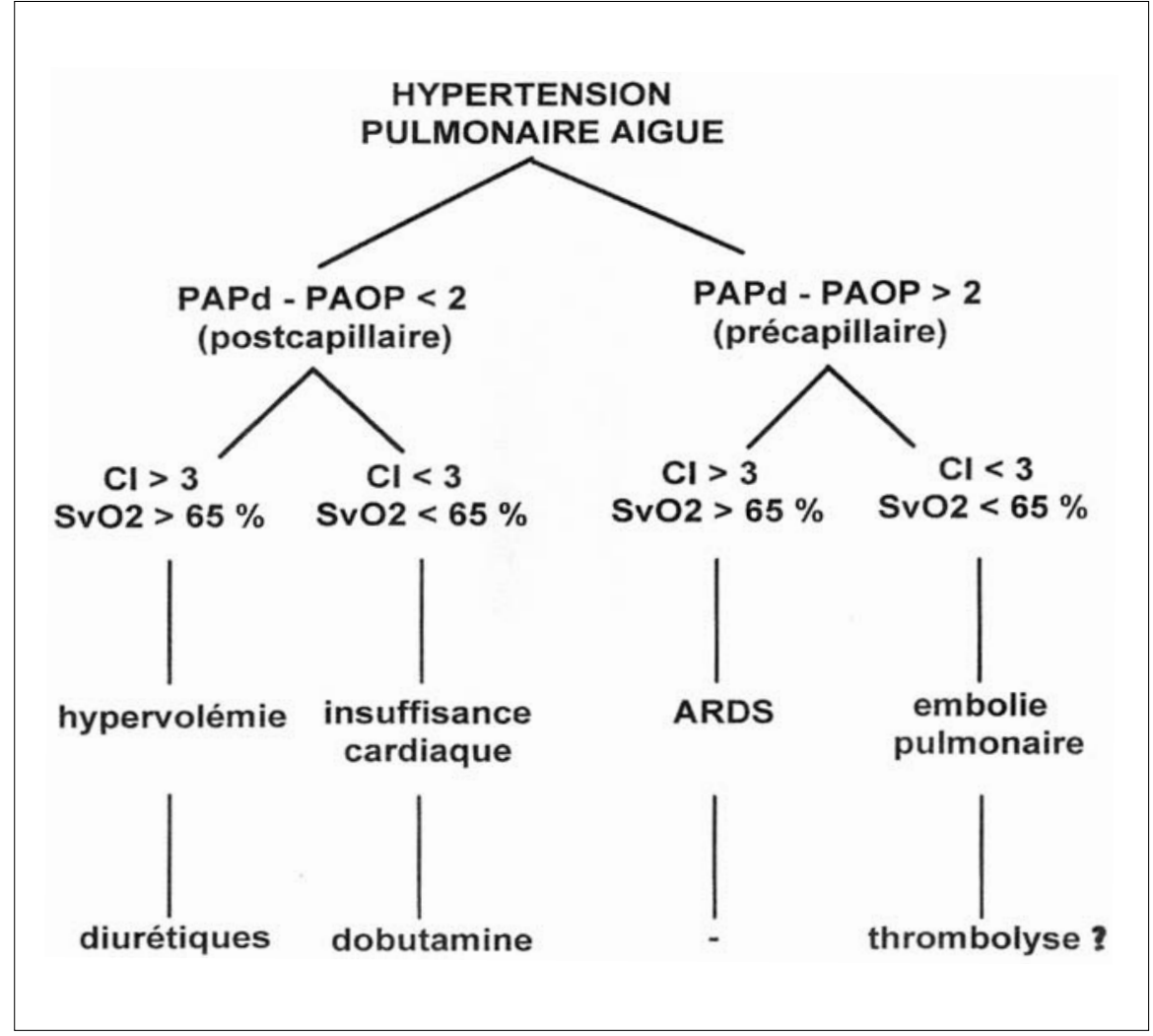

Fig. 9 - Interprétation d'une hypertension artérielle pulmonaire en fonction des autres paramètres.

Tableau IV - Causes principales d'hypertension artérielle pulmonaire primaire ou précapillaire.

\section{Chronique:}

- pathologie pulmonaire chronique: BPCO, fibrose, cyphoscoliose, pneumoconiose, mucoviscidose...

- pathologie vasculaire chronique: maladie thromboembolique, vasculite... élévation chronique de la PAPO, corrigée par le traitement (remplacement de valve mitrale, transplantation cardiaque...)

- compressions extrinsèques: tumeur, anévrisme...

- hypertension artérielle pulmonaire primitive

\section{Aiguë:}

- hypoxémie $\left(\mathrm{PaO}_{2}<60 \mathrm{mmHg}\right)$ ou hypercapnie

- ARDS

- pneumopathie infectieuse

- asthme sévère

- embolie pulmonaire 
Tableau V - Interprétation du gradient de pressions PAPO-POD.

\begin{tabular}{|l|l|l|}
\hline Gradient PAPO - POD & $\begin{array}{l}\text { diminué ou inversé } \\
(\text { PAPO }<\text { POD })\end{array}$ & $\begin{array}{l}\text { Augmenté } \\
(\text { PAPO }>\text { POD })\end{array}$ \\
\hline Situations cliniques & $\begin{array}{l}\text { Hypertension artérielle } \\
\text { pulmonaire (ARDS, } \\
\text { embolie pulmonaire, } \\
\text { BPCO, etc) }\end{array}$ & $\begin{array}{l}\text { Insuffisance cardiaque } \\
\text { gauche }\end{array}$ \\
\hline & $\begin{array}{l}\text { Infarctus ventriculaire } \\
\text { droit }\end{array}$ & $\begin{array}{l}\text { Pathologie coronarienne } \\
\text { Valvulopathie mitrale ou } \\
\text { aortique }\end{array}$ \\
\hline & Insuffisance tricuspide & Hypertension artérielle \\
\hline
\end{tabular}

fluid challenge
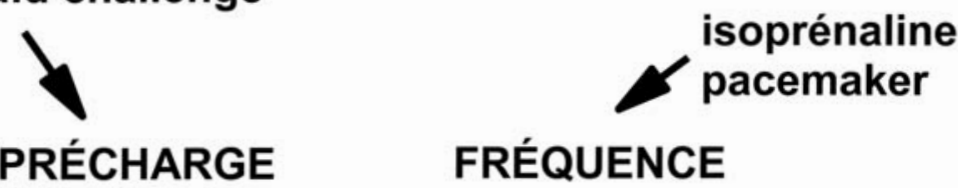

PRÉCHARGE

\section{FRÉQUENCE}

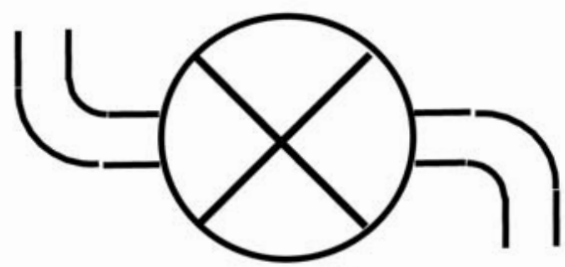

CONTRACTILITÉ

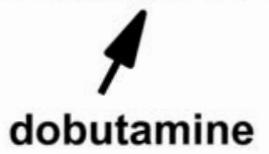

\section{POSTCHARGE}

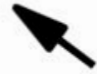

vasodilatateurs

Fig. 10 - Les quatre déterminants du débit cardiaque avec les interventions thérapeutiques correspondantes.

que c'est la pression hydrostatique dans le vaisseau qui est le déterminant le plus direct de la formation d'œè̀me.

La pression veineuse centrale ou de l'oreillette droite (POD) est généralement un bon reflet de la pression télédiastolique du ventricule droit, mais ces pressions sont 
influencées par différents paramètres: contractilité ventriculaire, pressions de l'artère pulmonaire, compliance ventriculaire, volume plasmatique, retour veineux, tonus vasculaire veineux.

La POD ne donne donc pas nécessairement une information fiable concernant la PAPO, en cas de pathologie cardio-pulmonaire.

La mise en relation de la PAPO et du débit cardiaque permet d'apprécier la fonction cardiaque selon la relation de Frank-Starling (fig. 12) et d'envisager des options thérapeutiques correspondantes (fig. 13).

\begin{tabular}{|c|c|c|c|c|c|}
\hline $\begin{array}{c}\text { Pression } \\
\text { artérielle }\end{array}$ & $\begin{array}{c}\text { P artère } \\
\text { pulmonaire }\end{array}$ & PAPO & $\begin{array}{c}\text { Débit } \\
\text { cardiaque }\end{array}$ & $\begin{array}{c}\text { Résistances } \\
\text { vasculaires } \\
\text { systémiques }\end{array}$ & Problème \\
\hline $\begin{array}{c}\text { Normale ou } \\
\text { abaissée }\end{array}$ & Élevée & Élevée & Bas & Élevées & $\begin{array}{c}\text { Insuff. } \\
\text { cardiaque } \\
\text { gauche }\end{array}$ \\
\hline $\begin{array}{c}\text { Normale ou } \\
\text { abaissée }\end{array}$ & Basse & Basse & Bas & Élevées & Hypovolémie \\
\hline $\begin{array}{c}\text { Normale ou } \\
\text { abaissée }\end{array}$ & Élevée & Normale & Bas & Élevées & $\begin{array}{c}\text { Embolie } \\
\text { pulmonaire }\end{array}$ \\
\hline $\begin{array}{c}\text { Normale ou } \\
\text { abaissée }\end{array}$ & $\begin{array}{c}\text { Normale ou } \\
\text { élevée }\end{array}$ & Normale & Élevé & Basses & $\begin{array}{c}\text { Inflammation } \\
\text { Sepsis }\end{array}$ \\
\hline Élevée & Élevé & Élevée & Élevé & Normales & $\begin{array}{c}\text { Hypervolémie } \\
\text { (Insuff. rénale) }\end{array}$ \\
\hline Élevée & Normale & Normale & Élevé & Normales & $\begin{array}{c}\text { Stress } \\
\text { Exercice }\end{array}$ \\
\hline Élevée & Normale & Basse & Bas & Élevées & $\begin{array}{c}\text { Vasoconstriction } \\
\text { sévère }\end{array}$ \\
\hline
\end{tabular}

Fig. 11 - Altérations hémodynamiques attendues dans certaines situations cliniques.

\section{VOLUME ÉJECTIONNEL}

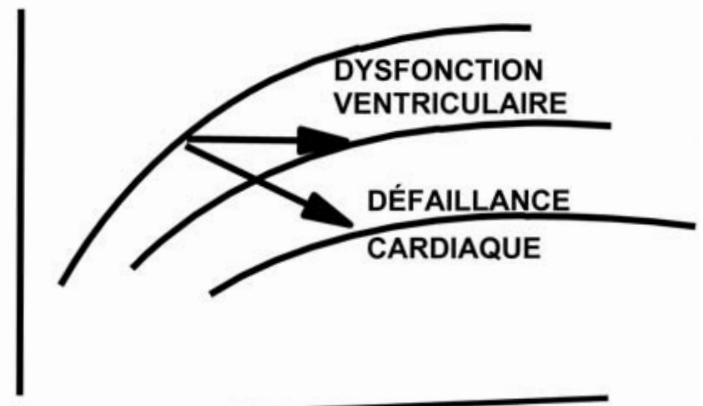

VOLUME TÉLÉ-DIASTOLIQUE

Fig. 12 - Relation de Starling avec courbe de fonction ventriculaire. 


\section{HYPOTENSION}

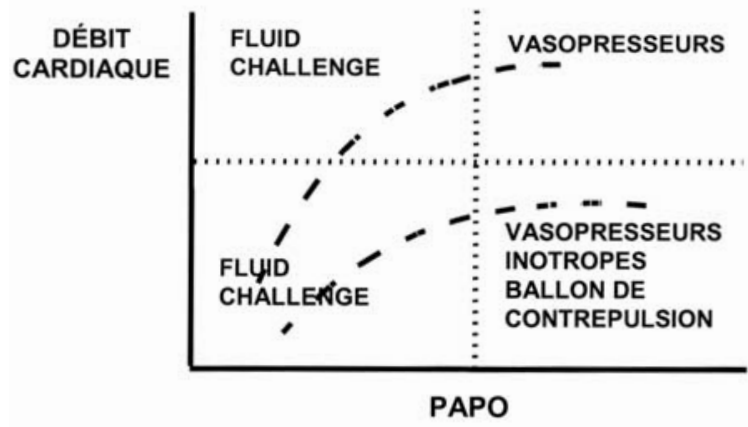

\section{PAS D'HYPOTENSION}

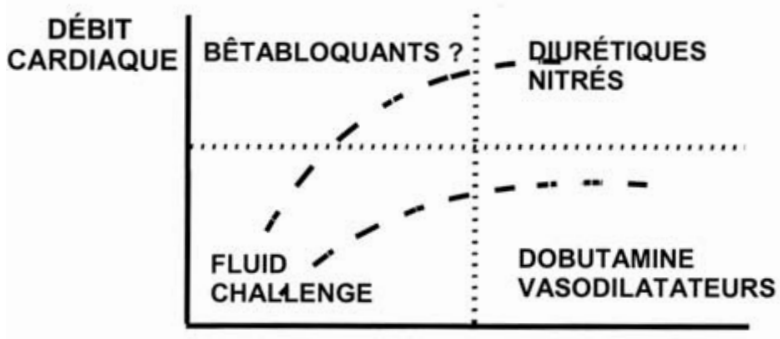

PAPO
Fig. 13 - Options thérapeutiques basées sur l'examen de la courbe de fonction ventriculaire en présence (partie supérieure) et en l'absence (partie inférieure) d'hypotension.

Un débit cardiaque élevé n'exclut pas l'insuffisance cardiaque (tableau VII).

La mesure du débit cardiaque doit être systématiquement complétée d'une évaluation simultanée de la $\mathrm{SvO}_{2}$, pour en permettre l'interprétation (fig. 13).

\section{$\mathrm{ScvO}_{2}$}

Une diminution de la $\mathrm{SvO}_{2}$ peut refléter trois situations (à évaluer successivement).

On peut estimer grossièrement la $\mathrm{SvO}_{2}$ à partir de la $\mathrm{SO}_{2}$ de la veine cave supérieure. Il s'agit de mesures soit itératives (prélèvements sanguins par le cathéter veineux central), soit continues au moyen de cathéters centraux modifiés, présentant des fibres optiques (Pre-sep, Edwards) ou encore une sonde qui peut être introduite dans le cathéter.

Il faut toutefois savoir que dans les conditions normales, la $\mathrm{ScvO}_{2}$ est inférieure à la $\mathrm{SvO}_{2}$, en raison du contenu élevé en oxygène du sang veineux rénal, mais que la $\mathrm{ScvO}_{2}$ devient superieure à la $\mathrm{SvO}_{2}$ en cas de diminution de la $\mathrm{DO}_{2}$ (hypovolémie, bas débit cardiaque, anémie...). La mesure est donc approximative. 
Tableau VI- Principaux paramètres hémodynamiques et gazométriques dérivés (abbréviations internationales).

\begin{tabular}{|c|c|}
\hline MAP, mmHg & $\frac{\text { PA syst. }+2 \text { PA diast. }}{3}$ \\
\hline PAP, $\mathrm{mmHg}$ & $\frac{\text { PAP syst. + 2 PAP diast. }}{3}$ \\
\hline $\mathrm{CI}, \mathrm{m} / \mathrm{min} / \mathrm{M}^{2}$ & $\frac{\mathrm{CO}}{\mathrm{BSA}}$ \\
\hline $\mathrm{SV}, \mathrm{mL}$ & $\frac{\mathrm{CO} \times 1000}{\mathrm{HR}}$ \\
\hline $\mathrm{SI}, \mathrm{mL} / \mathrm{M}^{2}$ & $\frac{\mathrm{CI} \times 1000}{\mathrm{HR}}$ \\
\hline SVR, dynes. sec. $\mathrm{cm}^{-5}$ & $\frac{(\mathrm{MAP}-\mathrm{RAP}) \times 79,9}{\mathrm{CO}}$ \\
\hline PVR, dynes. sec. $\mathrm{cm}^{-5}$ & $\frac{(\mathrm{PAP}-\mathrm{PAPO}) \times 79,9}{\mathrm{CO}}$ \\
\hline LVSWI, gm. m/beat/M² & $(\mathrm{MAP}-\mathrm{PAPO}) \times \mathrm{SI} \times 0,0136$ \\
\hline RVSWI, gm. m/beat $/ \mathrm{M}^{2}$ & $(\mathrm{PAP}-\mathrm{RAP}) \times \mathrm{SI} \times 0,0136$ \\
\hline $\mathrm{PAO}_{2}, \mathrm{mmHg}$ & $\left(\mathrm{P}_{\mathrm{bar}}-47\right) \times \mathrm{FiO}_{2}-(\mathrm{PaCO} 2 \times 1,25)$ \\
\hline (A-a) $\mathrm{DO}_{2}, \mathrm{mmHg}$ & $\mathrm{P}_{\mathrm{A}} \mathrm{O}_{2}-\mathrm{PaCO}_{2}$ \\
\hline $\mathrm{CcO}_{2}, \mathrm{~mL} \%$ & $(\mathrm{Hb} \times 1,34)+0,0031 \times \mathrm{PaO}_{2}$ \\
\hline $\mathrm{CaO}_{2}, \mathrm{~mL} \%$ & $\left(\mathrm{Hb} \times 1,34 \times \mathrm{SaO}_{2}\right)+0,0031 \times \mathrm{PaO}_{2}$ \\
\hline $\mathrm{CvO}_{2}, \mathrm{~mL} \%$ & $\left(\mathrm{Hb} \times 1,34 \times \mathrm{SvO}_{2}\right)+0,0031 \times \mathrm{PvO}_{2}$ \\
\hline $\mathrm{VO}_{2}, \mathrm{~mL} / \mathrm{min} / \mathrm{M}^{2}$ & $\left(\mathrm{CaO}_{2}-\mathrm{CvO}_{2}\right) \times \mathrm{CI} \times 10$ \\
\hline $\mathrm{DO}_{2}, \mathrm{~mL} / \mathrm{min} / \mathrm{M}^{2}$ & $\mathrm{CaO}_{2} \times \mathrm{CI} \times 10$ \\
\hline $\mathrm{O}_{2}$ extr, $\%$ & 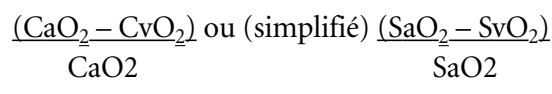 \\
\hline Qs/Qt, \% & $\frac{\mathrm{CcO} 2-\mathrm{CaO} 2}{\mathrm{CcO}_{2}-\mathrm{CvO}_{2}}$ \\
\hline
\end{tabular}


Tableau VII - Causes principales d'insuffisance cardiaque à haut débit.

\section{Sepsis}

Anémie

Hyperthyroïdie

Béri-béri

Maladie de Paget

Fistules artério-veineuse

Myélome multiple

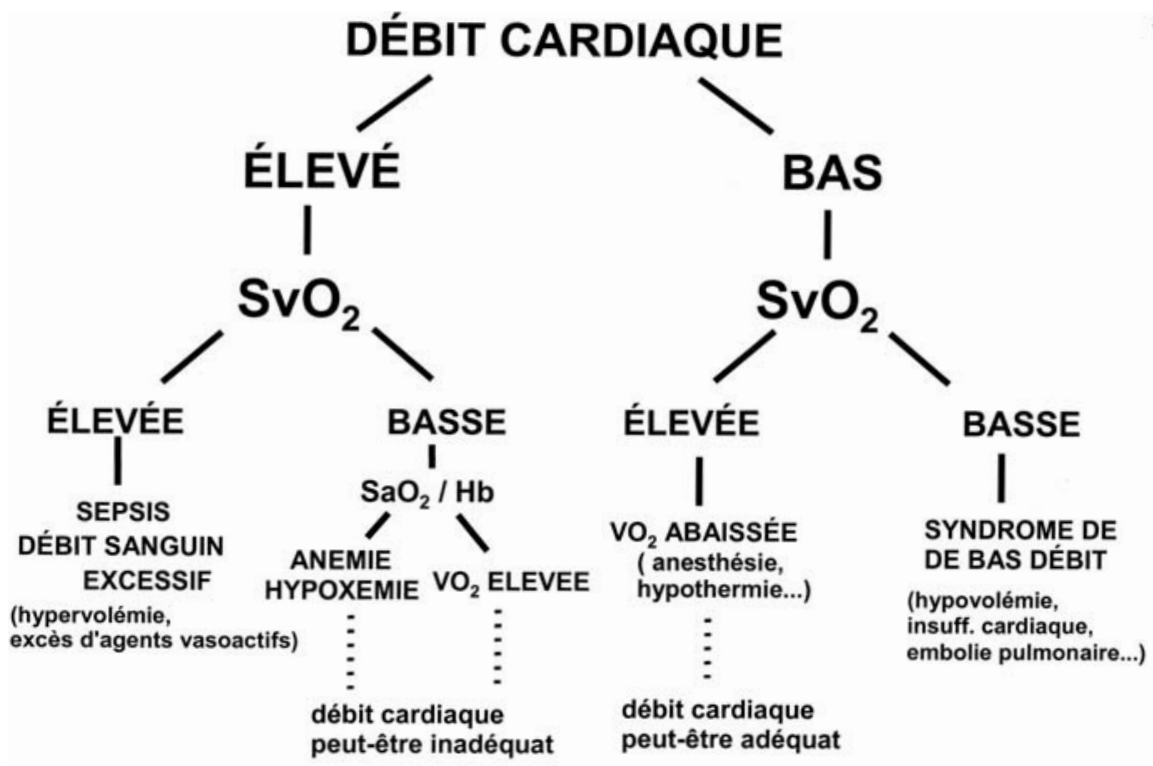

Fig. 14 - Interprétation du débit cardiaque en fonction de la $\mathrm{SvO}_{2}$.

\section{Transport d'oxygène $\left(\mathrm{DO}_{2}\right)$ et consommation d'oxygène $\left(\mathrm{VO}_{2}\right)$}

Le transport ou la délivrance en oxygène (oxygen delivery ou $\mathrm{DO}_{2}$ ) est déterminé par le débit cardiaque (DC) et le contenu en oxygène du sang artériel $\left(\mathrm{CaO}_{2}\right)$ :

$\mathrm{DO}_{2}=\mathrm{DC} \times \mathrm{CaO}_{2} \times 10$

(le facteur de 10 est nécessaire à la conversion du litre au décilitre)

et la $\mathrm{CaO}_{2}$ est calculée à son tour par la relation suivante:

$\mathrm{CaO}_{2}=\left(\mathrm{Hb} \times \mathrm{SaO}_{2} \times 1,39\right)+0,031 \times \mathrm{PaO}_{2}$ 
dans laquelle $\mathrm{SaO}_{2}$ est la saturation artérielle du sang artériel et 1,39 la constante représentant la quantité d'oxygène liée à $1 \mathrm{~g}$ d'hémoglobine. En fait, la deuxième partie de l'équation, représentant l'oxygène dissout dans le sang, peut être négligée.

La $\mathrm{DO}_{2}$ représente la quantité d'oxygène transportée dans l'aorte (fig. 15), mais ne tient pas compte de facteurs régulant la distribution du sang en périphérie.

\section{TRANSPORT D'OXYGÈNE}

\section{$\mathrm{DO}_{2}=$ Contenu artériel en $\mathrm{O}_{2} \times$ Débit cardiaque}

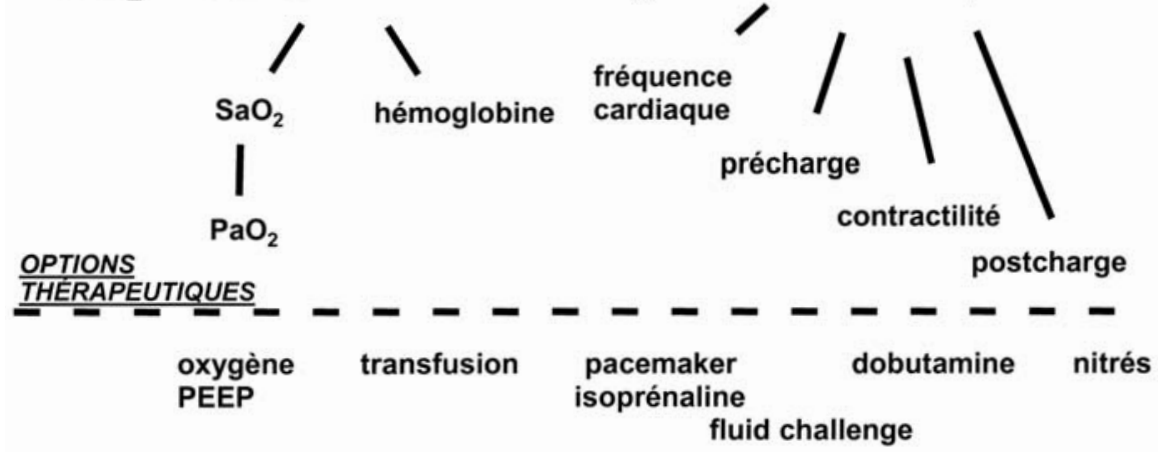

Fig. 15 - Paramètres déterminants le transport d'oxygène avec les interventions thérapeutiques s'y rapportant.

La disponibilité en $\mathrm{O}_{2}$ des cellules (oxygen availability) dépend en fait de cinq facteurs:

- la saturation en oxygène de l'hémoglobine;

- la concentration en hémoglobine;

- le débit cardiaque;

- la distribution du sang dans la microcirculation;

- l'avidité de l'hémoglobine pour l'O ${ }_{2}$ (définie par la courbe de dissociation de l'hémoglobine, et dépendant notamment du pH, de la $\mathrm{PCO}_{2}$, de la température et de la concentration en 2,3 DPG).

L'hypoxémie et l'anémie sont généralement compensées par une augmentation du débit cardiaque, si bien qu'elles entraînent rarement une hypoxie cellulaire. Si la fonction cardio-circulatoire est normale, la $\mathrm{PaO}_{2}$ doit être abaissée en dessous de $30 \mathrm{mmHg}$ pour que s'installe une acidose lactique.

L'hypoxie tissulaire est généralement liée à une insuffisance circulatoire aiguë (choc).

$\mathrm{La} \mathrm{VO}_{2}$ est normalement égale à la demande en oxygène. Elle est normalement au repos aux environs de $250 \mathrm{ml} / \mathrm{min}$ ou $150 \mathrm{~mL} / \mathrm{min} . \mathrm{m}^{2}$.

La demande en oxygène est augmentée par:

- la fièvre (elle augmente de 10 à $15 \%$ par $^{\circ} \mathrm{C}$ ); 
- la réaction inflammatoire (infection, chirurgie récente, trauma, brûlures...);

- le degré de douleur, anxiété, énervement...;

- le type de ventilation (la dyspnée augmente la $\mathrm{VO}_{2}$, la ventilation mécanique la diminue);

- les actes médicaux, paramédicaux et infirmiers (physiothérapie, toilette...).

Une augmentation de la demande en $\mathrm{O}_{2}$ peut être assurée par une augmentation du débit cardiaque et/ou par une augmentation de l'extraction d'oxygène.

À l'opposé, elle est diminuée par:

- la diminution de température corporelle (contrôle de la fièvre ou hypothermie);

- la diminution des facteurs de stress et la sédation;

- la ventilation mécanique (qui diminue le travail respiratoire).

Une diminution de la demande en $\mathrm{O}_{2}$ se caractérise par une diminution du débit cardiaque et une élévation de la $\mathrm{SvO}_{2}$.

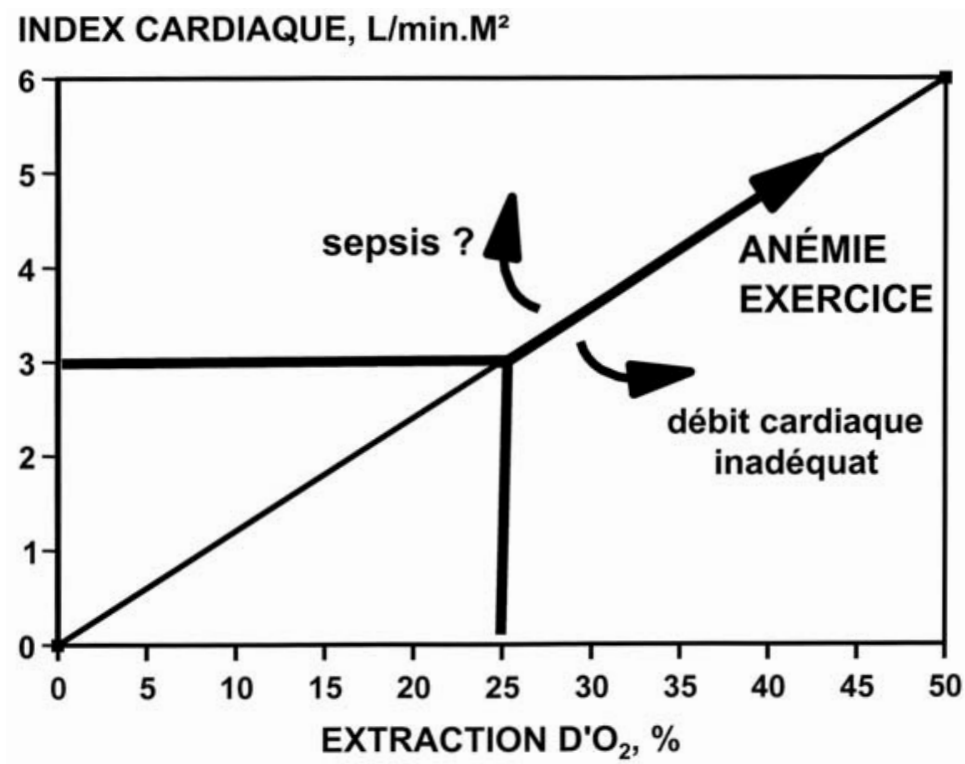

Fig. 16 - Diagramme mettant l'index cardiaque en rapport avec l'extraction d'oxygène.

On peut déterminer la $\mathrm{VO}_{2}$ soit de manière directe soit de manière indirecte.

Méthode indirecte: en appliquant l'équation de Fick, à partir des mesures de débit cardiaque et les analyses de gaz sanguins. 
Méthode directe; par la mesure des contenus en oxygène des gaz inspirés et expirés (technique de calorimétrie indirecte):

- chez le patient non intubé: elle est difficile à réaliser, car elle nécessite une enceinte close autour de la bouche et du nez (système « canopy »);

- chez le patient intubé: la mesure est sujette à une série de limitations, et est peu précise lorsque la $\mathrm{FiO}_{2}$ est élevée (au-delà de $50 \%$ ).

De toute manière, la détermination de la $\mathrm{VO}_{2}$ n'a que peu d'applications dans la prise en charge du malade. Elle peut éventuellement préciser les besoins caloriques du malade.

\section{Hypoxie tissulaire}

L'hypoxie est définie par une disponibilité insuffisante en oxygène dans la cellule.

Le monitorage de l'hypoxie cellulaire est très complexe.

\section{Causes}

- insuffisance circulatoire aiguë (choc) : le plus fréquent ;

hypoxie associée à bas débit circulatoire (« hypoxie stagnante », dans les chocs cardiogénique, hypovolémique et obstructif) ou à un désordre microcirculatoire (« dysoxie », dans les états de choc distributif);

- hypoxémie sévère ( hypoxie hypoxémique ») ou anémie sévère (" hypoxie anémique »), si l'augmentation du débit cardiaque n'est pas suffisante pour compenser la diminution de contenu artériel en oxygène. Il s'agit donc d'hypoxémies sévères $\left(\mathrm{PaO}_{2}\right.$ généralement $\left.<40 \mathrm{mmHg}\right)$ ou d'anémies sévères (taux d'hémoglobine généralement $<5 \mathrm{~g} / \mathrm{dL}$ ) pour que ces altérations soient le seul facteur responsable;

- présence de poisons cellulaires (« hypoxie histotoxique») tel le cyanure (brûlés).

\section{Acidose lactique}

L'augmentation du lactate sanguin, reflète généralement le développement de métabolisme anaérobie en hypoxie. Ce processus produit seulement deux molécules d'ATP par molécule de glucose, au lieu de 36 molécules par voie aérobie.

La valeur normale du lactate sanguin est aux environs de $1 \mathrm{mEq} / \mathrm{L}$ (de 0,7 à $1,2 \mathrm{mEq} / \mathrm{L})$. Une valeur supérieure à $2 \mathrm{mEq} / \mathrm{L}$ suggère le diagnostic de choc circulatoire. Une valeur supérieure à $4 \mathrm{mEq} / \mathrm{L}$ est associée à un mortalité élevée (>50\%).

Remarquons qu'on dose le lactate et pas l'acide lactique, qui est quasi entièrement dissocié dans le sang.

L'hyperlactatémie (augmentation du lactate dans le sang) n'est pas nécessairement associée à une acidose lactique (qui représente l'association d'une 
hyperlactatémie et d'une acidose métabolique). En fait, ce n'est pas la production de lactate mais la dégradation d'ATP qui est responsable d'acidose métabolique. Néanmoins, les deux phénomènes sont concomitants au cours de l'hypoxie tissulaire, résultant en acidose lactique.

Toute hyperlactatémie doit suggérer le diagnostic d'insuffisance circulatoire aiguë, mais certaines limitations doivent être gardées à l'esprit (tableau VIII).

Tableau VIII - Les limitations de l'hyperlactatémie dans le diagnostic d'insuffisance circulatoire aiguë.

Le lactate sanguin peut être du non seulement à une production accrue, mais aussi à une altération de l'élimination, en présence d'insuffisance hépatique

Les changements de lactatémie sont trop lents pour pouvoir directement guider le traitement

L'hyperlactatémie dans le sepsis peut être due à d'autres facteurs que l'hypoxie tissulaire

L'hyperlactatémie peut refléter d'autres altérations que l'insuffisance circulatoire aiguë (épilepsie, tumeurs importantes...)

L'hyperlactatémie est un paramètre global, qui ne renseigne pas sur la perfusion individuelle des organes

Il est intéressant de répéter les mesures de lactate sanguin (au moins toutes les 8 heures, parfois toutes les 2-3 heures) pour s'assurer de la résolution progressive de l'hyperlactatémie.

Le taux sanguin de lactate reflète la balance entre la production et l'élimination du lactate. Le lactate est métabolisé principalement par le foie, mais aussi par le rein et d'autres organes. L'insuffisance hépatique (chronique ou aiguë) ralentit l'élimination du lactate. En cas d'insuffisance hépatique même sévère, le taux de lactate est généralement normal à l'état stable, si bien que le diagnostic de cirrhose ou d'insuffisance hépatique n'est pas suffisant pour expliquer une hyperlactatémie. Toutefois, chez ces patients, une insuffisance circulatoire même modérée entraîne une hyperlactatémie sévère et prolongée.

Au cours du sepsis sévère, l'hyperlactatémie peut être en partie due à d'autres phénomènes que l'hypoxie cellulaire:

- augmentation de la glycolyse aérobie;

- altération du métabolisme du pyruvate, par suite de l'inactivation de la pyruvate deshydrogénase.

Les organes enflammés (comme le poumon dans l'ARDS) peuvent contribuer davantage à l'élévation du lactate.

D’autres phénomènes peuvent contribuer à l'hyperlactatémie:

- Le travail musculaire intense, comme au cours de l'exercice, de la crise d'épilepsie, de l'agitation ou même des frissons; 
- l'hyperventilation: par l'augmentation du travail des muscles respiratoires et éventuellement l'activation de la phosphofructokinase en cas d'alcalose ainsi que par la diminution éventuelle de la perfusion hépatique;

- le diabète décompensé (surtout en cas d'hypovolémie associée);

- l'intoxication éthylique;

- certains cancers avancés (principalement suite à l'hypoxie du centre de la tumeur).

L'acidose lactique par elle-même ne doit pas être traitée. L'administration de bicarbonate a plutôt des effets défavorables.

L'administration de dichloroacétate peut diminuer les taux sanguins de lactate, mais n'améliore pas la mortalité.

\section{Augmentation de la $\mathrm{PCO}_{2}$ veineuse et augmentation de la différence veino-artérielle en $\mathrm{PCO}_{2}$}

La stagnation du sang dans les capillaires entraîne une accumulation de $\mathrm{PCO}_{2}$ produite. La production accrue d'ions $\mathrm{H}+$ au cours de l'hypoxie cellulaire peut contribuer à augmenter la production de $\mathrm{CO}_{2}$.

L'accumulation de $\mathrm{PCO}_{2}$ peut aussi être mesurée au niveau de la muqueuse gastrique, par la mise en place d'une sonde gastrique équipée d'un ballonnet perméable à la $\mathrm{PCO}_{2}$. On mesure alors la $\mathrm{PCO}_{2}$ de la muqueuse gastrique $\left(\mathrm{PgCO}_{2}\right)$ par tonométrie. Un gradient élevé entre la $\mathrm{PgCO}_{2}$ et la $\mathrm{PaCO}_{2}$ suggère une altération des apports en oxygène à la muqueuse gastrique au cours des états d'insuffisance circulatoire.

La tonométrie sublinguale peut apporter des informations comparables en mesurant la $\mathrm{PslCO}_{2}$ en présentant moins de limitations pratiques.

\section{Choc circulatoire}

Le choc circulatoire est le tableau clinique traduisant une insuffisance circulatoire aiguë généralisée. Quelle que soit la cause du choc, les cellules ne disposent plus de la quantité d'oxygène nécessaire à leur bon fonctionnement. Il s'agit donc d'une situation extrêmement sévère, entre la vie et la mort. Même en cas de survie, la souffrance cellulaire se complique souvent d'insuffisance des organes (MOF). Le choc est une complication fréquente d'une série d'états pathologiques, allant du traumatisme à l'infection sévère, en passant par l'infarctus myocardique étendu ou l'embolie pulmonaire massive.

\section{Tableau clinique}

Quel que soit le type de choc circulatoire, on retrouve en général l'hypotension artérielle, associée à des signes d'altérations de perfusion des organes (tableau IX). 
Tableau IX - Signes de choc circulatoire.

\section{Hypotension artérielle}

- la pression artérielle systolique est en général au-dessous de $90 \mathrm{mmHg}$ (ou la moyenne en-dessous de $70 \mathrm{mmHg}$ ). Il est important de noter que la pression artérielle n'est pas toujours fort abaissée, en particulier chez le patient hypertendu chronique.

\section{Altération de la perfusion des organes}

- oligurie (diurèse $<20 \mathrm{~mL} / \mathrm{h}$ ) : Ce signe peut être difficile à évaluer chez le malade qui n'était pas sondé auparavant;

- altération de l'état mental: il s'agit souvent d'une confusion modérée avec somnolence et/ou agitation: typiquement, le malade ne comprend pas ce qu'on lui veut, désire qu'on le laisse en paix et ne se laisse nullement convaincre!

- vasoconstriction cutanée: typiquement caractérisée par des marbrures, une peau froide et moite (ce que les Anglo-Saxons décrivent par "clammy ", faisant référence à l'aspect des coquillages). Les anomalies cutanées ne sont pas toujours évidentes dans les désordres de type distributif.

Augmentation du lactate sanguin $(>2 \mathrm{mEq} / \mathrm{L})$ : traduisant le développement de métabolisme anaérobie.

\section{Physiopathologie}

Dans tous les cas d'insuffisance circulatoire aiguë, il existe un déséquilibre entre les besoins en oxygène et les apports en oxygène aux cellules. L'hypoxie cellulaire se traduit par le développement de métabolisme anaérobie (acidose lactique).

Dans les cas de choc hypovolémique, cardiogénique ou distributif, c'est la diminution du débit cardiaque et donc du transport en oxygène qui représente l'anomalie fondamentale, tandis que les besoins en oxygène sont relativement normaux.

On peut reconnaître quatre altérations physiopathologiques sous-jacentes (fig. 17).

\section{Hypovolémique}

C'est la forme de choc la plus fréquente. Il s'agit le plus souvent d'hémorragie, en présence de traumatisme, d'hémorragie digestive, de pertes sanguines postopératoires, d'anévrisme rompu de l'aorte, etc. Il peut s'agir de pertes non hémorragiques en cas de déshydratation sévère (diarrhées profuses ou vomissements incoercibles, états de coma prolongé, etc.). 


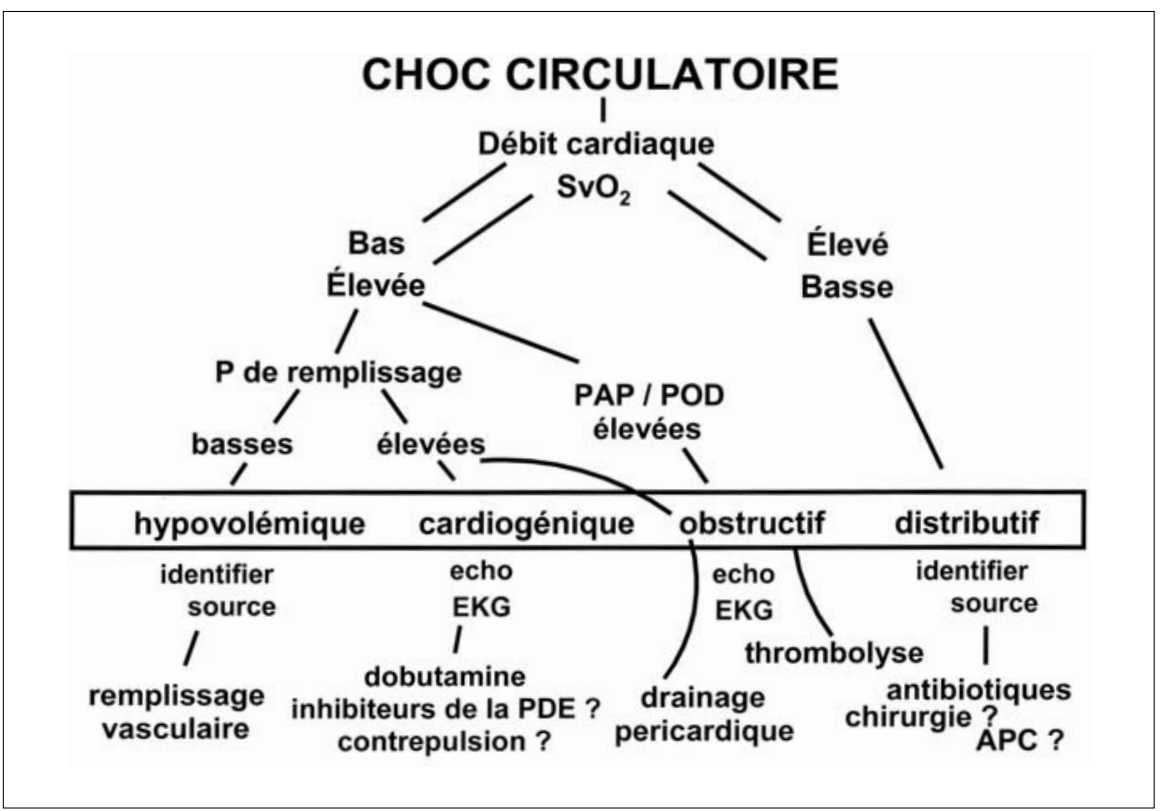

Fig. 17 - Les quatre types de choc circulatoire avec les interventions thérapeutiques qui s'y rapportent.

La présentation la plus caractéristique est celle d'un débit cardiaque abaissé (due à la diminution du retour veineux), de résistances vasculaires systémiques élevées et de pressions de remplissage basses.

\section{Cardiogénique}

Il s'agit le plus souvent d'infarctus myocardique étendu. On considère que le choc cardiogénique survient lorsqu'au moins $40 \%$ du myocarde total a été infarci. Il s'agit parfois de cardiomyopathie avancée de cause autre, d'états de bas débit cardiaque après chirurgie cardiaque, ou encore d'arythmie sévère empêchant une contraction myocardique organisée (tachycardie ventriculaire, tachy-arythmie supraventriculaire très rapide).

Il s'agit d'anomalies de microcirculation secondaires à la libération de médiateurs. La présentation la plus caractéristique est celle d'un débit cardiaque abaissé (faillite de la pompe), de résistances vasculaires systémiques élevées et de pressions de remplissage élevées.

\section{Obstructif}

Il s'agit ici d'un obstacle le long du système cardiovasculaire: les causes les plus fréquentes sont l'embolie pulmonaire massive, la tamponnade et la dissection aortique. 
La présentation la plus caractéristique est celle d'un débit cardiaque abaissé et de résistances vasculaires systémiques élevées, d'hypertension artérielle pulmonaire en cas d'embolie pulmonaire et de pressions de remplissage élevées (droite dans l'embolie pulmonaire, gauche et droite dans la tamponnade).

\section{Distributif}

Il s'agit d'anomalies de microcirculation secondaires à la libération de médiateurs. Le prototype du choc distributif est le choc septique, après remplissage vasculaire.

La présentation la plus caractéristique est celle d'un débit cardiaque normal ou élevé, de résistances vasculaires systémiques abaissées et de pressions de remplissage souvent abaissées.

Certains états de choc combinent les caractéristiques de différents types physiopathologiques. Ainsi, le choc anaphylactique combine les aspects de choc distributif et de choc hypovolémique. Il peut en être de même des états de choc associés aux pancréatites sévères.

Dans tous les cas d'insuffisance circulatoire aiguë, il existe un déséquilibre entre les besoins en oxygène et les apports en oxygène aux cellules. Il en résulte:

- une hypoxie cellulaire qui se traduit par le développement de métabolisme anaérobie (acidose lactique);

- une dépendance de la $\mathrm{VO}_{2}$ par rapport à la $\mathrm{DO}_{2}$.

En présence d'hypoxie cellulaire, la quantité d'oxygène consommée par les tissus dépend directement de la quantité d'oxygène qui est apportée. En d'autres termes, la $\mathrm{VO}_{2}$ devient dépendante de la $\mathrm{DO}_{2}$. (fig. 17). L'utilisation d'un diagramme mettant en relation l'index cardiaque et l'extraction d'oxygène peut être utile à la compréhension des altérations hémodynamiques.

Dans les cas de choc hypovolémique, cardiogénique ou distributif, c'est la diminution du débit cardiaque et donc du transport en oxygène qui représente l'anomalie fondamentale, tandis que les besoins en oxygène sont relativement normaux.

\section{Présentation hémodynamique du choc septique}

La physiopathologie du choc septique est très complexe, mettant en jeu une série de médiateurs de trois types:

- les cytokines pro-inflammatoires, qui jouent un rôle important dans l'initiation du processus: le tumor necrosis factor (TNF) et l'interleukine 1 (IL-1);

- d'autres interleukines, comme l'IL-8 (chemokine, qui active les polynucléaires) et l'IL-6 (principalement responsable de la libération de protéines de la phase aiguë comme la CRP;

- une série de petites molécules agissant plus distalement dans la cascade, comme le platelet activating factor (PAF), les produits de l'acide arachidonique, les radicaux libres d'oxygène, le monoxyde d'azote (NO), etc. 
Les conséquences en sont:

- une augmentation de la demande en oxygène par la réponse inflammatoire (donc la $\mathrm{VO}_{2}$ attendue est plus élevée que normalement);

- une vasodilatation importante (résistance vasculaire systémique abaissée);

- une altération des possibilités d'extraction d'oxygène par les tissus, qui est secondaire à plusieurs facteurs:

- une moins bonne régulation du contrôle de la microcirculation, aboutissant à un phénomène de " maldistribution » du débit sanguin en périphérie,

- le développement d'agrégats leucocytaires et plaquettaires responsables de la formation de micro-thrombi dans la microcirculation,

- des altérations de fonction et de structure de l'endothélium vasculaire,

- des altérations de perméabilité capillaire avec formation d'œè̀me interstitiel,

- désordres métaboliques cellulaires responsables d'une altération de la consommation d'oxygène dans la cellule (semblent toutefois survenir plus tardivement que les altérations circulatoires);

- une limitation de la $\mathrm{DO}_{2}$ suite à la dépression myocardique: la contractilité myocardique est altérée précocement, c'est-à-dire, même quand le débit cardiaque est normal ou élevé. La diminution des résistances vasculaires systémiques peut en effet expliquer que le débit cardiaque est maintenu malgré la diminution de contractilité. La dépression myocardique peut toutefois être démontrée dans ces conditions par des mesures de fraction d'éjection ou l'évaluation des courbes de fonction ventriculaire (travail ventriculaire en fonction des pressions de remplissage). La fonction ventriculaire droite est parfois particulièrement altérée en raison de l'hypertension artérielle pulmonaire qui est généralement présente dans le choc septique.

Ces éléments expliquent qu'un débit cardiaque normal ou même élevé n'est pas nécessairement adapté; il peut encore être insuffisant.

Le choc septique se distingue des autres formes de choc par le fait que le débit cardiaque est généralement normal ou élevé. Il en résulte que les anomalies caractéristiques des téguments (peau moite et froide, vasoconstriction, cyanose, marbrures) ne sont pas toujours présentes (tableau X). Aussi la diurèse est parfois préservée au cours du choc septique, en raison de la vasodilatation rénale.

Des études anciennes faisaient aussi état de différentes présentations hémodynamiques: la forme hypokinétique ou hypodynamique, faisait référence à un bas débit cardiaque et la forme hyperkinétique ou hyperdynamique, se traduisant par un débit cardiaque élevé avec vasodilatation périphérique. Eu égard à l'état de perfusion des téguments, on parlait parfois de « choc froid» dans le premier cas et de « choc chaud» dans le second. Cette terminologie est tombée en désuétude pour plusieurs raisons:

- Le choc septique à bas débit, qui est en fait généralement lié soit à une hypovolémie soit à une insuffisance cardiaque, est devenu rare suite à l'amélioration des techniques de remplissage et l'administration plus généreuse d'agents inotropes. Autrefois, le choc septique à bas débit était principalement $\mathrm{du}$ à un remplissage vasculaire insuffisant, associé à l'administration intempestive d'agents vasopresseurs tels que la noradrénaline et même des 
Tableau X - Principales caractéristiques cliniques et biologiques du choc septique et des autres types de chocs circulatoires.

\begin{tabular}{|l|l|l|}
\hline \multicolumn{1}{|c|}{$\begin{array}{c}\text { Type de choc } \\
\text { circulatoire }\end{array}$} & $\begin{array}{c}\text { Hypovolémique, cardio- } \\
\text { génique ou obstructif }\end{array}$ & \multicolumn{1}{|c|}{ Septique } \\
\hline Hypotension artérielle & présente & présente \\
\hline Tachycardie & présente & présente \\
\hline Débit cardiaque & abaissé & $\begin{array}{l}\text { normal ou élevé (rare- } \\
\text { ment abaissé) }\end{array}$ \\
\hline Vasoconstriction cutanée & présente & souvent absente \\
\hline Oligurie & présente & généralement présente \\
\hline Altération de l'état mental & présente & présente \\
\hline Péristaltisme intestinal & souvent absent & souvent absent \\
\hline Altérations de coagulation & parfois présentes & souvent présentes \\
\hline Hyperlactatémie & présente & présente \\
\hline
\end{tabular}

Tableau XI - Monitorage de l'insuffisance circulatoire aiguë (choc).

\begin{tabular}{|l|l|}
\hline Indispensable & Optionnel \\
\hline Placement de cathéter artériel. & $\begin{array}{l}\text { Pressions de l'artère pulmonaire, débit } \\
\text { cardiaque, gaz artériels et veineux } \\
\text { Placement d'un cathéter veineux central. } \\
\text { Placement de sonde vésicale pour } \\
\text { monitoriser la diurèse. }\end{array}$ \\
$\begin{array}{l}\text { Biologie courante avec gazométrie et } \\
\text { taux de lactate artériel. }\end{array}$ & $\begin{array}{l}\text { Mesure de la } \mathrm{PCO}_{2} \text { régionale gastrique } \\
\text { (tonométrie). } \\
\text { Température cutanée (du gros orteil). }\end{array}$ \\
\hline
\end{tabular}

agents comme la méphentermine ou l'aramine, qui ne sont plus guère utilisés aujourd'hui. L'amélioration des techniques de réanimation associée à une meilleure compréhension des phénomènes physiopathologiques et aux développements du monitorage invasif a conduit à l'administration plus généreuse de liquides intraveineux et au contraire, à l'utilisation plus prudente d'agents vasopresseurs. Les concepts de déséquilibre entre transport et besoins en oxygène ont mené à l'utilisation plus fréquente d'agents inotropes comme la dobutamine ;

- cette séparation est trop arbitraire, et il vaut mieux considérer un continuum d'altérations. Le choc septique représente un déséquilibre entre les besoins et les apports en oxygène, si bien qu'un débit cardiaque élevé n'est pas nécessairement adéquat, eu égard aux besoins élevés en oxygène et aux altérations d'extraction d'oxygène par les tissus ; 
- la dépression myocardique peut être présente même lorsque le débit cardiaque n'est pas abaissé.

Des études anciennes ont tenté de lier la présentation hémodynamique au type de micro-organisme qui est impliqué. Toutefois, la réponse hémodynamique est similaire quel que soit le type de micro-organisme.

\section{CONSOMMATION D'OXYGĖNE}

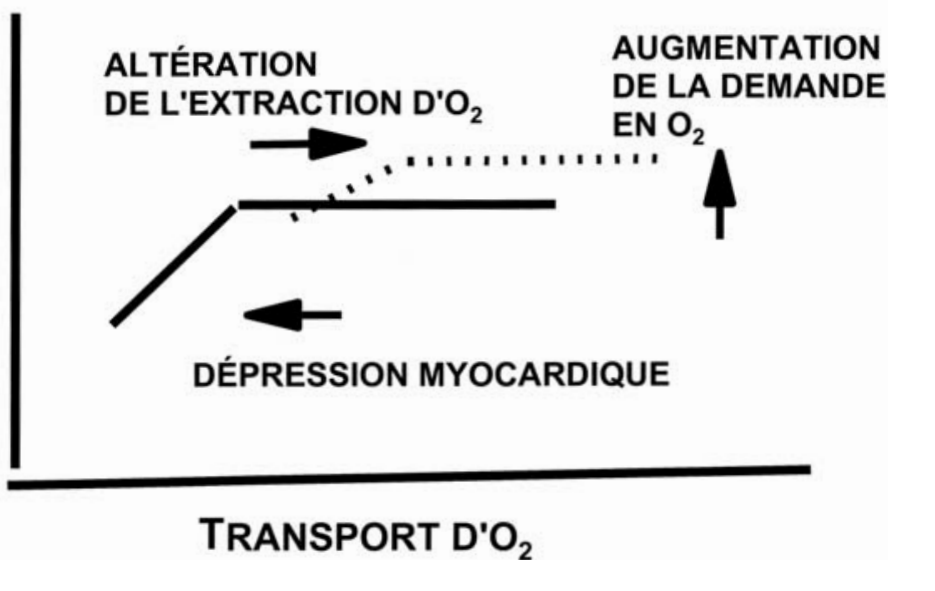

Fig. 18 - Altérations de la relation entre consommation et transport d'oxygène au cours du choc septique.

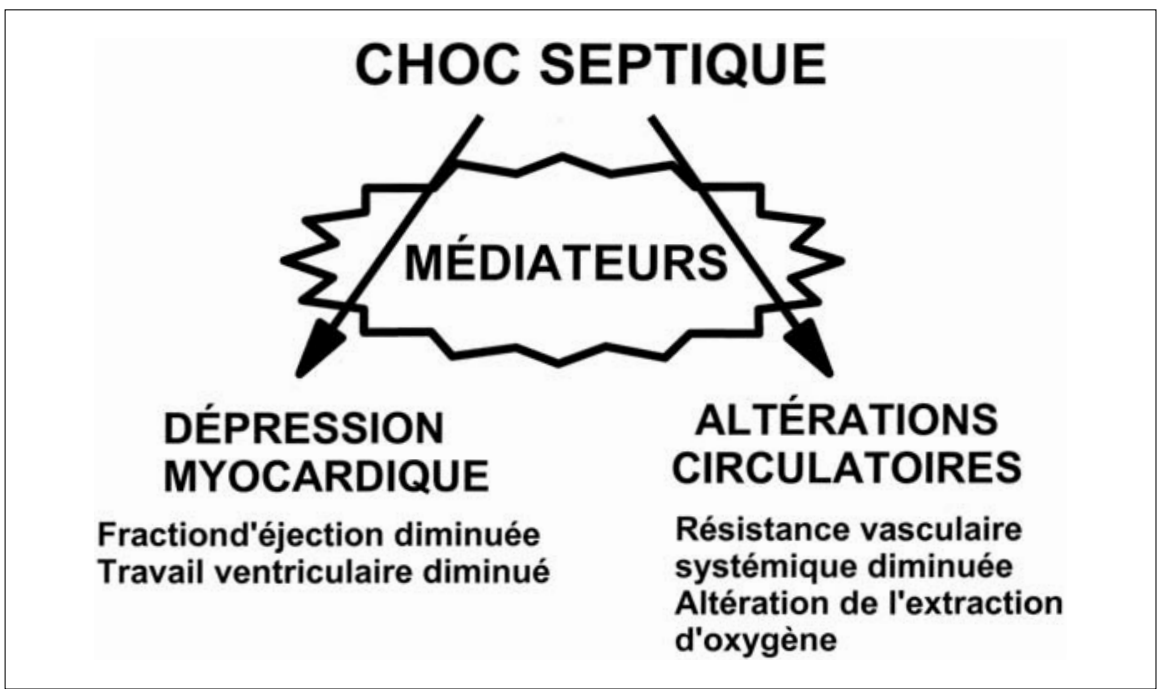

Fig. 19 - Responsabilité des médiateurs dans les altérations myocardiques et périphériques du choc septique. 


\section{Traitement du choc circulatoire}

Il doit être à la fois causal et supportif (l'un n'est pas moins important que l'autre!)

\section{Supprimer la cause}

Choc hémorragique: arrêter la cause du saignement.

Choc septique: éradication de la source d'infection (chirurgie, drainage) et traitement antibiotique approprié.

Choc obstructif: drainage péricardique en cas de tamponnade, thrombolyse ou éventuellement embolectomie dans l'embolie pulmonaire massive.

Choc cardiogénique sur infarctus: thrombolyse et surtout l'angioplastie percutanée.

\section{Supportif: règle du VIP}

$\mathrm{V}=$ VENTILATION/ÉCHANGES GAZEUX: de rétablir ou de maintenir les voies aériennes perméables; ces aspects sont les mêmes que pour la réanimation cardiorespiratoire (voir chapitre $\mathrm{CPR}$ ).

Même si le patient n'est pas très hypoxémique au départ, il faut systématiquement administrer de l'oxygène, dans le but d'assurer une $\mathrm{DO}_{2}$ suffisante et de réduire la vasoconstriction pulmonaire hypoxique, risquant de compromettre la fonction ventriculaire droite. L'utilisation d'un "non-rebreathing mask » permet d'administrer une $\mathrm{FiO}_{2}$ élevée. La toxicité de l'oxygène est un facteur très secondaire dans ces situations aiguës.

Lorsque l'analyse des gaz sanguins est possible, on peut éventuellement diminuer la quantité d'oxygène administrée, en se souvenant qu'il ne faut pas nécessairement viser l'hyperoxie: la quantité d'oxygène transportée aux tissus est essentiellement déterminée par la saturation en oxygène de l'hémoglobine, si bien que le gain apporté par une $\mathrm{PaO}_{2}$ élevée est négligeable. D'autre part, une $\mathrm{PaO}_{2}$ élevée peut entraîner une vasoconstriction périphérique qui limite les apports cellulaires en oxygène.

$\mathrm{Au}$ cours du choc circulatoire, on n'hésite pas à instaurer la ventilation artificielle pour trois raisons:

- assurer les échanges gazeux optimaux;

- diminuer la postcharge du ventricule gauche par suite de l'augmentation des pressions intrathoraciques, et ainsi diminuer le travail du cœur;

- mettre les muscles respiratoires au repos, et ainsi réduire la demande en oxygène de l'organisme. Ceci est d'autant plus nécessaire que la compensation de l'acidose métabolique (lactique) entraîne généralement une hyperventilation qui augmente encore la demande en oxygène des muscles respiratoires.

$\mathrm{I}=$ «INFUSION » (perfusions intraveineuses)

L'administration de liquides intraveineux représente le traitement de base de tout choc circulatoire pour ses effets périphériques (amélioration de la perfusion 
capillaire par augmentation du volume plasmatique), et centraux (augmentation du volume éjecté par le phénomène de Frank-Starling).

Même les états de choc cardiogénique peuvent parfois être améliorés par l'administration de perfusions intraveineuses étant donné d'une part la diminution fréquente du volume plasmatique (qui accompagne généralement la formation aiguë d'œdème aux dépends du volume plasmatique) et d'autre part l'augmentation possible du volume éjectionnel (phénomène de Frank-Starling).

L'administration de perfusions doit toutefois être très prudente, suivant la technique du «fluid challenge» (test de remplissage).

Il est difficile de donner des recommandations en termes de transfusions au cours du choc: on vise généralement un taux d'hémoglobine de 9 ou $10 \mathrm{~g} / \mathrm{dL}$. Dans le traitement du choc circulatoire, des solutions colloïdes (albumine, hydroxyethylamidon, gélatines...) sont souvent préférées aux cristalloïdes en raison de leur plus grande persistance dans l'espace vasculaire: il faut environ 3 fois moins de liquides pour atteindre le but fixé cependant, les solutions cristalloïdes salées (lactate $\operatorname{Ringer}^{\circledR}$ ) ne sont pas contre-indiquées.

Dans l'attente de perfusions intraveineuses, l'élévation des jambes permet d'accroître le retour veineux au cœur.

La technique du "fluid challenge » doit être appliquée lorsque la réponse à l'administration de liquides intraveineux n'est pas prévisible à coup sûr.

Il s'agit alors d'administrer rapidement des liquides avec l'idée:

- d'évaluer la réponse du patient à cette épreuve de « remplissage »;

- de corriger rapidement tout déficit volémique;

- d'éviter le développement d'œdème pulmonaire par excès de " remplissage ».

Il faut préciser quatre éléments (dans la communication avec l'infirmier(e) au début de l'épreuve:

- le type de liquide à administrer;

- le débit de perfusion;

- le but à atteindre (niveau de pression artérielle, de fréquence cardiaque, de diurèse...);

- les limites à ne pas dépasser (pression veineuse centrale ou PAPO).

Ces deux derniers éléments, évalués toutes les 10 minutes par l’infirmier(e), détermineront la fin du «fluid challenge» soit par atteinte de l'objectif (le patient a alors bénéficié de l'administration de liquides) soit par atteinte des limites de sécurité (indiquant un rapport risque/bénéfice trop élevé).

$\mathrm{P}=\mathrm{POMPE}$ : traitement par agents vasoactifs.

Les agents adrénergiques restent les premiers agents vasoactifs à administrer dans les cas d'hypotension et/ou de débit cardiaque insuffisant. Dans certains cas d'insuffisance cardiaque, on peut ajouter un inhibiteur de la phosphodiesterase.

\section{Agents adrénergiques}

Nous disposons d'une série d'agents adrénergiques (tableau XII). Plutôt que de choisir dans cette liste un agent préféré, valable en toutes circonstances, il est souhaitable de choisir l'agent le plus indiqué face à une situation donnée, en fonction des effets alpha (vasoconstricteurs), bêta (vasodilatateurs et inotropes) et éventuellement dopaminergiques (vasodilatateurs surtout de la région rénale et splanchnique). 


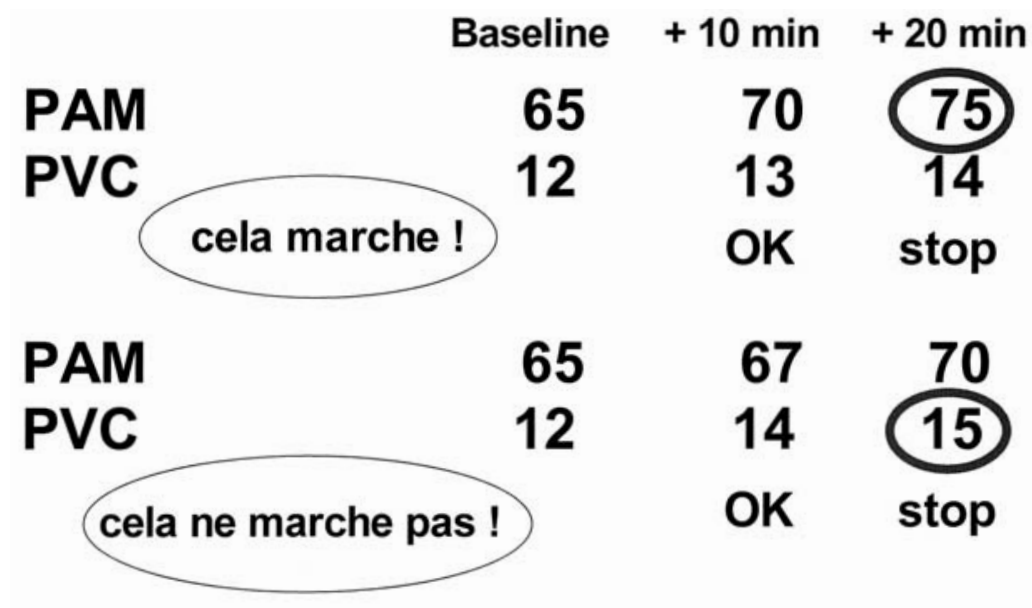

Fig. 20 - Exemple de "fluid challenge ", utilisant une mesure de pression veineuse centrale, pour un problème d'hypotension artérielle: 1-type de solution: RL solution; 2-débit de perfusion: $1000 \mathrm{~mL} / 30 \mathrm{~min}$; 3-but à atteindre: MAP $75 \mathrm{mmHg}$; 4-limite à ne pas dépasser: CVP $15 \mathrm{mmHg}$.

\section{Bon}

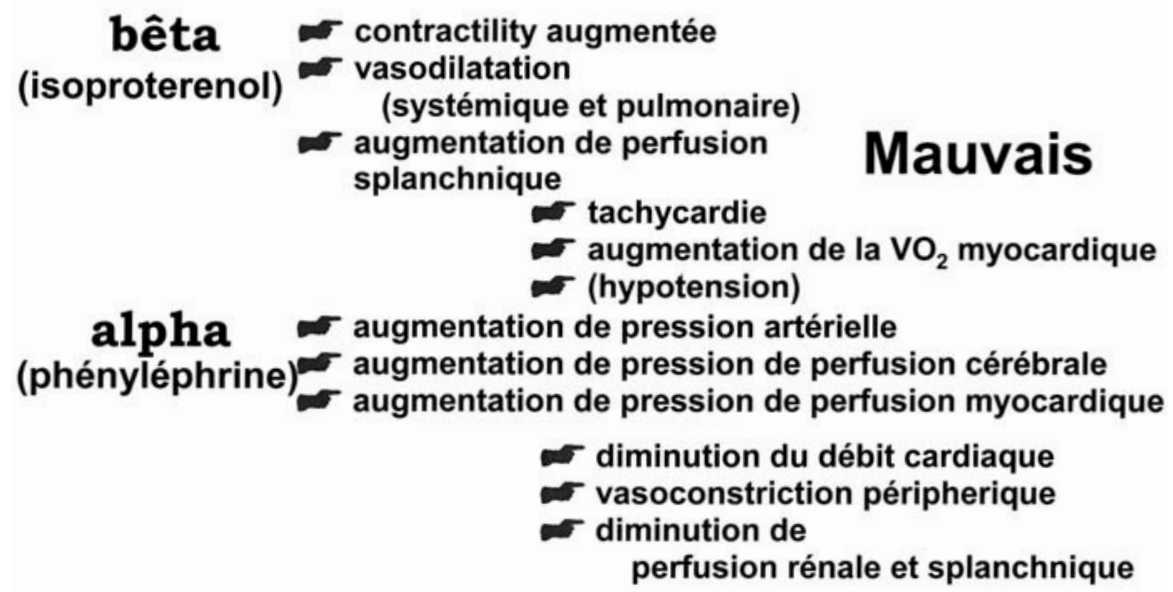

Fig. 21 - Les effets de la stimulation alpha- et bêta- adrénergiques. 
Tableau XII - Principaux agents adrénergiques en fonction de leurs effets alpha-, bêta- et dopaminergiques.

\begin{tabular}{|l|c|c|c|c|}
\hline \multicolumn{1}{|c|}{ Agent } & Effets Alpha & Effets Bêta-1 & Effets Bêta-2 & $\begin{array}{c}\text { Effets } \\
\text { Dopaminergique }\end{array}$ \\
\hline $\begin{array}{l}\text { Isoprénaline } \\
\text { (isoprotérénol })\end{array}$ & - & ++ & ++ & - \\
\hline Dopexamine & - & $(+)$ & ++ & + \\
\hline Dobutamine & + & ++ & ++ & - \\
\hline Dopamine & ++ & ++ & + & + \\
\hline Adrénaline & ++ & ++ & + & - \\
\hline Noradrénaline & ++ & ++ & - & - \\
\hline Phényléphrine & ++ & $(+)$ & - & - \\
\hline
\end{tabular}

\section{Isoprénaline ou isoprotérénol (Isuprel $\left.{ }^{\circledR}\right)$}

Il s'agit d'un agent synthétique bêta-adrénergique pur. Pour ces effets inotropes et vasodilatateurs, l'isoprotérénol a été longtemps utilisé dans l'insuffisance cardiaque. Toutefois, son administration peut entraîner une ischémie myocardique par le fait que l'augmentation de la demande en oxygène (tachycardie + effet inotrope) excède généralement l'augmentation des apports en oxygène (débit coronaire). Dès lors, l'administration d'isoprotérénol est aujourd'hui essentiellement réservée aux tableaux de bas débit associés à des bradycardies. Il peut s'agir d'arythmies majeures (sinusales ou secondaires à un bloc $\mathrm{A}-\mathrm{V}$ ) et mal tolérées. Cet agent est très utile dans les états de bas débit de cœurs dénervés (après transplantation cardiaque). La dose administrée doit être adaptée à la réponse clinique (fréquence cardiaque).

\section{Dopexamine (Dopacard ${ }^{\circledR}$ )}

Cette catécholamine de synthèse combine surtout des effets bêta-2 et dopaminergique (pas d'effet alpha-adrénergique). Il s'agit donc d'un agent " inodilatateur» augmentant sélectivement le débit cardiaque dans les régions splanchnique et rénale. En raison de la tachycardie et du risque d'hypotension, les doses sont limitées à un maximum de $4-5 \mathrm{mcg} / \mathrm{kg}$. min.

\section{Dobutamine (Dobutrex ${ }^{\circledR}$ )}

Cette catécholamine de synthèse est devenue l'agent inotrope de référence. La dobutamine a surtout des effets bêta-adrénergiques, mais aussi des effets alphaadrénergiques, si bien qu'elle influence peu la pression artérielle. Une diminution de 
pression artérielle sous dobutamine doit suggérer la possibilité d'une hypovolémie. La dobutamine augmente le débit cardiaque à la fois par une augmentation du volume éjectionnel et une accélération de la fréquence cardiaque.

La dose habituelle est de 5 à 15 (éventuellement 20) mcg/kg. min. À doses plus élevées, la dobutamine peut être mal tolérée.

\section{Dopamine (Dynatra ${ }^{\circledast}$ )}

Les effets alpha, bêta et dopaminergiques de la dopamine dépendent de la dose utilisée: les effets dopaminergiques ne sont notables qu'à doses faibles (max. 2-3 $\mathrm{mcg} / \mathrm{kg}$. min). Leur avantage potentiel est d'augmenter sélectivement le débit sanguin dans la région splanchnique et rénale. Le bénéfice clinique est cependant douteux. Les effets bêta-adrénergiques prédominent à des doses moyennes. Au-delà de doses de 8 à $12 \mathrm{mcg} / \mathrm{kg} / \mathrm{min}$, les effets alpha-adrénergiques prédominent. La dopamine est donc un agent "inoconstricteur » de choix en cas d'hypotension persistante malgré le «fluid challenge ». La dose de dopamine de doit pas excéder 20$25 \mathrm{mcg} / \mathrm{kg}$. $\mathrm{min}$.

\section{Adrénaline ou épinéphrine}

L'adrénaline est la catécholamine de choix dans le traitement du choc anaphylactique: dans ces situations d'urgence, la dose est de $0,5 \mathrm{mg}$ par voie intramusculaire pour corriger rapidement le désordre distributif. En cas de grande urgence (proche de l'arrêt cardiaque), on peut donner un mini-bolus d'adrénaline $(0,1 \mathrm{mg})$ par voie intraveineuse.

Les effets dépendent également de la dose: l'effet vasopresseur est directement proportionnel à la dose. L'adrénaline a plusieurs effets indésirables:

- une diminution du débit hépato-splanchnique;

- une tachycardie importante;

- une élévation du lactate sanguin, surtout imputable à une augmentation du métabolisme cellulaire.

Après tout, l'adrénaline est une hormone de stress, que nous libérons de manière pulsée dans des situations très aiguës. C'est pourquoi l'adrénaline a été largement remplacée par la dopamine comme agent de première intention. On la réserve en général à des états de choc très sévères, associant hypotension sévère et bas débit cardiaque (situation proche de l'arrêt cardiaque).

Pour des raisons de commodité, on évalue souvent la dose d'adrénaline en $\mathrm{mg} /$ heure. La dose de 1 à $10 \mathrm{mg} /$ heure est à adapter à la réponse clinique (pression artérielle - débit cardiaque).

\section{Noradrénaline ou norépinéphrine (Levophed ${ }^{\circledR}$ )}

Avec ses effets alpha- plus que bêta-adrénergiques, la noradrénaline est un agent vasopresseur extrêmement puissant, augmentant la pression artérielle, mais risquant de diminuer le débit cardiaque. L'administration de noradrénaline est généralement 
réservée aux cas d'hypotension sévère résistant à des doses importantes de dopamine (20-25 mcg/kg. min) Lorsque la perfusion de noradrénaline est instaurée, certains réduisent les doses de dopamine à $2-3 \mathrm{mcg} / \mathrm{kg}$. min dans l'espoir de maintenir la perfusion rénale, mais un tel effet protecteur n'est pas démontré. Les doses sont à adapter en raison de la réponse clinique (pression artérielle), sont en général de 10$100 \mathrm{mcg} / \mathrm{min}$.

Pour maintenir le débit cardiaque, on associe quasi systématiquement la dobutamine à la noradrénaline.

\section{Phényléphrine (Néosynéphrine ${ }^{\circledast}$ )}

Les effets de la phényléphrine sont quasi uniquement alpha-adrénergiques. La vasoconstriction est si sévère que la chute de débit cardiaque est rapide. Cet agent adrénergique (qui n'est pas à proprement parler une catécholamine) est à réserver à des situations exceptionnelles.

Quel est l'agent de première intention dans le choc circulatoire?

Beaucoup pensent que la noradrénaline est préférable à la dopamine. Cette question reste débattue. Il ne fait aucun doute que la noradrénaline est un agent vasopresseur plus puissant que la dopamine, qui doit souvent être ajoutée à la dopamine si celle-ci est utilisée en première ligne. Toutefois, par ses effets vasoconstricteurs importants, la noradrénaline risque de limiter les apports en oxygène aux cellules; ce phénomène peut cependant être limité par l'adjonction de dobutamine.

L'administration de dopamine pourrait avoir d'autres effets défavorables, dont la diminution de libération de prolactine (rôle immunosuppresseur), et peut-être une altération de perfusion de la muqueuse digestive. Une vaste étude multicentrique est en cours pour comparer les effets de ces deux agents dans le traitement du choc.

L'adrénaline doit probablement être gardée en deuxième ligne.

Tableau XIII - Dangers de la stimulation bêta- et alpha-adrénergique.

\begin{tabular}{|c|c|}
\hline Dangers de la stimulation bêta-adrénergique & Dangers de la stimulation alpha-adrénergique \\
\hline $\begin{array}{l}\text { Tachyarythmies. } \\
\text { Augmentation des besoins en oxygène du } \\
\text { myocarde (effets chronotrope et inotrope } \\
\text { positif). } \\
\text { Risque d'hypotension artérielle. } \\
\text { Vasodilatation excessive de certains territoires. }\end{array}$ & $\begin{array}{l}\text { Vasoconstriction artériolaire, qui peut limiter les } \\
\text { apports en oxygène aux tissus. } \\
\text { Vasoconstriction rénale et splanchnique. } \\
\text { Accroissement des besoins en oxygène du } \\
\text { myocarde (par augmentation de la postcharge). } \\
\text { Risque de diminution progressive du débit car- } \\
\text { diaque (par augmentation de la postcharge) et } \\
\text { donc du transport en oxygène. } \\
\text { Risque d'augmentation des pressions de } \\
\text { remplissage (formation d'œème, limitation des } \\
\text { possibilités d'administration de liquides). }\end{array}$ \\
\hline
\end{tabular}




\section{Inhibiteurs de la phosphodiestérase}

Les inhibiteurs de la phosphodiestérase sont des agents « inodilateurs » dont les effets sur l'AMP cyclique peuvent être additifs à ceux des agents adrénergiques (les agents adrénergiques augmentent la synthèse d'AMP cyclique et les inhibiteurs de la phosphodiestérase en empêchent la dégradation). Ces substances ont une demi-vie longue (de plusieurs heures), si bien que leur administration peut se faire par voie intraveineuse directe mais très lente (en surveillant de près la pression artérielle), plutôt que sous forme de perfusion continue. Ceci est particulièrement vrai chez le malade instable.

Les principaux agents sont la milrinone et l'énoximone.

Doses: $25 \mathrm{mcg} / \mathrm{kg}$ de milrinone ou 0,125 à 0,25 $\mathrm{mg} / \mathrm{kg}$ d'énoximone par voie intraveineuse lente.

\section{Levosimendan}

Le levosimendan est un nouvel agent inotrope positif, agissant principalement en augmentant la sensibilité des myofibrilles au calcium. Son efficacité a été démontrés dans les états d'insuffisance cardiaque sévère et de choc cardiogénique. L'inconvénient est le prix élevé.

\section{Agents vasodilatateurs}

Des agents vasodilatateurs peuvent être utiles pour augmenter le débit cardiaque en réduisant la résistance à l'éjection

ventriculaire, au cours de l'insuffisance cardiaque sévère (activation du système sympathique, rénine-angiotensine et vasopressine entraîne une vasoconstriction qui augmente la postcharge du ventricule gauche).

Ils ont donc une place limitée au cours du choc, étant donné le risque de diminuer davantage la pression artérielle et d'ainsi compromettre davantage la perfusion tissulaire. Dans tous les cas, leur utilisation doit donc être très prudente, sous monitorage constant de la pression artérielle (généralement invasif) et de la fréquence cardiaque. En cas de diminution de pression artérielle et de tachycardie, il faut songer à la possibilité de diminution de retour veineux, qui pourrait être corrigée par " fluid challenge».

Les agents vasodilatateurs que l'on peut se permettre d'administrer dans le choc circulatoire, une fois l'hypotension contrôlée, sont les dérivés nitrés et éventuellement le nitroprussiate de sodium:

- dérivés nitrés (nitroglycérine, dinitrate d'isosorbide ou molsidomine): perfusion de $20-300 \mathrm{mcg} / \mathrm{min}$. Les effets veineux prédominent sur les effets artériels: plus indiqués en cas de tendance à l'hypotension artérielle et/ou en cas d'œdème pulmonaire hémodynamique; les dérivés nitrés ont peut-être aussi un effet plus favorable sur la circulation coronaire;

- nitroprussiate de sodium: perfusion de $20-300 \mathrm{mcg} / \mathrm{min}$ : les effets veineux sont comparables aux effets artériels: plus indiqué en cas de bas débit cardiaque associé à un certain degré d'hypertension artérielle; 
Le traitement vasodilatateur sera traité plus en détail dans la section sur l'insuffisance cardiaque.

\section{Complications du choc circulatoire}

Puisque le choc circulatoire représente un phénomène généralisé, il peut entraîner la défaillance de tous les organes. Les complications du choc circulatoire aboutissent souvent au syndrome de défaillance multisystémique (Multiple Organ Failure ou MOF), dont la mortalité dépasse $50 \%$.

Citons les principaux dans un ordre à peu près chronologique.

\section{Troubles de coagulation}

Une coagulation intravasculaire disséminée (CIVD) est souvent observée dans la phase aiguë du choc circulatoire. Elle se caractérise par un prolongement du PT, de l'APTT et d'une diminution du taux de plaquettes. Parfois la thrombopénie est isolée.

Elle se résout avec l'amélioration de la circulation et ne nécessite généralement pas de traitement.

Toutefois, l'administration de protéine $\mathrm{C}$ activée augmente la survie au cours du sepsis sévère et du choc septique.

\section{CEdème pulmonaire lésionnel}

L'Acute Respiratory Distress Syndrome (ARDS) apparaît dans les 24 h à 48 h après le début du choc circulatoire et peut persister plusieurs semaines.

Il se caractérise par trois éléments:

- hypoxémie $\left(\mathrm{PaO}_{2} / \mathrm{FiO}_{2}<200 \mathrm{mmHg}\right)$;

- infiltrats bilatéraux assez diffus à la radiographie du thorax;

- l'absence d'évidence d'une PAPO élevée (si elle est mesurée, elle doit être inférieure à $18 \mathrm{mmHg}$ ); dans le cas contraire, il faudra plutôt conclure à un œdème pulmonaire hémodynamique;

L'Acute Lung Injury (ALI) représente la forme moins sévère, avec un rapport $\mathrm{PaO}_{2} / \mathrm{FiO}_{2}$ inférieur à $300 \mathrm{mmHg}$.

Au moment où on reconnaît l'ARDS, il existe souvent une hypocapnie associée à l'hypoxémie (l'organisme tente de compenser l'hypoxémie par une hyperventilation).

\section{Insuffisance rénale}

La diminution de perfusion rénale mène à l'oligurie qui fait partie du tableau de choc. L'insuffisance rénale aiguë (nécrose tubulaire) peut persister plusieurs semaines, voire définitivement. L'insuffisance rénale peut aussi réapparaître après la résolution des signes de choc. 


\section{Altération des tests hépatiques}

Il s'agit principalement d'une hyperbilirubinémie sans cholestase évidente. Une élévation modérée des enzymes de cytolyse est fréquente.

\section{Altération de l'état mental}

Sans cause évidente, le liquide céphalo-rachidien est généralement normal, de même que le CT -scan et l'électroencéphalogramme montre une dysrythmie lente diffuse.

\section{Facteurs incriminés}

Le MOF peut être induit par une réponse immunitaire excessive et prolongée. La libération excessive de médiateurs pro-inflammatoires comme le TNF ou l'IL-1 est susceptible d'accroître la demande en oxygène, d'altérer l'extraction d'oxygène et de limiter le transport en oxygène (voir plus haut). L'hypoxie à son tour est susceptible d'accroître la libération de médiateurs par les cellules immunitaires. Il peut ainsi exister un cercle vicieux conduisant au MOF.

Le tube digestif pourrait jouer un rôle prépondérant (= «moteur » du MOF): la perfusion splanchnique est généralement sacrifiée précocement dans les insuffisances circulatoires, pour tenter de maintenir la perfusion des organes vitaux. Pourtant, la demande en oxygène est généralement accrue dans la région splanchnique et la muqueuse digestive est particulièrement sensible à l'ischémie. Les altérations de perméabilité de la muqueuse digestive sous l'effet de l'ischémie et de la libération de médiateurs pourraient aussi être responsables de la translocation de bactéries et de produits bactériens.

\section{Anaphylaxie}

Une réaction allergique sévère peut mettre la vie en danger par suite de l'hypotension artérielle (choc) et de l'insuffisance respiratoire aiguë.

Une réaction anaphylactique implique l'interaction d'allergène avec des anticorps spécifiques de type IgE, liés aux récepteurs Fc pour les IgE sur les mastocytes et basophiles, entraînant la libération d'histamine et d'autres médiateurs.

Une réaction anaphylactoïde, généralement moins sévère, n'implique pas d'anticorps de type IgE. La distinction est cependant peu importante en médecine d'urgence.

Les conséquences de l'activation de ces médiateurs sont:

- les altérations de perméabilité capillaire, avec formation d'œè̀me;

- les altérations de tonus vasculaire avec hypotension et choc circulatoire;

- la contraction des muscles lisses respiratoires responsable de bronchospasme;

- les réactions cutanées avec érythème et urticaire prurigineux; la rhinite, la conjonctivite... 
Les causes les plus fréquentes sont:

- certains types de nourriture: crustacés, champignons, noix, poissons, plats exotiques...;

- venins d'insectes: abeille;

- médicaments: pénicillines, aspirine, vaccins...;

- produits de contraste;

- latex.

Le délai d'apparition des symptômes n'est en général pas immédiat. Dans l'allergie au latex, les symptômes apparaissent 30 à 60 min après l'examen ou la procédure ayant nécessité les gants.

Diagnostic:

Il est essentiellement clinique; un dosage de tryptase mastocytaire peut être utile pour documenter l'activation mastocytaire.

Traitement:

- règle du VIP;

- adrénaline par voie intramusculaire $(0,5 \mathrm{mg})$ ou éventuellement intraveineuse sous forme d'une « rinçure» $(0,1 \mathrm{mg})$ en cas d'urgence extrême;

- perfusions intraveineuses abondantes: les colloïdes sont préférables, en raison de la perméabilité capillaire accrue, entraînant des fuites importantes d'albumine;

- hydrocortisone $200 \mathrm{mg}$ par voie intraveineuse (ou intramusculaire): pour prévenir les récidives et pour le bronchospasme;

-antihistaminiques.

Mise au point ultérieure:

Parfois la cause de la réaction ne peut être déterminée avec précision, ce qui peut nécessiter une mise au point ultérieure.

Il faut évidemment éviter l'exposition ultérieure au même produit. Si ceci n'est pas possible (allergie aux piqûres de guêpes), on peut éventuellement donner au patient une seringue préparée d'adrénaline.

\section{Grands syndromes hémodynamiques}

\section{Hypotension artérielle}

L'algorithme décisionnel est basé sur les pressions de remplissage et le débit cardiaque (fig. 22).

\section{Hypovolémie}

Le diagnostic d'hypovolémie n'est pas toujours facile. Il est relativement facile face à un malade en état de choc traumatique au bord de la route, mais devient beaucoup plus difficile quand le même malade est réexaminé après la réanimation initiale. 


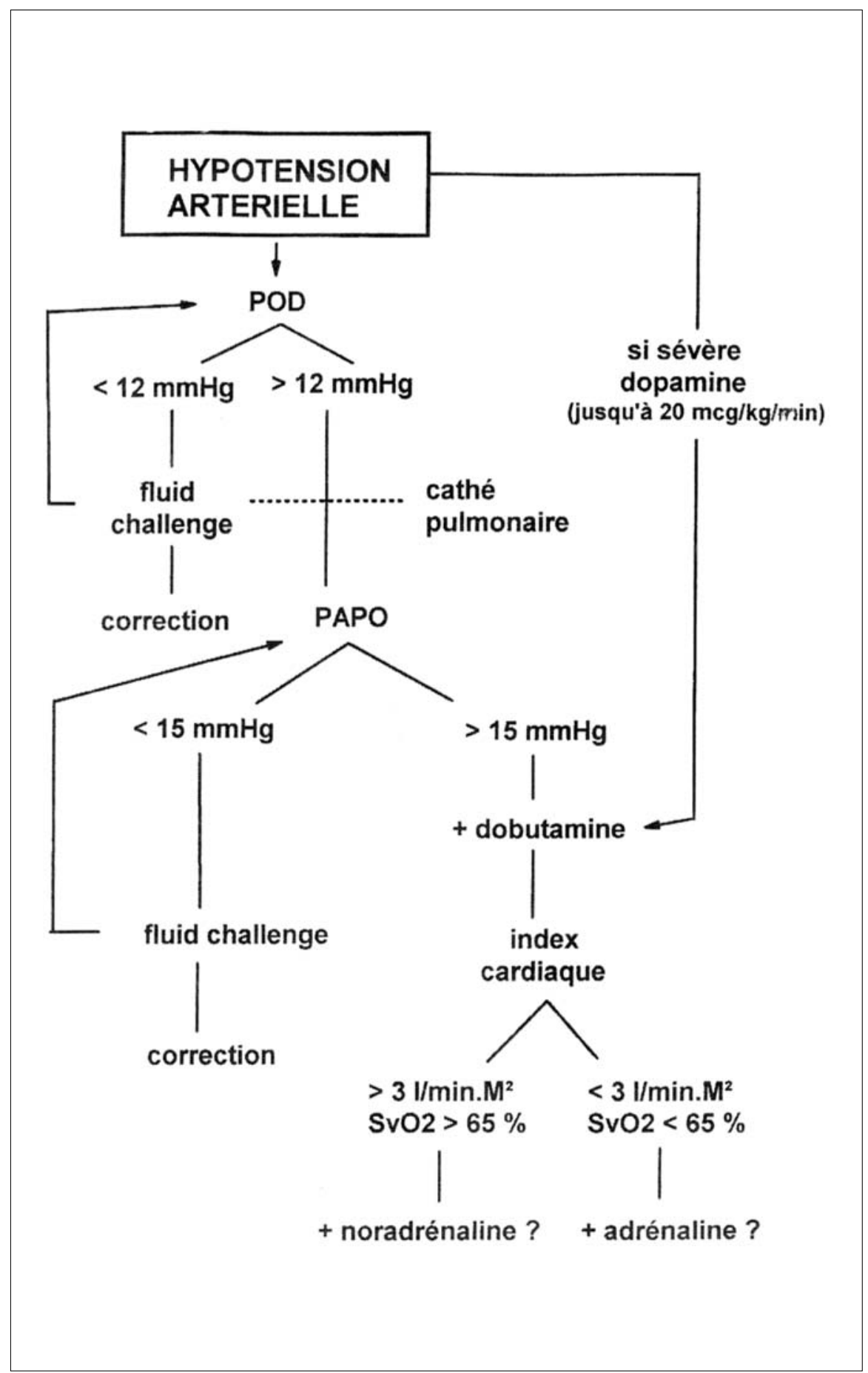

Fig. 22 - Algorithme de prise en charge d'un problème d'hypotension artérielle. 


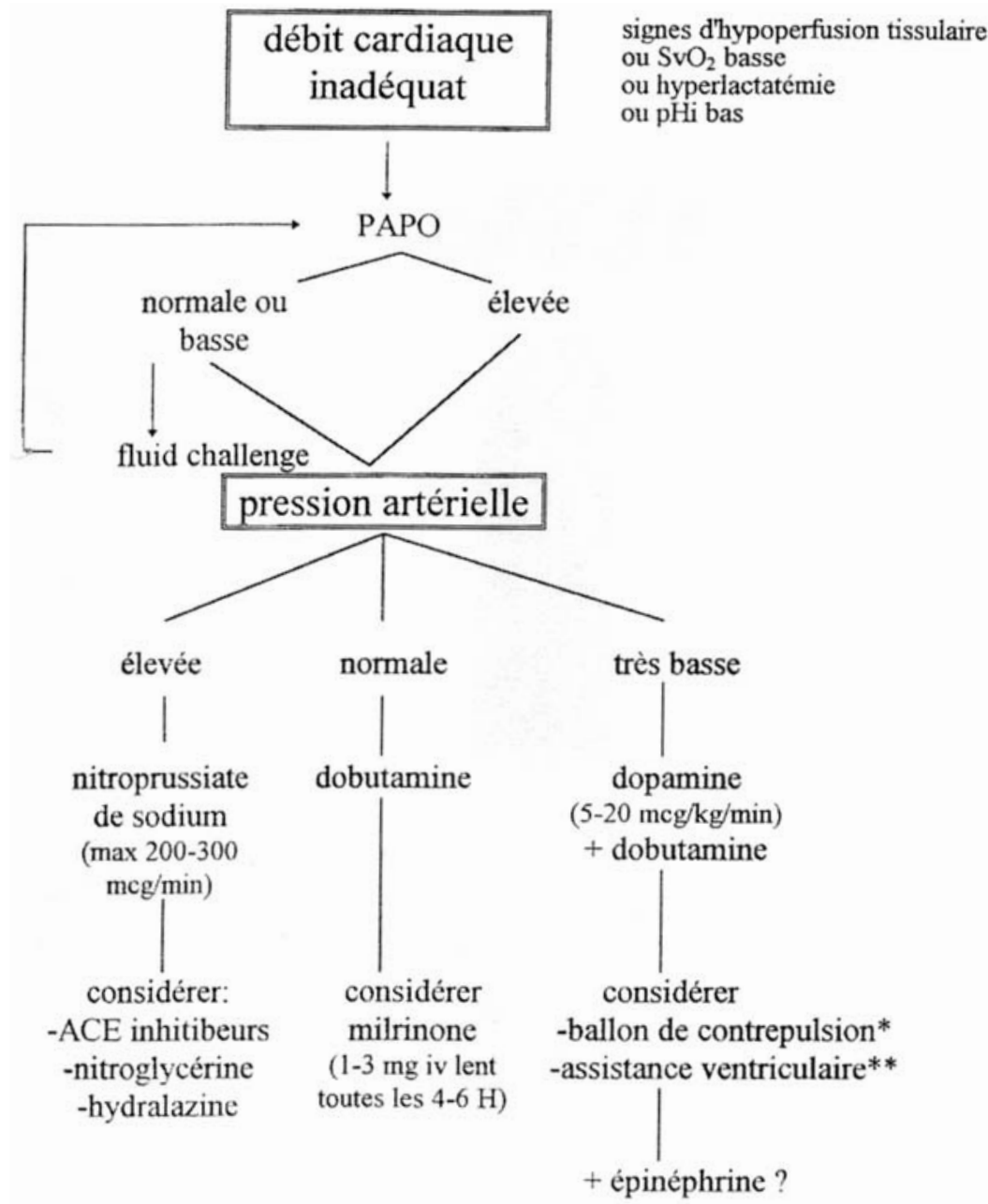

* surtout si patient avec insuffisance coronarienne, insuffisance mitrale ou rupture septale, si une intervention est envisagée

** surtout si patient $<65$ ans, candidat à transplantation cardiaque

Fig. 23 - Débit cardiaque inadéquat. 
Signes hémodynamiques:

- tachycardie inexpliquée: suite à l'activation du système adrénergique;

- hypotension inexpliquée: l'hypotension artérielle est toutefois un indice tardif, qui ne survient que lorsque les pertes dépassent 1,5 litres de liquide, ou lorsque la fonction cardiaque est compromise. Des signes plus précoces sont:

- le pincement de la pression différentielle (systolo-diastolique),

- les fluctuations des courbes de pression au cours du cycle respiratoire chez les malades sous ventilation mécanique (voir section sur le monitorage cardio-circulatoire),

- l'hypotension orthostatique, qui peut être jugée chez le malade alité par la prise de pression artérielle en position allongée, puis assise;

- vasoconstriction cutanée, pouls capillaire ralenti; signes de déshydratation cutanée (globes oculaires hypotoniques, creux axillaires secs, signe du mouchoir...);

- oligurie: signe relativement tardif;

- pression veineuse centrale (PVC) basse: argument assez faible en soi (une pression de remplissage basse peut être normale), mais une pression de remplissage élevée est un argument contre l'hypovolémie;

- petits volumes ventriculaires à l'échocardiographie.

Signes biologiques:

- persistance d'une hyperlactatémie même modérée (indice relativement tardif, plutôt indicateur de choc circulatoire);

- urines concentrées: osmolarité urinaire $>450 \mathrm{mOsm} / \mathrm{kg}$, natriurèse $<30$ $\mathrm{mEq} / \mathrm{L}$;

- hémoconcentration: hypernatrémie, urémie, élévation de l'hématocrite et de la protéinémie.

Traitement d'épreuve:

- régression des symptômes hémodynamiques (tachycardie, hypotension artérielle) lors du «fluid challenge » ou simplement lors de la surélévation des jambes;

- apparition ou aggravation des symptômes hémodynamiques lors de l'installation de la ventilation mécanique ou l'application d'une PEEP.

Débit cardiaque inadéquat

L'algorithme décisionnel est basé sur les pressions de remplissage et la pression artérielle (fig. 23).

\section{Sepsis}

\section{Signes de sepsis}

Bien que la fièvre soit un signe important de sepsis, elle peut accompagner tout état de stress (même l'œdème pulmonaire cardiogénique ou l'infarctus myocardique). D'autre part, les altérations de perfusion peuvent empêcher l'apparition de fièvre. Dans environ $10 \%$ des cas, il peut exister une hypothermie qui est associée à un plus mauvais pronostic. 
La tachycardie est un signe peu spécifique puisqu'elle est généralement présente dans tous les états de choc (elle tend à compenser le bas volume éjectionnel dans les états de choc à bas débit). Un tableau hyperkinétique (débit cardiaque et $\mathrm{SvO}_{2}$ élevés) est déjà plus spécifique.

Tableau XIV - Sept principaux signes de sepsis.

Fièvre (parfois hypothermie).

Tachycardie par ailleurs inexpliquée - État hyperkinétique.

Hyperventilation par ailleurs inexpliquée, associée à une alcalose respiratoire (hypocapnie) entraînant souvent initialement une alcalémie.

Altération de la leucocytose (hyperleucocytose - parfois leucopénie).

Élévation de la C-reactive protein (CRP), de la procalcitonine, de l'IL-6 et d'autres cytokines.

Instabilité hémodynamique, par ailleurs inexpliquée (surtout en présence d'un état hyperkinétique).

Altération de la conscience (obnubilation, désorientation) par ailleurs inexpliquée.

Altérations de la coagulation (thrombocytopénie) par ailleurs inexpliquées.

Altérations de la fonction hépatique (hyperbilirubinémie) par ailleurs inexpliquée.

Altération des échanges gazeux (hypoxémie) par ailleurs inexpliquée.

Altération de la fonction rénale par ailleurs inexpliquée.

L'hyperventilation peut aussi se rencontrer dans tous les états de stress. Elle peut aussi représenter une compensation respiratoire d'une acidose métabolique (principalement lactique ou rénale) au cours du choc. Toutefois, une alcalémie due à une alcalose respiratoire peut suggérer à elle seule la présence d'un sepsis. Cette alcalose respiratoire est indépendante de la $\mathrm{PaO}_{2}$ et n'est guère modifiée par l'administration d'oxygène.

L'analyse de la fréquence respiratoire perd évidemment beaucoup de sa valeur chez le malade ventilé artificiellement.

Classiquement, le sepsis est accompagné d'une leucocytose élevée, mais la reconnaissance de cette anomalie est en fait peu utile, car elle est très fréquente, et donc non spécifique, chez le malade grave. La leucocytose est élevée dans tous les états de choc, et traduit encore la réaction de stress. Une leucopénie brutale, définie en général comme une leucocytose en dessous de $4000 / \mathrm{mm}^{3}$, peut survenir dans 10 à $15 \%$ des cas. Elle reflète l'activation leucocytaire en périphérie, sous l'effet d'une libération massive de médiateurs, et est associée à un plus mauvais pronostic. 
Le dosage d'autres marqueurs inflammatoires, comme la $C$-reactive protein (CRP), sont probablement plus utiles. Toutefois, la CRP est élevée dans d'autres réactions inflammatoires. L'élévation de la procalcitonine dans les états septiques a été une découverte de hasard. Bien que la raison ne soit pas élucidée, il s'agit aussi d'un marqueur potentiellement intéressant, mais plus cher que la CRP. De même les dosages de cytokines comme l'IL-6 ne font pas partie de la pratique courante, car les variations sont parfois difficilement interprétables, et le coût de ces mesures est plus élevé. L'élévation des taux sanguins de cytokines comme le TNF, l'interleukine (IL) 6, l'IL-8 ou l'IL-10 peut être corrélée avec la sévérité du choc septique dans des groupes de patients, mais leur contribution au diagnostic individuel de choc septique n'est pas établie.

On parle de sepsis sévère lorsque le sepsis est compliqué d'une insuffisance d'organes qui lui est attribuée (cf. score SOFA):

Cardiovasculaire: hypotension jusqu'au choc circulatoire; le débit cardiaque est typiquement élevé (état hyperkinétique).

Neurologique: désorientation, delirium, obnubilation, coma.

Rénale: oligurie, élévation de la créatinine.

Coagulation: thrombocytopénie, CIVD.

Respiratoire: hypoxémie (ALI/ARDS).

Hépatique: hyperbilirubinémie.

En résumé, la recherche de signes de sepsis est évidemment nécessaire tant dans la phase qui précède le développement de choc qu'au cours de celui-ci, mais l'interprétation doit en rester prudente. Les signes de sepsis peuvent se retrouver dans d'autres formes de choc et peuvent aussi être absents au cours du choc septique. Il ne faudrait donc pas dénier un traitement antibiotique sur base de l'absence de température et d'hyperleucocytose au cours du choc.

\section{Faut-il diminuer la fièvre?}

Le problème est difficile car il y a des arguments en faveur et en défaveur du contrôle de la température.

La fièvre peut avoir une série d'effets indésirables, principalement par l'augmentation des besoins en oxygène qu'elle entraîne, elle peut:

- exercer des effets stimulants sur le système cardio-respiratoire (augmentation de la demande en oxygène du myocarde);

- accroître les besoins métaboliques des tissus (catabolisme);

- augmenter la production de radicaux libres d'oxygène;

- altérer les fonctions cérébrales - favoriser le développement de convulsions.

Toutefois, la réaction fébrile améliore aussi la riposte immunitaire à l'infection. Une série d'expériences a montré que le contrôle de la fièvre augmentait la mortalité secondaire aux infections. La fièvre ne doit donc pas être systématiquement combattue!

Les indications de traitement antipyrétique sont:

- œdème cérébral sévère (pour limiter les besoins en oxygène du cerveau);

- diminution critique des apports en oxygène aux cellules (ARDS sévère);

- augmentation importante de la température $\left(>40{ }^{\circ} \mathrm{C}\right)$;

- inconfort du patient. 
On préfère en général le traitement médicamenteux à l'application d'un matelas hypothermiant, qui est au total moins efficace et qui entraîne une vasoconstriction cutanée (avec risque d'escarres).

\section{Protéine $C$ activée}

L'administration de protéine C activée (drotrécogine alpha activée ou Xigris ${ }^{\circledR}$ ) diminue la mortalité du sepsis sévère.

Administration sous forme d'une perfusion continue de $24 \mathrm{mcg} / \mathrm{kg} / \mathrm{h}$ pendant 96 heures; les doses ne sont pas modifiées en cas d'insuffisance hépatique ou rénale.

Il s'agit évidemment d'un anticoagulant, qui ne peut donc être administré en cas de risque hémorragique majeur.

Le médicament est onéreux (traitement de l'ordre de 7000 chez l'adulte, en fonction de son poids).

L'indication retenue en Europe est le sepsis sévère associé à au moins deux défaillances d'organe parmi les suivantes:

- choc circulatoire;

- hyperlactatémie;

- insuffisance rénale aiguë;

- hypoxémie;

- diminution du taux de plaquettes (soit de $50 \%$, soit en-dessous de $\left.100000 / \mathrm{mm}^{3}\right)$.

La demi-vie est assez courte, si bien que les effets anticoagulants sont entièrement éliminés deux heures après l'arrêt de la perfusion. On arrête donc la perfusion 2 heures avant une procédure sanglante pour la reprendre entre 2 heures (après placement d'un drain ou d'un cathéter veineux central, par exemple) à 12 heures (après laparotomie par exemple) après la procédure. En cas de saignement, il n'y a pas d'antidote particulier.

\section{Place des stéroïdes dans le choc septique}

La place des corticostéroïdes dans le choc septique est un problème complexe et longuement débattu.

$1^{\text {re }}$ phase: des études anciennes ont proposé l'administration de doses modérément élevées de stéroïdes (300 mg/jour) dans les infections sévères, jusqu’à ce que les effets défavorables en soient démontrés.

$2^{\mathrm{e}}$ phase: plusieurs études ont proposé l'administration de doses massives de méthylprednisolone $(30 \mathrm{mg} / \mathrm{kg}$, à répéter éventuellement une ou quelques fois), jusqu'à ce que deux larges études en montrent l'absence d'efficacité.

$3^{e}$ phase: le concept d'insuffisance surrénalienne relative conduit à l'administration de doses modérées d'hydrocortisone (Solu-Cortef ${ }^{\circledR}$ ), de l'ordre de $200 \mathrm{mg} /$ jour, seulement dans le choc septique (nécessitant l'administration d'agents vasopresseurs pendant plusieurs heures). De plus, il est généralement proposé de réserver cette intervention aux patients pour lesquels l'insuffisance surrénalienne relative est démontrée par une réponse anormale à un test à l'ACTH: un taux de cortisol est prélevé avant et 30 et 60 minutes après l'injection de 250 mcg de Synacthen ${ }^{\circledR}$ : le 
cortisol de base doit dépasser $250 \mathrm{mcg} / \mathrm{L}$ et s'élever d'au moins $90 \mathrm{mcg} / \mathrm{dL}$ après Synacthen ${ }^{\circledR}$. L'administration de stéroïdes est commencée dès la fin du test, sans en attendre les résultats. On réévalue alors la nécessité de poursuivre les stéroïdes lorsque les dosages de cortisol sont fournis par le laboratoire. Si les résultats sont anormaux, on continue l'administration de stéroïdes jusqu'à la résolution du choc.

L'administration de stéroïdes a encore certaines indications dans les infections sévères:

- fièvre typhoïde;

- méningites tuberculeuses ou à pneumocoques (voir ce chapitre);

- infections sévères à Pneumocystis carinii.

\section{Présence d'infection}

Le diagnostic de choc septique peut donc être orienté par la présentation hémodynamique de choc à haut débit cardiaque et résistances vasculaires abaissées, éventuellement appuyé par la présence de certains signes de sepsis, mais aussi souvent par la présence d'infection.

Les principales sources de choc septique sont:

- les poumons (environ $35 \%$ des cas);

- l'abdomen (environ $30 \%$ des cas);

- les voies urinaires, est devenue moins fréquente (notamment suite à la diminution des manœuvres urologiques invasives);

- la peau (plaies et escarres).

\section{Infections nosocomiales}

Une infection nosocomiale est une infection qui n'était ni présente ni en incubation lors de l'entrée du patient à l'hôpital.

Tableau XV - Les cinq sources les plus fréquentes d'infections nosocomiales (encore appelées les «big five»).

Poumons.

Abdomen.

Urine.

Peau et tissus sous-cutanés (plaies, escarres).

Cathéter.

Contrairement aux infections pulmonaires extra-hospitalières, les infections nosocomiales sont plus généralement polymicrobiennes. Les germes les plus fréquents sont le Pseudomonas aeruginosa (pyocyanique) et le staphylocoque doré. 
Les champignons sont aussi fréquemment retrouvés. Par contre, le pneumocoque et d'autres germes banals, ainsi que les anaérobies sont plus rarement impliqués.

Les infections nosocomiales sont le résultat de deux facteurs concomitants:

- liés au malade: diminution des réserves, immunosuppression, malnutrition) et pathologie sous-jacente (ex.: pulmonaire chronique);

- liés au traitement et à l'environnement: surtout liés au caractère invasif des interventions (intubation endotrachéale, cathéters, drains, etc.) et à la contamination éventuelle de l'équipement.

\section{Pneumopathies nosocomiales}

Chez les malades de soins intensifs, les pneumopathies représentent de loin les causes les plus fréquentes, surtout chez le malade traité par ventilation mécanique.

La prévention des infections pulmonaires nosocomiales comprend une série de mesures (tableau XVI).

La colonisation des voies aériennes par la flore bactérienne se développant dans l'estomac, peut également participer au développement d'infections nosocomiales. Dans ce contexte, l'administration prophylactique d'antibiotiques dirigés contre les bactéries aérobies chez les malades à haut risque de MOF (décontamination sélective du tube digestif $=$ SDD) a montré une diminution de l'incidence d'infections respiratoires nosocomiales. Les risques d'apparition de résistance bactérienne sont un frein majeur à l'application de la SDD.

La colonisation des voies aériennes supérieures peut être secondaire à l'inhalation de bactéries contenues dans le tractus digestif, et l'administration de

Tableau XVI - Mesures visant à la prévention des infections respiratoires nosocomiales.

Précautions pour limiter la transmission de micro-organismes: lavage de mains, éventuellement port de gants et de blouse.

Maintien en position semi-assise en l'absence de contre-indication.

Éviter la distension gastrique.

Toilette des voies aériennes, aspiration des secrétions sus-glottiques.

Kinésithérapie; spirométrie incitative, mobilisation précoce.

Réduire les traitements immunosuppresseurs.

Décontamination sélective du tractus digestif (mais risque d'apparition de résistances bactériennes).

Éviter les sondes gastriques autant que possible.

Stérilisation/changements fréquents d'appareils respiratoires.

Utilisation de sucralfate plutôt que d'anti- $\mathrm{H}_{2}$ dans la prévention des ulcérations de stress (?).

Acidification de la solution nutritive (?).

Alimentation jéjunale (?). 
Tableau XVII - Principaux facteurs favorisant le développement d'infections respiratoires nosocomiales.

État critique (score de gravité élevé).

Hospitalisation prolongée.

Intubation endotrachélae, trachéotomie.

Réintubations.

Les facteurs favorisant l'inhalation de contenu gastrique: position allongée, altération de la conscience, altération de la déglutition ou du réflexe de nausée, diminution de la motilité gastro-intestinale.

Présence d'une sonde gastrique surtout de gros calibre.

État pulmonaire altéré, BPCO.

Traitement antibiotique.

Immunosuppression.

La colonisation d'appareils (aérosols).

Pullulation microbienne gastrique: traitement anti- $\mathrm{H}_{2}$, présence de bilirubine dans le liquide gastrique, alimentation entérale, âge avancé, achlorhydrie, diminution de motilité gastroduodénale.

Chirurgie abdominale ou thoracique.

Polytrauma.

médications anti- $\mathrm{H}_{2}$ dans le cadre de la prévention d'ulcérations digestives favorise la pullulation microbienne dans l'estomac. Certains travaux ont proposé que l'administration de sucralfate, qui ne modifie pas le $\mathrm{pH}$ gastrique, pourrait être préférée. Cette littérature reste toutefois controversée, et le sucralfate semble avoir un effet protecteur moins efficace vis-à-vis des hémorragies digestives.

Le diagnostic d'infection respiratoire n'est pas facile chez le malade de soins intensifs, qui présentent très souvent un certain degré d'hypoxémie, une auscultation un peu anormale, un foyer possible à la radiographie de thorax, et une colonisation des voies aériennes supérieures par des agents pathogènes.

Il peut donc être préférable de recourir à des prélèvements bactériologiques protégés:

- lavage broncho-alvéolaire (LBA) à l'aveugle ou dirigé;

- prélèvement par brosse (moins souvent pratiqué aujourd'hui, car pas plus efficace, mais plus coûteux).

- ou d'effectuer des cultures quantitatives des aspirations endotrachéales.

\section{Infections de la peau et des tissus mous}

\section{Cellulite}

La cellulite est une infection aiguë de la peau et des tissus mous, se manifestant par un érythème œdémateux assez bien défini, qui peut entraîner une lymphangite. La cellulite se développe en général dans un contexte de traumatisme ou de brèche 
locale. Les organismes les plus souvent impliqués sont le streptocoque bêtahémolytique du groupe A et le staphylocoque doré.

Les cas les plus sévères sont la fasciite nécrosante et la gangrène gazeuse.

La fasciite nécrosante (impliquant principalement les fascias) survient surtout chez les malades présentant des facteurs de comorbidité comme le diabète ou l'artérite, ou encore la toxicomanie. Elle peut être due à des streptocoques bêtahémolytiques ou des staphylocoques, mais aussi d'autres micro-organismes, aérobies ou anaérobies. La grande majorité des infections sont polymicrobiennes. La fasciite nécrosante commence souvent par une lésion bénigne comme une piqûre d'insecte, ou un traumatisme mineur. La gangrène de Fournier est le cas particulier d'une fasciite nécrosante de la région périnéale, entreprenant la bourse chez l'homme.

La gangrène gazeuse ou myonécrose est généralement due à un Clostridium (anaérobie à Gram +). Il existe en général une crépitation causée par la formation de gaz par l'anaérobie. Elle survient souvent après une laparotomie ou un traumatisme pénétrant.

Dans les deux cas, la survie dépend d'une reconnaissance précoce du problème, et consiste en une antibiothérapie associée à un débridement large des tissus infectés. En cas d'atteinte des extrémités, une amputation peut être nécessaire. Le caisson hyperbare peut être utile.

\section{Traitement antibiotique}

Le traitement antibiotique ne peut être traité à la légère pour plusieurs raisons:

- il favorise la sélection de germes résistants (surtout à large spectre) qui représentent un danger à la fois pour le patient traité et pour les autres patients dans l'unité, l'hôpital et la communauté;

- il présente des effets secondaires non négligeables;

- il représente un coût important.

Il faut donc tenter:

- de restreindre le traitement antibiotique;

- si le traitement antibiotique est décidé, de garder le spectre le plus étroit, couvrant le(s) micro-organisme(s) en cause; le spectre peut souvent être réduit lors de l'obtention des résultats microbiologiques. On ne peut pas argumenter de la bonne réponse clinique pour poursuivre l'antibiothérapie si l'intensité de celle-ci peut être réduite.

Plusieurs éléments doivent guider l'antibiothérapie:

- l'examen direct, la culture et l'antibiogramme de spécimens bactériologiques;

- la source d'infection (cet élément est encore plus important en l'absence d'information bactériologique spécifique, puisque le type d'infections peut orienter vers les germes le plus probablement impliqués);

- le statut immunitaire du malade, qui dépend de différents facteurs: le patient peut être immunodéprimé (neutropénique, transplanté, SIDA...), éthylique, diabétique... et la durée de séjour à l'hôpital; 
- l'écologie de l'hôpital et surtout de l'unité de soins intensifs;

- le traitement antibiotique antérieur éventuel.

L'antibiothérapie doit être commencée dès la prise de spécimens bactériologiques dans les cas suivants:

- patients septiques immunodéprimés: surtout neutropéniques ou aspléniques;

- sepsis sévère ou choc d'allure septique;

- infection documentée, surtout si particulièrement torpide: méningites, nécroses cutanées.

\section{Type d'antibiotiques}

Les bactéricides sont toujours préférés dans les infections sévères et chez les patients immunodéprimés, de même que dans les altérations locales de la réponse immunitaire (endocardite, méningite, ostéomyélite).

\section{Combinaison d'antibiotiques}

En vue d'assurer une couverture large ; en particulier:

- lorsque le type de germes est indéterminé;

- lorsque le germe suspecté a une sensibilité variable aux antibiotiques;

- en cas de sepsis sévère ou d'immunodéficience sévère, c'est-à-dire lorsque la situation serait catastrophique en cas de couverture inappropriée.

En cas d'infection polymicrobienne (ex.: péritonite secondaire à une rupture de viscère).

Pour obtenir une synergie: en particulier dans les endocardites à entérocoque ou un sepsis à Gram négatif chez le patient neutropénique.

Pour prévenir l'émergence de germes résistants: cette indication concerne surtout la tuberculose.

\section{Traitement probabiliste - désescalade}

Dans les infections sévères, il est établi qu'un traitement antibiotique couvrant le ou les organismes responsables est associé à une meilleure survie. Il est dont souvent nécessaire, faute d'information, de commencer une antibiothérapie à large spectre. Toutefois, dès que l'organisme est indentifié, et éventuellement que l'antibiogramme est connu, les antibiotiques à large spectre (céphalosporines de $3^{\mathrm{e}}$ ou $4^{\mathrm{e}}$ génération, penems) doivent si possible être remplacées par des antibiotiques à spectre plus restreint (céphalosporine de $2^{\mathrm{e}}$ génération, association amoxicilline-acide clavulanique, témocilline...).

Tableau XVIII - Contrôle infectieux en soins intensifs — Perspectives d'avenir.

Diagnostic rapide d'infections - reconnaissance immédiate de micro-organismes. Antibiothérapie plus centrée sur les microorganismes responsables.

Isolation plus judicieuse des patients.

Utilisation de matériel résistant aux bactéries: cathéters intraveineux, sondes vésicales...

Immunoprophylaxie. 
Durée de traitement antibiotique

Pour des infections banales, on compte en général 7 à 10 jours de traitement. Toutefois, le traitement peut éventuellement être arrêté quelque 72 heures après la disparition des signes de sepsis. Des infections de certains sites (endocardites, arthrite septique, ostéomyélite) nécessitent des traitements prolongés.

\section{Principaux antibiotiques}

Cette revue se limitera aux principaux antibiotiques utilisés en soins intensifs.

Bêta-lactams:

Pénicillines, céphalosporines, céphamycines, carbacéphems, carbapenems et monobactams:

Les bêta-lactams altèrent les membranes bactériennes en se liant aux proteines membranaires (penicillin-binding proteins ou PBP). La résistance aux bêta-lactams peut provenir soit de la dégradation de l'antibiotique par des bêta-lactamases soit d'altérations de la membrane bactérienne.

\section{Pénicillines}

La pénicilline G est active vis-à-vis de la plupart des coques Gram + et Gram -, et de beaucoup d'anaérobies sus-diaphragmatiques, y compris les coques et les Clostridium. Elle est disponible sous forme de sel de potassium ou de sodium.

L'indication principale de la pénicilline $\mathrm{G}$ reste l'infection à pneumocoque. Il faut toutefois noter l'importance croissante du pneumocoque dont la sensibilité à la pénicilline est diminuée (environ $12 \%$ en Belgique). L'administration de pénicilline garde sa place dans certaines infections de la sphère ORL (pharyngite aiguë, abcès). Pour le traitement de la pneumonie à pneumocoque chez l'hôte sain, les doses doivent toutefois être élevées: $2-3 \times 106$ unités $\times 6 / 24 \mathrm{~h}$.

Toxicité: les réactions d'allergie sont les plus fréquentes (fièvre, éosinophilie, anaphylaxie). Une anémie hémolytique, une neutropénie ou une thrombocytopénie peuvent survenir. Des crises d'épilepsie peuvent rarement survenir.

Les pénicillines semi-synthétiques résistantes à la pénicillinase (oxacilline) sont indiquées dans les infections à staphylocoques produisant la pénicillinase. Ils sont moins actifs que la pénicilline $\mathrm{G}$ vis-à-vis des coques à Gram + qui ne produisent pas de bêta-lactamase. Les staphylocoques résistants à ces agents sont aussi résistants aux céphalosporines et à l'imipenem.

Dose habituelle: $8 \mathrm{~g} / 24 \mathrm{~h}$.

Toxicité: néphrite interstitielle, altération des tests hépatiques, neutropénie.

Les aminopénicillines (ampicilline, amoxicilline) sont des dérivés semisynthétiques ayant une activité vis-à-vis des bacilles à Gram -, tels que entérobactéries, Hémophilus et Neisseria. Ils ont gardé beaucoup de l'activité de la pénicilline, sauf que l'activité vis-à-vis du pneumocoque est moindre. Ces antibiotiques sont peu actifs vis-à-vis du Klebsiella et de beaucoup de Gram -. 
Les carboxy- et acylaminopénicillines (ticarcilline, piperacilline) ont un spectre étendu principalement au Pseudomonas aruginosa et autres bacilles à Gram -, ainsi que d'anaérobies de type Bacteroïdes fragilis. En cas d'infection sévère à Pseudomonas, Enterobacter ou Serratia, ces agents doivent être administrés avec un aminoside, pour bénéficier de la synergie. (NB Les antibiotiques ne peuvent toutefois pas être mélangés dans la même perfusion, car ils risquent de s'inactiver l'un l'autre).

Toxicité: cf. autres pénicillines + hypokaliémie, prolongement du temps de saignement.

La témocilline $\left(\right.$ Negaban $\left.^{\circledR}\right)$

Le spectre de cet antibiotique couvre la plupart des bacilles à Gram négatifs aérobies à l'exception du Pseudomonas ceruginosa. Cet antibiotique n'a pas d'activité vis-à-vis des coques à Gram + ni sur les anaérobies. Il induit peu de production de bêta-lactamases par les bacilles à Gram -.

Dose habituelle: $2 \times 2 \mathrm{~g}$ /jour.

Indications:

- infections mono-microbiennes à entérobactéries sensibles;

- infections mixtes en association avec d'autres antibiotiques actifs sur les cocci à Gram + et les anaérobies.

\section{Inhibtieurs de bêta-lactamase}

L'acide clavulanique, le sulbactam et le tazobactam sont des inhibiteurs puissants de bêta-lactamases. Toutefois, ils ne sont pas indiqués dans le traitement d'infections sévères à Pseudomonas aruginosa ou Enterobacter.

L'association d'amoxycilline et d'acide clavulanique comme inhibiteur de bêtalactamase (Augmentin ${ }^{\circledR}$ ) élargit le spectre antibactérien en y incluant certaines entérobactéries, l'Homophilus, la Moraxella, le staphylocoque doré sensible à l'oxacilline et le Bacteroïdes fragilis.

Indications :

- infections broncho-pulmonaires extrahospitalières;

- infections périnéales et abcès intra-abdominaux d'origine extrahospitalière;

(éventuellement en association avec un aminoglycoside).

Dose habituelle: $3 \times 2 \mathrm{~g} / 24 \mathrm{~h}$.

Pipéracilline tazobactam. Cette combinaison élargit la sensibilité de la pipéracilline si bien que cet antibiotique a un spectre voisin de celui des céphalosporines de troisième génération et des fluoroquinolone vis-à-vis des entérobactéries. Cette association est généralement active vis-à-vis du Pseudomonas aeruginosa mais il faut savoir qu'un certain pourcentage de souche (10\% dans notre institution) peut être résistant. Lorsqu'une infection à Pseudomonas est suspectée, l'addition d'amikacine est de toute façon recommandée. Cette antibiotique est actif sur les streptocoques et les anaérobies ainsi que les staphylocoques sensibles à l'oxacilline.

Indications:

- infections intra-abdominales;

- pleuro-pneumopathie nosocomiales;

- infections polymicrobiennes pelviennes;

- granulopénie fébrile. 


\section{Céphalosporines}

Les nouvelles générations tendent à avoir une meilleure activité vis-à-vis des Gram -, au prix d'une diminution d'activité vis-à-vis des Gram + (toutefois, la ceftriaxone et les céphalosporines de $4^{\mathrm{e}}$ génération gardent une bonne activité vis-à-vis des Gram +). Des résistances sont apparues, en particulier d'Enterobacter, Pseudomonas et Citrobacter. Ces agents ne sont pas indiqués en cas d'infections à entérocoques.

Toxicité: allergie (certaines allergies aux pénicillines sont étendues à ces agents), parfois coagulopathies répondant à la vitamine $\mathrm{K}$.

\section{Première génération}

Les céphalosporines de $1^{\text {re }}$ génération comme la céfazoline sont actifs vis-à-vis de la plupart des coques à Gram + et à Gram - (y compris Klebsiella) en dehors de l'hôpital, mais Pseudomonas, Enterobacter et Bacteroïdes fragilis sont en général résistants. Ces antibiotiques passent mal la barrière hémato-méningée.

Ces antibiotiques ne sont plus prescrits à l'hôpital que dans la prophylaxie chirurgicale autre que pour la chirurgie cardiaque et la chirurgie colorectale.

\section{Deuxième génération}

Cefuroxime, céfamandole.... ces antibiotiques, étendent le spectre vis-à-vis des Gram -, restent assez actifs vis-à-vis de nombreux germes hospitaliers comme le staphylocoque sensible à l'oxacilline, le pneumocoque, l'hémophilus et le Moraxella et leur activité sur les entérobactéries intrahospitalières est irrégulière. Ces antibiotiques ne sont pas actifs sur Pseudomonas aruginosa.

Indications:

- association avec l'amikacine dans le traitement d'infections nosocomiales à germes inconnus, pour autant que Pseudomonas aruginosa soit raisonnablement exclu;

- prophylaxie de la chirurgie colorectale: cefotétan, pour son activité antianaérobie.

\section{Troisième génération}

céfotaxime, ceftriaxone, céftazidime, céfopérazone: ces antibiotiques sont en général plus actifs sur les germes à Gram -.

La ceftazidime est la seule céphalosporine active sur Pseudomonas aruginosa; elle est par contre moins active sur les Gram + .

Indications:

- infections sévères présumées à bacille à Gram négatif multirésistant ;

- méningite postneurochirurgicale;

- infections chez l'immunodéprimé (généralement en asssociation).

Quatrième génération - céfépime, cefpirome

Ces antibiotiques ont une meilleure activité sur les cocci à Gram positif, l'Entérobacter, le Citrobacter et le Serratia, que les céphalosporines de $3^{\text {e }}$ génération. Leur activité sur Pseudomonas aruginosa est similaire à celle de la ceftazidime. Globalement ces antibiotiques ont donc un spectre comparable à celui des carbapénèmes sauf pour les anaérobies et les ESBL

Indications :

- infections nosocomiales. 


\section{Carbapenems: Imipénem, méropénem}

Ces antibiotiques présentent un spectre très étendu comprenant les cocci à Gram positifs (sauf l'Enterocoque fecium et les MRSA), les entérobactéries et Pseudomonas. Ce spectre inclut les bacilles à Gram négatifs producteurs de bêta-lactamases (Enterobacter, Citrobacter, Serratia, Pseudomonas et les anaérobies). Le méropénem est un peu plus actif que l'imipénem sur les bacilles à Gram négatif.

Indications :

- infections polymicrobiennes aérobies et anaérobies nosocomiales (péritonite, abcès intra-abdominaux, certaines pleuro-pneumopathies);

- épisodes fébriles chez le granulopénique;

- choc septique nosocomial à germe inconnu;

- infections nosocomiales à germes multirésistants;

L'imipénem peut parfois induire des crises d'épilepsie, surtout en assocation avec d'autres médications proconvulsivantes comme la ciclosporine.

\section{Aztreonam}

Monobactam dont l'activité est limitée aux bacilles Gram -, y compris Pseudomonas euriginosa et Serratia. Inactif vis-à-vis des coques Gram + ou des anaérobes. Peut être particulièrement utile chez les patients allergiques à la pénicilline, car il ne semble pas y avoir de réaction croisée.

\section{Aminosides}

Aminosides: amikacine $\left(\right.$ Amukin $\left.{ }^{\circledR}\right)$, gentamicine $\left(\right.$ Geomicine ${ }^{\circledR}$ ), nétilmicine (Nétromycine $\left.{ }^{\circledR}\right)$, tobramycine (Obracin $\left.{ }^{\circledR}\right)$.

L'amikacine est le plus prescrit aujourd'hui et la tobramycine peut encore trouver une indication dans les infections à Pseudomonas aruginosa (notamment chez le patient mucoviscidosique) et la gentamicine dans le traitement des infections graves à entérocoque et à Listeria. L'utilisation d'aminoglycosides en monothérapie n'est pas recommandée.

Indications

Les aminosides sont surtout indiqués en combinaison avec un bêta-lactam dans le traitement d'infections sévères à Gram - (surtout Pseudomonas aruginosa) ou en cas d'endocardite à streptocoque (surtout entérocoque). Ils ne sont pas actifs en l'absence d'oxygène ou à $\mathrm{pH}$ bas, si bien qu'ils sont inefficaces vis-à-vis des anaérobies ou dans le traitement d'abcès. Leur activité est directement dépendante de la dose. La résistance aux aminosides provient d'enzymes médiés par des plasmides.

Infections graves présumées à bacille à Gram négatif (en combinaison).

- Infections à Pseudomonas aruginosa (en combinaison).

L'administration de l'aminoside est en général arrêtée lorsque l'antibiogramme indique que la bactérie est sensible à l'autre antibiotique.

Doses: en raison de l'effet postantibiotique (persistance de l'inhibition de croissance du germe lorsque les concentrations sont descendues endessous de la CMI du germe) et la notion de saturation de l'accumulation intracellulaire de ces antibiotiques (responsables de leur toxicité), une administration quotidienne unique est recommandée aujourd'hui. 
Amikacine $15 \mathrm{mg} / \mathrm{kg} /$ jour; tobramycine $5 \mathrm{mg} / \mathrm{kg} /$ jour, gentamicine 4,5 mg/kg/jour.

Un dosage d'amikacine est souhaitable avant l'injection pour s'assurer que les taux sanguins à ce moment (vallée) est inférieur à $2 \mathrm{mg} /$ litre.

Les doses d'amikacine et de tobramycine peuvent éventuellement être plus élevées chez le malade mucoviscidosique.

Ces doses doivent être ajustées en fonction des taux sanguins. Surtout importants en cas d'altération de la fonction rénale.

\begin{tabular}{|l|l|l|}
\hline Taux & $\begin{array}{l}\text { de pic }(30 \text { min après la } \\
\text { fin de la perfusion) }\end{array}$ & vallée \\
\hline genta & $4-6 \mathrm{mcg} / \mathrm{mL}$ & $<2 \mathrm{mcg} / \mathrm{mL}$ \\
\hline amika & $20-35 \mathrm{mcg} / \mathrm{mL}$ & $<5 \mathrm{mcg} / \mathrm{mL}$ \\
\hline
\end{tabular}

Toxicité: néphrotoxicité généralement réversible, mais peut évoluer en insuffisance rénale aiguë

- ototoxicité: cochléaire ou vestibulaire, surtout en cas d'administration prolongée ( $>2$ semaines), chez les patients en insuffisance rénale, et en association avec d'autres agents ototoxiques, comme le furosémide.

- atteinte de la transmission neuromusculaire.

\section{Glycopeptides}

Vancomycine (Vancocin $\left.{ }^{\circledR}\right)$, teicoplanine (Targocid ${ }^{\circledR}$ )

L'usage de ces agents est principalement réservé aux infections pouvant incriminer un staphylocoque résistant à l'oxacilline (SAM ou methicilline resistant Staphylococus aureus ou MRSA).

Le traitement doit être arrêté dès que la présence de SAM (MRSA) peut être raisonnablement exclue. De même, la colonisation par ces SAM (MRSA) ne doit pas nécessairement être traitée. Le risque est en effet de voir apparaître des entérocoques multirésistants (problème devenu important aux USA et heureusement pas encore en Europe).

La vancomycine est bactéricide vis-à-vis de la plupart des germes à Gram + et bactériostatique vis-à-vis des entérocoques. Les indications sont:

- infections à staphylocoques résistants à l'oxacilline;

- infections (ou traitement prophylactique) chez les patients allergiques aux bêtalactams (allergie médiée par IgE);

- endocardite à entérocoque (avec un amisoside).

Dose: vancomycine $15 \mathrm{mg} / \mathrm{kg} \times 2 \mathrm{IV}$ par jour à adapter au taux sérique (vallée 5-15 mg/L). Elle doit être administrée lentement (en 1 heure); on peut aussi l'administrer en perfusion continue à une dose de l'ordre de $3 \mathrm{~g}$ par 24 heures. 
Les doses doivent être ajustées en fonction des dosages sanguins, surtout en présence d'altération de la fonction rénale. En cas d'administration intermittente, on recherche un pic sérique à 30 à $40 \mathrm{mg} / \mathrm{L}$. En cas de perfusion continue, on recherche un taux de 20 à $30 \mathrm{mg} / \mathrm{L}$.

Toxicité: flush (lié à la libération d'histamine) parfois accompagné d'hypotension et de frissons, lors de la première administration (" red man syndrome»). ototoxicité et néphrotoxicité.

La teicoplanine a peu d'avantage sur la vancomycine en dehors d'une demi-vie prolongée, plus pratique lorsque le malade quitte l'USI.

Doses: 6 mg/kg x 2 IV par jour à adapter au taux sérique (vallée 10 à 25 mg/L).

\section{Quinolones}

Ces agents exercent leur activité en inhibant la DNAgyrase. Ils peuvent être administrés par voie orale, car ils sont très bien résorbés. À éviter chez la femme enceinte et l'enfant.

Les fluroroquinolones : ciprofloxacine (Ciproxine ${ }^{\circledR}$ ), ofloxacine (Tarivid ${ }^{\circledR}$ ), péfloxacine (Peflacine $\left.{ }^{\circledR}\right)$.

Ils sont actifs surtout vis-à-vis des Gram - (y compris Pseudomonas ceruginosa) mais aussi des coques à Gram +, y compris certains staphylocoques, et des mycoplasmes et Legionella. Ils sont peu actifs vis-à-vis des streptocoques (surtout enterocoque) et des Pseudomonas non-ceruginosa et inactifs vis-à-vis des anaérobies.

Les nouvelles quinolones ont une activité antimicrobiennes comparable à celle des céphalosporines de $3^{\text {e }}$ génération vis-à-vis des germes à Gram négatifs et une activité relativement faible vis-à-vis des Gram positifs et absente vis-à-vis des anaérobies.

Par contre, elles sont actives vis-à-vis du Legionella, Rickettsia et Chlamydia.

Ces agents ont l'avantage d'être très bien résorbés par le tube digestif si bien qu'une administration parentérale peut facilement être poursuivie par l'administration entérale.

Indications:

- infections nosocomiales à bacilles à Gram négatif;

- infections de la sphère uro-urinaire (y compris les prostatites), infections biliaires, ostéite;

- entérites.

Doses: ciprofloxacine 2 à $3 \times 400 \mathrm{mg} / 24 \mathrm{~h}$.

Toxicité: nausées, bouche sèche, altération du goût. Peuvent interférer avec les taux de certains médicaments, dont la théophylline.

\section{Nitroimidazolés}

Le metronidazole $\left(\right.$ Flagyl $\left.^{\circledR}\right)$ a une activité bactéricide est puissante vis-à-vis de bactéries anaérobies (sauf les Propionibacterium) et certaines protozoaires (amibes, Giardia, Trichomonas). Ces substances sont prescrites dans le traitement de colite pseudo-membraneuse à Clostridium difficile.

Dose habituelle: $3 \times 500 \mathrm{mg} / 24 \mathrm{~h}$. 
Composé nitro-imidazolé actif vis-à-vis de la plupart des bactéries anaérobies àGram -, y compris le Bacteroïdes et beaucoup de Clostridium. Beaucoup de streptocoques anaérobies sont toutefois résistants.

La distribution est étendue, y compris au système nerveux central. Le métabolisme est hépatique avant d'être rénal.

\section{Triméthoprime/sulfaméthoxazole}

En inhibant le métabolisme de l'acide folique, la combinaison de triméthoprime/sulfaméthoxazole à dose fixe (rapport en poids de 1/5) a un large spectre vis-à-vis de beaucoup de Gram + et Gram -, à l'exception de Pseudomonas aruginosa et d'entérocoque. Utile au traitement d'infections urinaires, prostatiques, de la bronchite à germes extrahospitaliers, de la salmonellose. C'est l'agent de choix de l'infection à Pneumocystis carinii. Peut être utilisé dans les méningites ou ostéomyélites à germes sensibles.

Toxicité: hématologique (anémie, leucopénie, thrombocytopénie, aplasie médullaire).

\section{Macrolides}

Érythromycine, clarithromycine (Biclar $\left.{ }^{\circledR}\right)$

Le spectre antimicrobien comprend les cocci à Gram positifs, Moraxella, Legionella, Chlamydia, mycoplasmes.

Tableau XIX - Choix de l'antibiotique en fonction du micro-organisme.

\begin{tabular}{|l|l|l|}
\hline Pathogène & $\begin{array}{l}\text { Antibiotique(s) de } \\
\text { premier choix }\end{array}$ & Alternatives \\
\hline Acinetobacter $s p$. & meropenem \pm amikacine & $\begin{array}{l}\text { cotrimoxazole } \\
\text { ceftazidime } \\
\text { ciprofloxacine } \\
\text { pipéracilline }\end{array}$ \\
\hline Eromonas hydrophila & ciprofloxacine & $\begin{array}{l}\text { meropenem } \\
\text { céfuroxime }\end{array}$ \\
\hline Bacterö̈des fragilis & métronidazole & $\begin{array}{l}\text { amoxicilline - } \\
\text { acide clavulanique } \\
\text { meropenem }\end{array}$ \\
\hline Citrobacter freundii & témocilline & $\begin{array}{l}\text { meropenem } \\
\text { ciprofloxacine } \\
\text { cotrimoxazole }\end{array}$ \\
\hline Clostridium perfringens & pénicilline & $\begin{array}{l}\text { clindamycine } \\
\text { céfazoline } \\
\text { meropenem } \\
\text { métronidazole }\end{array}$ \\
\hline
\end{tabular}




\begin{tabular}{|c|c|c|}
\hline Clostridium difficile & métronidazole & vancomycine \\
\hline Corynebacterium sp. & pénicilline & vancomycine \\
\hline Enterobacter sp. & meropenem & $\begin{array}{l}\text { témocilline } \\
\text { ciprofloxacine, céfépime }\end{array}$ \\
\hline $\begin{array}{l}\text { Enterobacter cerogenes } \\
\text { multirésistant }\end{array}$ & meropenem + gentamicine & céfépime + gentamicine \\
\hline Enterococcus sp. & ampicilline + gentamicine & $\begin{array}{l}\text { vancomycine + } \\
\text { gentamicine }\end{array}$ \\
\hline Escherichia coli & ampicilline & $\begin{array}{l}\text { amox-ac. clav. } \\
\text { témocilline }\end{array}$ \\
\hline Hafnia alvei & témocilline & $\begin{array}{l}\text { impipénem } \\
\text { ciprofloxacine } \\
\text { cotrimoxazole }\end{array}$ \\
\hline Hemophilus influenze & & \\
\hline$\beta$ lactamase - & ampicilline & $\begin{array}{l}\text { ceftriaxone (méningite) } \\
\text { cotrimoxazole }\end{array}$ \\
\hline$\beta$ lactamase + & amox-ac. clav. ou céfuroxime & $\begin{array}{l}\text { ceftriaxone (méningite) } \\
\text { cotrimoxazole }\end{array}$ \\
\hline Klebsiella sp. & céfazoline & $\begin{array}{l}\text { témocilline } \\
\text { ciprofloxacine } \\
\text { cotrimoxazole }\end{array}$ \\
\hline Legionella sp. & $\begin{array}{l}\text { érythromycine (IV) } \\
\pm \text { rifampicine }\end{array}$ & ciprofloxacine \\
\hline Listeria monocytogenes & ampicilline + gentamicine & $\begin{array}{l}\text { cotrimoxazole } \\
\text { (hautes doses) }\end{array}$ \\
\hline Moraxella catarrhalis & cotrimoxazole & $\begin{array}{l}\text { amox-ac. clav. } \\
\text { érythromycine }\end{array}$ \\
\hline Morganella morganii & témocilline & $\begin{array}{l}\text { pipéracilline } \\
\text { imipénem } \\
\text { cotrimoxazole } \\
\text { ciprofloxacine }\end{array}$ \\
\hline Mycoplasma pneumonice & clarithromycine & doxycycline \\
\hline Neisseria gonorrhoea & ciprofloxacine & $\begin{array}{l}\text { ceftriaxone } \\
\text { spectinomycine }\end{array}$ \\
\hline Neisseria meningitides & pénicilline & ceftriaxone \\
\hline Peptostreptococcus sp. & Pénicilline & $\begin{array}{l}\text { céfazoline } \\
\text { clindamycine }\end{array}$ \\
\hline Proteus mirabilis & ampicilline & $\begin{array}{l}\text { amox-ac. clav. } \\
\text { témocilline } \\
\text { cotrimoxazole } \\
\text { céfazoline }\end{array}$ \\
\hline $\begin{array}{l}\text { Streptococcus pneumonice } \\
\text { a. Infections } \\
\text { extraméningées } \\
\text { Pénicilline }\end{array}$ & pénicilline & $\begin{array}{l}\text { amoxicilline (hautes doses) } \\
\text { ceftriazone } \\
\text { céfotaxime } \\
\text { vancomycine }\end{array}$ \\
\hline
\end{tabular}




\begin{tabular}{|c|c|c|}
\hline b. Infections méningées & & \\
\hline Pénicilline S & pénicilline (hautes doses) & $\begin{array}{l}\text { ceftriaxone } \\
\text { céfotaxime }\end{array}$ \\
\hline Pénicilline I & $\begin{array}{l}\text { ceftriaxone, } \\
\text { céfotaxime }\end{array}$ & vancomycine \\
\hline Pénicilline $\mathrm{R}$ & $\begin{array}{l}\text { vancomycine }+ \text { ceftriaxone } \\
\pm \text { rifampicine? } \\
\text { consulter un infectiologue }\end{array}$ & $\begin{array}{l}\text { meropenem } \\
\text { céfépime } \\
\text { consulter un infectiologue }\end{array}$ \\
\hline Proteus vulgaris & témocilline & $\begin{array}{l}\text { aztréonam } \\
\text { pipéracilline } \\
\text { ceftriaxone } \\
\text { ciprofloxacine }\end{array}$ \\
\hline Providenciasp. & témocilline & $\begin{array}{l}\text { aztréonam } \\
\text { ceftriaxone } \\
\text { meropenem } \\
\text { ciprofloxacine }\end{array}$ \\
\hline Pseudomonas aruginosa & pipéracilline + amikacine & $\begin{array}{l}\text { ceftazidime }+ \text { amikacine } \\
\text { ciprofloxacine }+ \text { amikacine } \\
\text { meropenem }+ \text { amikacine }\end{array}$ \\
\hline $\begin{array}{l}\text { Salmonella typhi } \\
\text { et non typhi }\end{array}$ & ciprofloxacine & $\begin{array}{l}\text { cotrimoxazole } \\
\text { ceftriaxone } \\
\text { amoxicilline }\end{array}$ \\
\hline Serratia marcescens & meropenem & $\begin{array}{l}\text { aztréonam } \\
\text { témocilline } \\
\text { céfépime } \\
\text { ciprofloxacine } \\
\end{array}$ \\
\hline Shigella sp. & ciprofloxacine & $\begin{array}{l}\text { cotrimoxazole } \\
\text { ampicilline }\end{array}$ \\
\hline $\begin{array}{l}\text { Staphylococcus } \\
\text { (aureus et autres) } \\
\text { oxa S } \\
\text { oxa R }\end{array}$ & $\begin{array}{l}\text { oxacilline } \\
\text { vancomycine }\end{array}$ & $\begin{array}{l}\text { céfazoline } \\
\text { clindamycine } \\
\text { teicoplanine }\end{array}$ \\
\hline $\begin{array}{l}\text { Stenotrophomonas } \\
\text { Maltophilia }\end{array}$ & cotrimoxazole & $\begin{array}{l}\text { ciprofloxacine } \\
\text { ceftazidime }\end{array}$ \\
\hline Streptococcus groupe B & pénicilline \pm gentamicine & $\begin{array}{l}\text { céfazoline } \\
\text { érythromycine } \\
\text { vancomycine } \\
\end{array}$ \\
\hline $\begin{array}{l}\text { Streptococcus pyogenes } \\
\text { groupe A }\end{array}$ & pénicilline & $\begin{array}{l}\text { érythromycine } \\
\text { céfazoline } \\
\text { clindamycine }\end{array}$ \\
\hline Streptococcus viridans & pénicilline \pm gentamicine & $\begin{array}{l}\text { ceftriaxone } \\
\text { vancomycine }\end{array}$ \\
\hline Streptococcus milleri & pénicilline & céfazoline \\
\hline Yersinia enterocolitica & ciprofloxacine & $\begin{array}{l}\text { doxycycline } \\
\text { céfuroxime } \\
\text { ceftriaxone }\end{array}$ \\
\hline
\end{tabular}


Tableau XX - Sensibilité de certains organismes aux antibiotiques les plus courants.

\begin{tabular}{|l|c|c|c|c|c|c|c|}
\hline & Pipe/tazo & Cefotax/cefria & Cefta & Aztreonam & Imipenem & Quinol & Aminosides \\
\hline Bacilles Gram- & 90 & 90 & 95 & 95 & 95 & 95 & 90 \\
\hline Pseudomonas & 85 & 5 & 95 & 50 & 95 & 95 & 95 \\
\hline Streptocoque & 95 & 85 & 10 & 0 & 85 & 20 & 40 \\
\hline Streptocoque fecalis & 95 & 0 & 0 & 0 & 50 & 0 & 50 \\
\hline Staphylocoque doré & 90 & 80 & 4 & 0 & 80 & 20 & 50 \\
\hline Anaérobies & 80 & 0 & 0 & 0 & 85 & 0 & 0 \\
\hline
\end{tabular}

Tableau XXI - Durée d'injection intraveineuse des antibiotiques.

\section{Injection rapide possible (2-5 minutes)}

- ampicilline, pipéracilline, oxacilline, amoxicilline-acide clavulanique

- céphalosporines (sauf ceftazidime)

- témocilline

- chloramphénicol

- teicoplanine

- meropenem

\section{Injection lente (30 minutes)}

- pénicilline G

- ceftazidime

- aminoglycosides (gentamicine, tobramycine, amikacine)

- clindamycine, érythromycine

- métronidazole

- ciprofloxacine

- fluconazole

- sulfadiazine

- éthambutol

- minocycline

\section{Injection en au moins une heure}

- vancomycine

- cotrimoxazole

- aciclovir, ganciclovir

- foscarnet

- rifampicine

- amphotéricine B

- pentamidine

- quinine 


\section{Infections chez l'immunodéprimé}

Les questions importantes à se poser chez l'immunodéprimé sont les suivantes.

- Quel est le type de déficit immunitaire (tableau XXII)?

-Congénital ou acquis (HIV, néoplasie, malnutrition...);

-Traitement immunosuppresseur ou chimiothérapeutique: type, dose, durée;

-Présence de neutropénie;

-Déficit leucocytaire (risque d'infection bactérienne ou mycotique) ou cellulaire (rique de mycobactéries, virus, mycoses, parasites).

Souvent les malades immunodéprimés présentent une combinaison d'anomalies

- Y a-t-il des anomalies métaboliques associées?

-Malnutrition;

-Diabète;

-Cirrhose, alcoolisme.

- Y a-t-il des anomalies de barrière?

-Tractus respiratoire;

-Tractus digestif;

-Présence de source d'infection: tissus nécrotique, collections...

- Quelle est la durée de l'immunosuppression?

Le type d'organismes dépend de la durée du traitement immunosppresseur (ex.: transplantations) ou du déficit (ex.: durée de la leucopénie) - ou encore le degré d'avancement de la maladie (stade SIDA).

On appelle infection opportuniste une infection causée par un non-pathogène (comme le Pneumocystis) ou encore une infection sévère par un organisme qui donne d'habitude lieu à un tableau clinique peu sérieux (ex.: infection sévère à Herpes).

Tableau XXII - Type de déficit immunitaire.

\begin{tabular}{|l|l|l|}
\hline Type de déficit & Conditions cliniques & $\begin{array}{l}\text { Micro-organismes à } \\
\text { considérer }\end{array}$ \\
\hline $\begin{array}{l}\text { Leucopénie (ou déficit de } \\
\text { fonction) }\end{array}$ & $\begin{array}{l}\text { Chimiothérapie, désordres } \\
\text { myéloprolifératifs }\end{array}$ & $\begin{array}{l}\text { Pseudomonas, } \\
\text { entérobactéries, Staph. doré, } \\
\text { flore orale, Aspergillus et } \\
\text { Candida }\end{array}$ \\
\hline $\begin{array}{l}\text { Déficiences humorales } \\
\text { (manque d'anticorps) }\end{array}$ & $\begin{array}{l}\text { SIDA, cancers } \\
\text { hématologiques }\end{array}$ & $\begin{array}{l}\text { Pneumocoque, Hémophilus, } \\
\text { méningocoque, entérovirus }\end{array}$ \\
\hline $\begin{array}{l}\text { Altérations de l'immunité } \\
\text { cellulaire }\end{array}$ & $\begin{array}{l}\text { SIDA, transplantés, } \\
\text { corticothérapie prolongée, } \\
\text { lymphomes }\end{array}$ & $\begin{array}{l}\text { Mycobactéries, Listeria, } \\
\text { Pneumocystis, Toxoplasma, } \\
\text { Herpes, Nocardia }\end{array}$ \\
\hline $\begin{array}{l}\text { Altérations de fonctions } \\
\text { opsonisantes }\end{array}$ & Splénectomie & $\begin{array}{l}\text { Bactéries encapsulées } \\
\text { (pneumocoque, } \\
\text { Hémophilus, } \\
\text { méningocoque) }\end{array}$ \\
\hline
\end{tabular}


L'insuffisance respiratoire aiguë est fréquente chez l'immunodéprimé. Les causes sont infectieuses dans environ $80 \%$ des cas (tableau XXIII). On ne peut se permettre d'attendre avant de traiter, et le traitement doit être large pour couvrir toutes les éventualités. En cas d'infection respiratoire, un prélèvement protégé (BAL) doit être réalisé (sauf si le malade est dans un état si précaire que l'examen nécessiterait une intubation endotrachéale que l'on tente d'éviter)

Dans les $20 \%$ des cas d'anomalies non infectieuses:

-récidive/extension de néioplasie;

-rejet de greffe;

-œdème pulmonaire hémodynamique ou ARDS;

-embolie ou hémorragie;

-toxicité médicamenteuse (fibrose);

-radiothérapie;

-ALI post-transfusions (TRALI).

\section{Syndromes cliniques}

\section{Le leucopénique}

Il s'agit le plus souvent de germes ordinaires et de champignons. Le traitement doit être précoce en cas de neutropénie fébrile, sans attendre d'avoir identifié une source d'infection. Dans ces conditions, on applique souvent une antibiothérapie à large spectre, associant éventuellement un traitement antifongique.

La fièvre chez le leucopénique a la distribution suivante:

-infections documentées cliniquement: $1 / 3$ des cas;

-infections documentées bactériologiquement: 25 à $30 \%$ des cas (le plus souvent avec hémocultures positives);

-infection d'origine non précisée: $1 / 3$ des cas;

-causes non infectieuses: 5 à $10 \%$ des cas.

\section{Le transplanté}

L'intervalle de temps entre la transplantation et le développement de l'infection est un élément important.

Premier mois: germes habituels (infections pulmonaires, de plaie, des urines, sur cathéter...). Le micro-organisme peut avoir été communiqué par le donneur d'organes (d'où l'importance de l'information bactériologique du donneur!).

De 1 à 6 mois après la transplantation: les virus (CMV, hépatite, EBV ...) ainsi que l'Aspergillus, Pneumocystis et Listeria.

Au-delà de 6 mois après la transplantation: chez la plupart des malades ayant une évolution favorable, l'infection redevient à germes banals; chez les malades souffrant d'infection virale chronique, on peut en voir l'évolution terminale (hépatite...); chez les malades ayant un rejet chronique, le risque d'infection à germes opportunistes (Pneumocystis, Nocardia, etc.) est élevé. 
Parmi les infections virales, les infections à Herpes sont les plus fréquentes (voir infections virales ci-dessous).

\section{Le SIDA}

L'infection à HIV entraîne une diminution des lymphocytes CD4 et altère l'immunité cellulaire.

Les formes cliniques sont variées. Les germes impliqués sont présentés dans le tableau XXIII.

\section{Infections fongiques}

Le nombre d'infections fongiques est en augmentation constante, notamment en raison du progrès de la médecine. Le nombre de malades immunodéprimés est en constante augmentation (transplantation, traitement de maladies autoimmunitaires, meilleure prise en charge des BPCO traités par corticoïdes etc.), et les malades de réanimation ont plus souvent des évolutions compliquées, avec traitements antibiotiques multiples et variés...

\section{Candida}

Les infections à Candida sont de loin les plus fréquentes. La source est soit endogène (translocation) soit exogène, principalement par les mains du personnel. Il s'agit généralement de Candida albicans, mais d'autres types ne sont pas rares: glabrata, tropicalis, krusei, parapsilosis, lusitanioe, neoformans, guilliermondii, etc. Les implications sont importantes, car les non-albicans sont parfois résistants au fluconazole.

Le diagnostic d'infection à Candida est difficile, car la colonisation est fréquente, mais ne nécessite pas de traitement. La présence de Candida dans les expectorations, les urines ou des liquides de drains ne signifie pas nécessairement une infection. Il est difficle de donner des instructions précises quant à la nécessité de traiter. De manière générale, On commence à traiter:

- en présence d'hémoculture(s) positive(s);

- en présence d'endophtalmite;

- en cas de documentation du Candida dans un milieu stérile ou un tissu (biopsie);

- en présence d'endocardite ou d'ostéomyélite à Candida;

- lorsque la colonisation devient importante (> 2 sites, prélèvements répétés);

- en cas de sepsis persistant sous antibiothérapie (surtout chez l'immunodéprimé ou le malade grave sous antibiothérapie préalable).

\section{Aspergillus}

L'incidence d'aspergillose augmente, notamment par le nombre croissant de patients immunodéprimés. La mortalité dépend évidemment du contexte, mais est 
Tableau XXIII - Type de micro-organisme en fonction du déficit immunitaire.

\begin{tabular}{|l|l|c|c|c|}
\hline Type d'infection & & \multicolumn{1}{|c|}{$\begin{array}{c}\text { Anomalies } \\
\text { leucocytaires }\end{array}$} & $\begin{array}{c}\text { Immunité } \\
\text { humorale }\end{array}$ & $\begin{array}{c}\text { Immunité } \\
\text { cellulaire }\end{array}$ \\
\hline Bactérienne & $\begin{array}{l}\text { Coques Gram }+ \\
\text { Entérobactéries, } \\
\text { Pseudomonas } \\
\text { Salmonella, Listeria, } \\
\text { mycobactéries, Nocardia }\end{array}$ & + & + & + \\
\hline Fongique & $\begin{array}{l}\text { Candida } \\
\text { Aspergillus }\end{array}$ & + & & + \\
& $\begin{array}{l}\text { Cryptococcus, } \\
\text { Histoplasma }\end{array}$ & + & & + \\
& $\begin{array}{l}\text { Herpes } \\
\text { (y compris CMV, EBV, } \\
\text { varicelle) }\end{array}$ & & $($ herpes simplex $)$ & + \\
\hline Virale & $\begin{array}{l}\text { Hépatite } \\
\text { Pneumocystis } \\
\text { Toxoplasma } \\
\text { Giardia }\end{array}$ & & + & + \\
\hline
\end{tabular}

Tableau XXIV - Micro-organismes principalement impliqués dans les infections chez les malades dont l'immunité cellulaire est déficiente.

\begin{tabular}{|l|l|}
\hline Type d'infection & Pathogènes fréquents \\
\hline Pneumonie & $\begin{array}{l}\text { Legionella, CMV, mycobactéries, } \\
\text { Candida, Aspergillus, Pneumocystis, } \\
\text { Nocardia }\end{array}$ \\
\hline Infection sur cathéter & Gram -, Candida \\
\hline Esophagite & Candida, Herpes simplex \\
\hline Entérite & $\begin{array}{l}\text { CMV, Salmonella, Shigella, Giardia, } \\
\text { Strongyloides, Cryptosporidium, } \\
\text { Campylobacter }\end{array}$ \\
\hline Méningite & Listeria, Cryptococcus \\
\hline Hépatite & CMV, herpes \\
\hline Rétinite & CMV, Candida \\
\hline
\end{tabular}


La radiographie peut aider au diagnostic (tableau XXV).

Tableau XXV - Diagnostics suggérés par les anomalies décelées à la radiographie de thorax.

\begin{tabular}{|l|l|l|}
\hline \multirow{2}{*}{ Anomalie } & \multicolumn{2}{|c|}{ Vitesse d'apparition } \\
\cline { 2 - 3 } & Rapide & Lente \\
\hline Consolidation & $\begin{array}{l}\text { Bactéries } \\
\text { y compris Legionnella) } \\
\text { hémorragies }\end{array}$ & $\begin{array}{l}\text { mycoses } \\
\text { tuberculose } \\
\text { tumeur } \\
\text { pneumopathie postradique } \\
\text { virus, Pneumocystis }\end{array}$ \\
\hline $\begin{array}{l}\text { Épaississements } \\
\text { péribroncho-vasculaires }\end{array}$ & $\begin{array}{l}\text { OPH } \\
\text { Leuco-agglutination }\end{array}$ & $\begin{array}{l}\text { vneumocystis } \\
\text { pneumopathie postradique } \\
\text { pneus }\end{array}$ \\
\hline Nodules & --- & $\begin{array}{l}\text { tumeur } \\
\text { mycose } \\
\text { nocardia } \\
\text { tuberculose }\end{array}$ \\
\hline Adénopathies & --- & $\begin{array}{l}\text { tumeurs } \\
\text { mycobactéries }\end{array}$ \\
\hline Cavitations & --- & $\begin{array}{l}\text { mycose } \\
\text { nocardiose }\end{array}$ \\
\hline
\end{tabular}

Tableau XXVI - Insuffisances respiratoires aiguës chez l'immunodéprimé.

\begin{tabular}{|l|l|}
\hline Infections pulmonaires $\mathbf{( 8 0} \%)$ & Non-infectieuses $\mathbf{( 2 0} \%)$ \\
\hline Bactériennes & Cdème pulmonaire hémodynamique \\
\hline Mycobactériennes & Récidive ou extension de néoplasie \\
\hline Virales & Toxicité médicamenteuse \\
\hline Mycotiques (Aspergillus, Cryptocoque) & Pneumopathie postradique \\
\hline Pneumocystis carinii & Rejet de greffe \\
\hline
\end{tabular}

généralement supérieure à $50 \%$. Aspergillus fumigatus est le plus fréquent, suivi du flavus. La source est environnementale: terre et plantes, matériaux de construction, systèmes de ventilation... 
Le diagnostic d'infection à Aspergillus n'est pas facile - il s'agit typiquement de patients immunodéprimés.

Tests microbiologiques: ils sont relativement peu sensibles, Aspergillus n'étant pas facilement isolé. Le BAL peut être très utile. La technique de PCR offre des possibilités intéressantes, mais n'est pas encore standardisée.

Tests sérologiques: le meilleur (ou le moins mauvais) est aujourd'hui la recherche (dans le sang ou le LCR) de galactomannan, un polysacchardide de la paroi de Aspergillus (il existe toutefois certains faux positifs).

Le CT-scan thoracique (surtout à haute résolution) est le meilleur examen, qui démontre la présence de nodule(s), entouré dans les cas typiques du signe du halo, dû à la présence de sang autour du nodule ou encore (plus tardivement) le croissant d'air, secondaire à la nécrose. La radiographie de thorax n'est en fait pas très utile au diagnostic. Rappelons la distinction entre aspergillome (boule se formant dans une ancienne cavité, souvent tuberculeuse) et aspergillose invasive, ou infection plus diffuse, le plus souvent (mais pas toujours) à point de départ pulmonaire.

La mise en évidence d'Aspergillus dans une biopsie, par exemple une biopsie transbronchique: il s'agit toutefois de procédure relativement invasive, et donc peu utilisée.

TableauXXVII - Facteurs de risque d'aspergillose invasive.

Neutropénie prolongée.

Traitement prolongé par corticoïdes.

Autre traitement immunosuppresseur: transplantation, malade auto-immunitaire, cancer hématologique.

SIDA.

\section{Azoles}

Ils agissent en inhibant une enzyme responsable de la synthèse d'ergostérol de la membrane des champignons.

Les effets secondaires sont une altération possible des tests hépatiques (en général peu sévères).

Les azoles interferent avec d'autres médicaments (par inhibition du cytochrome P 450).

Fluconazole (Diflucan ${ }^{\circledR}$ )

Actif vis-à-vis de la grande majorité de Candida albicans, et d'autres espèces, mais il est moins efficace sur le glabrata et inefficace sur le krusei.

Dose de 400 à $800 \mathrm{mg} /$ jour. 
Un traitement préemptif (sans infection documentée) a été proposé chez les malades présentant un sepsis intra-abdominal (à une dose de $400 \mathrm{mg} /$ jour). Il est clair que le bénéfice doit être pesé vis-à-vis du risque de résistance secondaire à l'utilisation massive de cet antifongique.

Voriconazole (Vfend $\left.{ }^{\circledR}\right)$

Efficace vis-à-vis des Candida et de l'Aspergillus.

Effets secondaires: troubles visuels, altération des tests hépatiques, rash cutané (photosensibilité)

Dose de 2 fois $6 \mathrm{mg} / \mathrm{kg}$ le premier jour, suivie de 2 fois $3 \mathrm{mg} / \mathrm{kg}$ les jours suivants. Il ne faut pas adapter à la fonction rénale.

Une forme orale est disponible pour le malade convalescent (ici les doses doivent être adaptées à la fonction rénale, en raison du solvant).

Itraconazole

Moins efficace, mais tire un avantage de son prix moins élevé et de sa forme orale, utile chez le malade convalescent.

Autres agents en développement: posaconazole, ravuconazole (voix orale surtout).

\section{Caspofongine}

Le mode d'action des echinocandines est original: ces substances inhibent une enzyme responsable de la synthèse de glucan dans la paroi du champignon. Actif visà-vis de la grande majorité d'espèces de Candida et l'Aspergillus; le risque d'apparition de résistances semble faible.

Dose de $70 \mathrm{mg}$ le premier jour, et de $50 \mathrm{mg} /$ jour les jour suivants; pas d'ajustement nécessaire en cas d'insuffisance hépatique ou rénale. Le produit est en effet remarquable par sa sécurité et tolérance. Il n'influence pas le chromosome P450.

\section{Amphotéricine $B$ et dérivés}

L'amphotéricine B qui agit en se combinant à l'ergosterol de la membrane. Le produit, déjà développé en 1952, a un très grand spectre antimycotique.

La dose est de 1 à $1,5 \mathrm{mg} / \mathrm{kg} /$ jour - (attention, la préparation doit se faire en solution glucosée en eau, sans électrolytes!)

La dose doit être adaptée à la fonction rénale.

Elle est de moins en moins prescrite, en raison de sa toxicité:

-fièvre et frissons lors de l'administration (ces phénomènes sont réduits en cas d'administration sur plusieurs heures, voire en perfusion continue)

-désordres hydroélectrolytiques;

-néphrotoxicité importante.

Les principales indications restantes sont:

-le traitement des Candida résistants au fluconazole;

-les cas sévères (choc septique) qui pourraient être dus à une infection fongique;

-infections à autres champignons que Candida et Aspergillus. 
Formes lipidiques:

Elles sont moins toxiques, mais nécessitent des doses plus élevées, de 3 à $5 \mathrm{mg} / \mathrm{kg} /$ jour.

Complexe lipidique: Abelcet ${ }^{\circledR}$ : dose de $5 \mathrm{mg} / \mathrm{kg} /$ jour, qui entraîne moins d'effets secondaires.

Forme liposomiale $\left(\right.$ AmBisome ${ }^{\circledR}$ ) la mieux tolérée (mais aussi un peu plus chère que l'Abelcet $\left.{ }^{\circledR}\right)$ : doses de 3 (parfois jusqu'à 6) mg/kg/jour.

\section{Association d'antifongiques}

pas d'indication en routine (possibilité à l'étude).

\section{Cytokines immunostimulantes}

Le G-CSF ( granulocyte-colony stimulating factor »), le GM-CSF ou l'interférongamma sont des possiblités thérapeutiques envisageables mais aussi onéreuses.

Durée de traitement et prophylaxie

La durée du traitement est variable. Elle peut être limitée à 15 jours dans les pneumopathies peu compliquées, mais nécessite souvent un mois. Une prophylaxie secondaire est parfois poursuivie pendant des semaines.

\section{Infections virales}

Elles sont surtout problématiques chez les malades immunodéprimés.

Il s'agit souvent d'infections respiratoires:

- virus à DNA: herpès (incl. CMV, Epstein-Barr) et adénovirus: les virus peuvent être présent de manière latente (généralement endogènes) ou transmis par la transfusion;

- virus à RNA: influenza (A et B), rhinovirus, parainfluenza, hantavirus: généralement acquis au contact d'autres personnes.

Parmi les infections virales chez les malades sous traitement immunosuppresseur, les infections à herpes sont les plus fréquentes (voir infections virales ci-dessous): surtout CMV. Les signes cliniques peuvent être variés: fièvre, parfois leucopénie et/ou thrombocytopénie, pneumonie, hépatite, ulcèrations digestives, rétinite, pyélonéphrites...

Les hépatites à virus de type $\mathrm{B}$ et $\mathrm{C}$ sont également fréquentes.

\section{Diagnostic}

$\mathrm{CMV}$ : inclusions à CMV dans un spécimen tissulaire, y compris BAL (sensible, mais signification clinique pas toujours déterminée), antigénémie CMV, reconnaissance par PCR, augmentation des anticorps (au moins un facteur 4).

$N B$ : les récidives sont fréquentes.

Herpes simplex: généralement associé à un herpès cutané. 


\section{Traitement}

CMV: ganciclovir $5 \mathrm{mg} / \mathrm{kg}$ IV $\times$ 2/jour; l'addition d'immunoglobulines est recommandée en cas d'infection sévère;

Herpes simplex ou zoster: acyclovir.

Adénovirus, RSV, parainfluenza: pas de traitement. 